\title{
ARCHIVING FRAGMENTS OF TIME
}

\author{
by \\ Alice Victoria Charles
}

A 120-point thesis

submitted to the Victoria University of Wellington in partial fulfillment of the requirements for the degree of Master of Architecture (Professional)

Victoria University of Wellington Wellington School of Architecture 


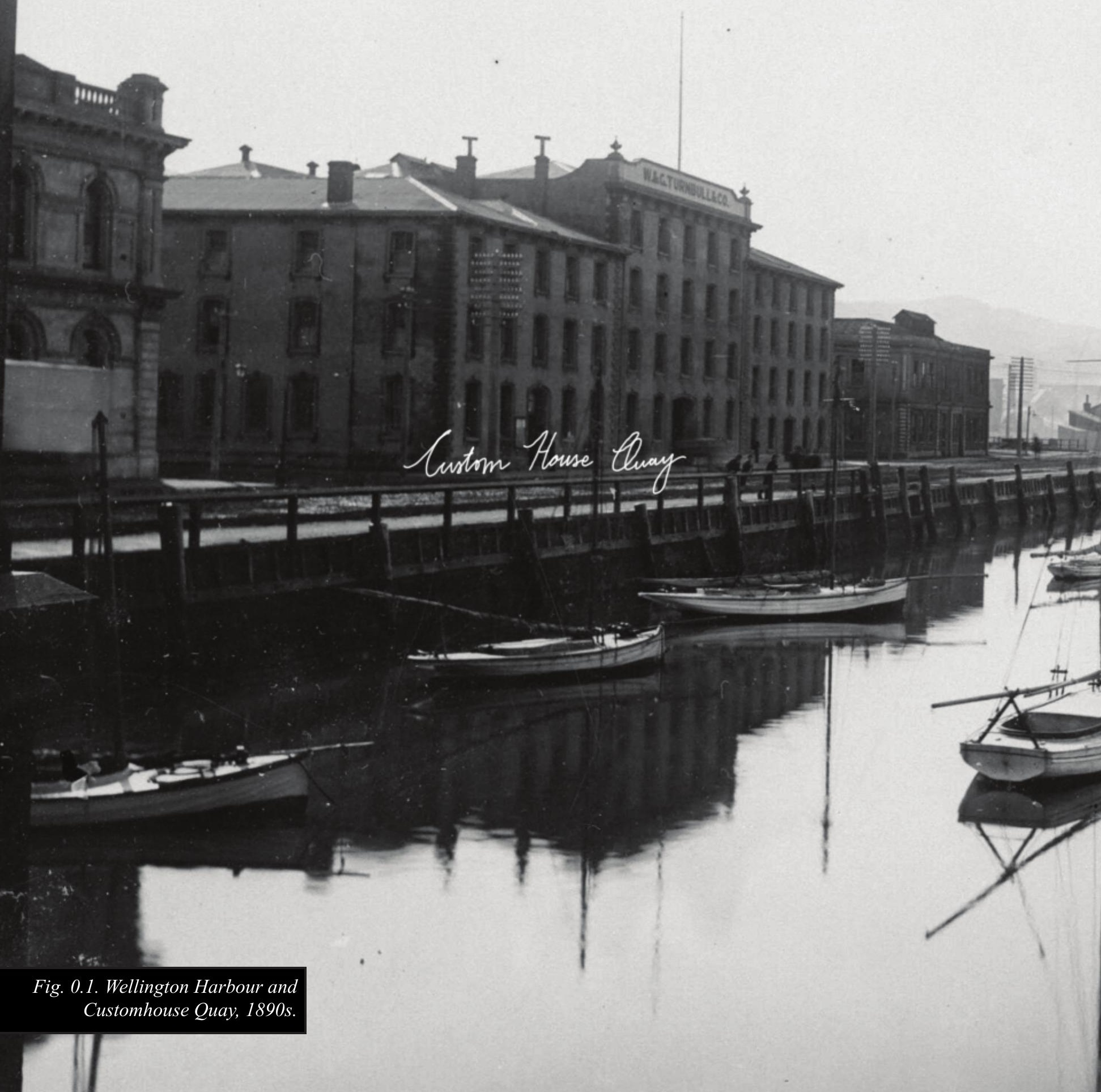




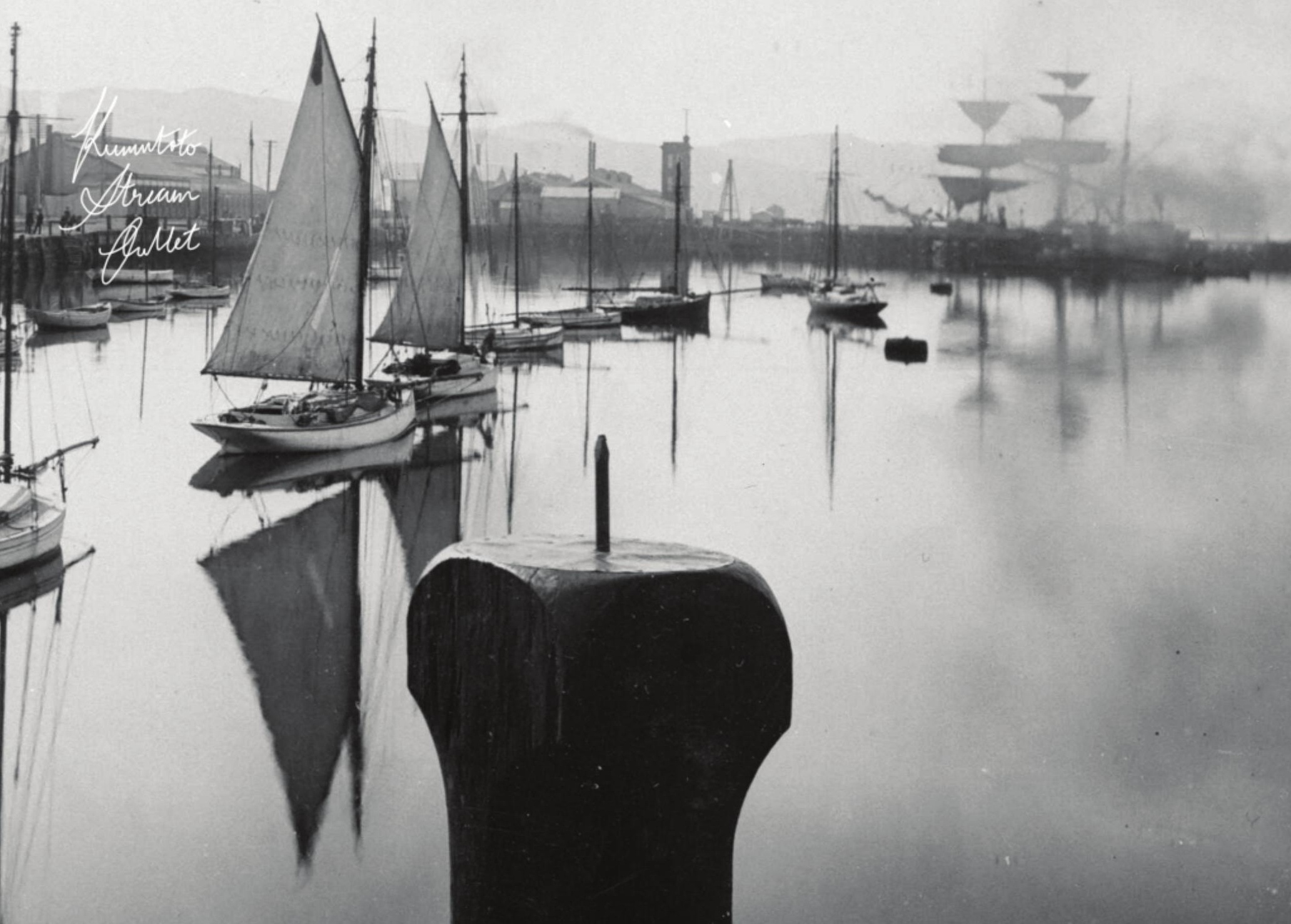



these stories, even as fragments, enables local inhabitants and a wider audience to begin to understand the significance of place.

Heritage stories transform from one time period to the next, creating overlapping layers of a site's identity evolving over time. Each layer, while potentially representing its own unique story, contributes to the metanarrative of a place. This design-led research investigation looks at the problem that arises when important stories of a place are lost when a site has transformed over time. The true story of a site is represented by the hidden layers from previous time periods, which have often fragmented or faded over time. This thesis proposes that lost layers, fragmented stories and faded voices can be reawakened through speculative architectural representation.

Fragments of stories can be used to stimulate the imagination. The allegorical interpretation of fragments can be used to generate dreamscapes. Within a dreamscape, the multiple voices of multiple fragments can be heard together, even when they represent stories from different times. When dreamscapes are captured as allegorical drawing fragments, these multiple voices can be heard and retained even when they have partially faded away.

This thesis explores how an allegorical architectural project, framed within techniques found in allegorical narrative fiction, can be successfully used as a critical method to help reawaken and unveil lost voices of place and generate speculative architectural outcomes that allow these voices to be heard. This design-led research proposes to reawaken lost voices of place through mapping the field of imagination, collage and the creation of dreamscapes, and allegorical drawing fragments.

Italo Calvino's Invisible Cities and Alan Lightman's Einstein's Dreams are examples of literary approaches to the allegorical interpretation of fragments. They are used in this investigation as literary provocateursallegorical generators to engage the imagination to reawaken lost voices as fragments and allow them to be heard in a collection-an archive of fragments. These two novels are effectively re-presenting place and time as dreamscapes. By enabling a series of fragmented stories to be heard as one, a richly polyvocal narrative is established that allows the reader to understand the significance of a place. 
Two neighbouring urban sites along the edge of Wellington Harbour have been selected for this investigation: the Taranaki Wharf Cut-out and the Kumutoto Stream Outlet. Both have unique tales to tell. The Kumutoto Stream Outlet is the site of the first culverted stream in Wellington. This entire stream has been silenced and has disappeared forever, yet it survives deep underground; this narrow outlet along the Wellington Harbour edge is the last vestigial remnant of its tale. The Taranaki Wharf Cut-out exposes the lost shoreline of Wellington before urban expansion. This shoreline has been silenced and has disappeared forever, and the cut-out provides the last visual connection to the lost landscape below. Fragments of the urban concrete have been removed from both these sites to reveal the lost remnants of the sites tales they once concealed. These sites are engaged as allegorical portals that invite a viewer below the surface of Wellington's urban concrete to explore the lost layers of fragmented stories that lay hidden beneath. These sites are presented as 'characters' that narrate 'stories' of Wellington waterfront's surrounding context and the transformation of the landscape over time.

The original heritage conditions of a place often cannot be physically returned to their sites without disrupting the contemporary urban context. In this investigation, sites are not engaged as grounds for architectural intervention. Instead, they are provocateurs for how an allegorical architectural project can dig below the urban concrete and reawaken and unveil lost voices of a place. These voices are presented as a speculative archive of fragmented artefacts that invite viewers to witness, through these allegorical artefacts, an urban environment's rich litany of heritage stories that may have been permanently lost or displaced. These artefacts take the form of maps, collages and drawings, and they are designed to read both as individual artefacts and together as a collection within an archive, this bound codex of work-an Archive of Fragments of Time.

\section{This thesis asks:}

How can an allegorical architectural project be successfully used as a critical method to reawaken and unveil lost voices of a place, and generate speculative architectural outcomes that allow these voices to be heard? 







\section{PREFACE}

In my fourth year of architecture school, my supervisor Daniel Brown opened my eyes to the poetic capability of architecture that arises when engaging narrative as a design method and mode of thinking through all design process stages. It was here that the perception of my architectural education shifted from the simple exploration of architecture as form to the critical investigation of ideas and creative imagination. The priority of my education became less about the final outcome of buildable design projects, as a presentation of rendered CAD models, and more about challenging myself to think critically and analytically about complex ideas and engage the imagination to explore these ideas creatively throughout the design process.

The introduction to narrative thought in architecture sparked a particular fascination with the implication of time in architecture-in particular, the implications of time in the understanding of place and its continuous transformation over time. I developed a fascination for exploring architecture and sites, not as static objects but as living entities that shift and transform over time, as vessels for memory and as narrators of stories of time and place.

Daniel introduced me to two novels, Einstein's Dreams by Alan Lightman and Invisible Cities by Italo Calvino. Both of these novels reinterpret uniquely framed, finite perceptions of time and place from a multitude of different points of view as allegorical stories. Both books challenge a reader to critically reflect and engage the imagination to fully understand time and a place as multi-dimensional and open to an endless possibility of interpretation. It was here that my mind began to wonder, how can these literary reinterpretations of time and place be reinterpreted in architecture to engage the imagination, to draw out a multitude of stories about a site that contribute to an understanding of its place in time, and enable these stories to be visually represented through architectural design? 
1.

Proveradion

if 1 (1)

6.7.

1. Where smidi nore poetry

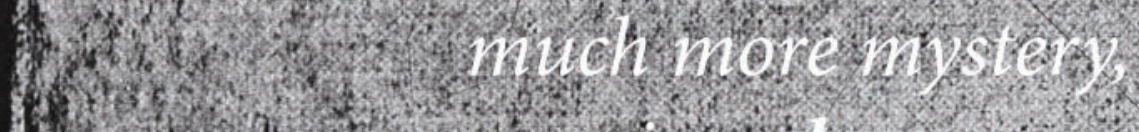

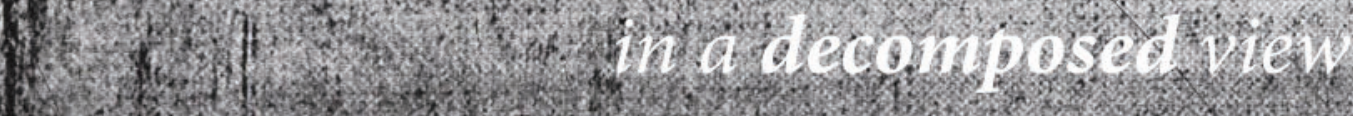

dhosen.

\section{- indertined.}

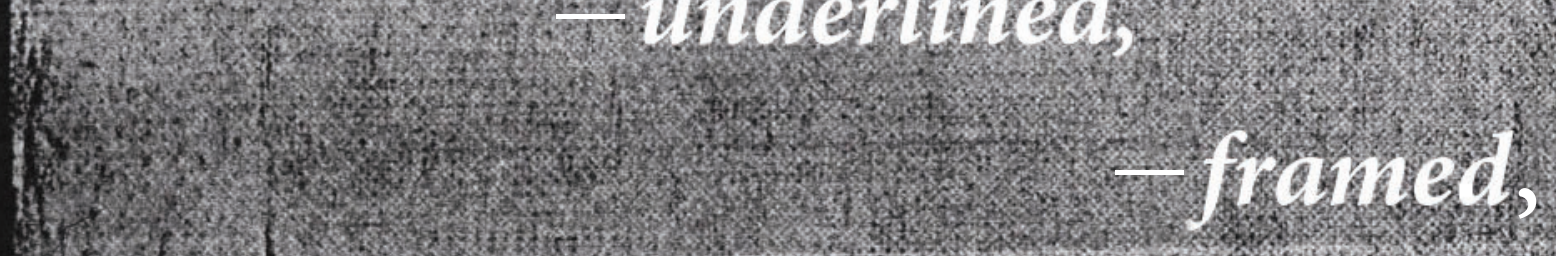

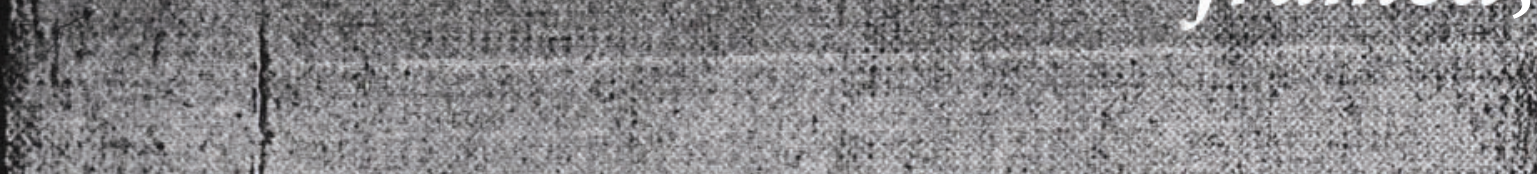

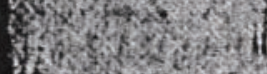

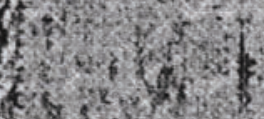

is

Sha



W.

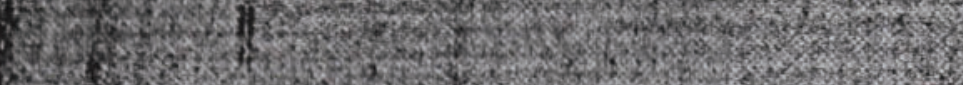

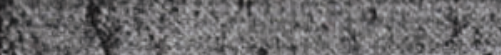

ming

is

10. $\mathrm{F}$.

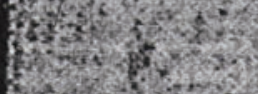


..than in an opening that offers

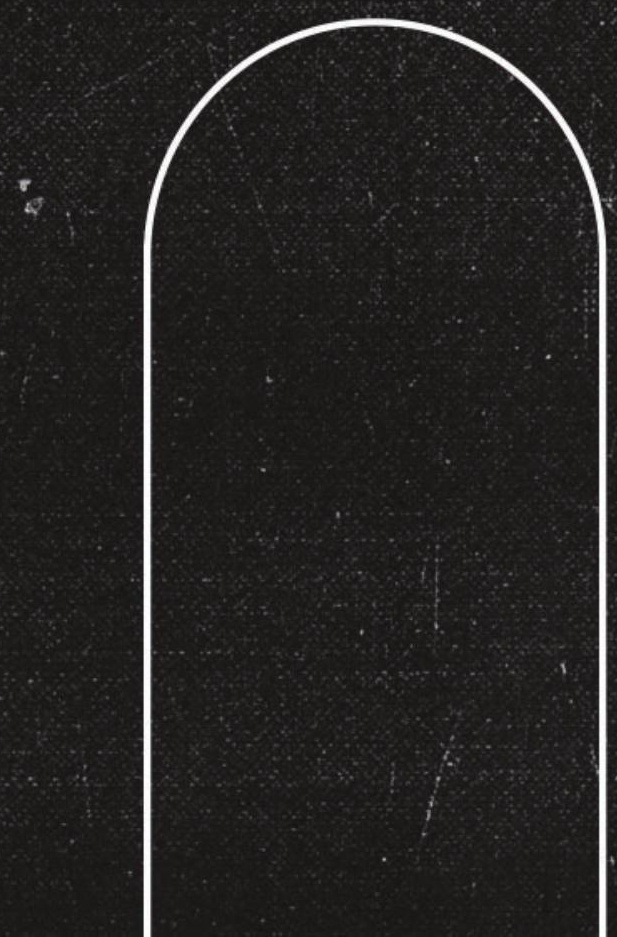



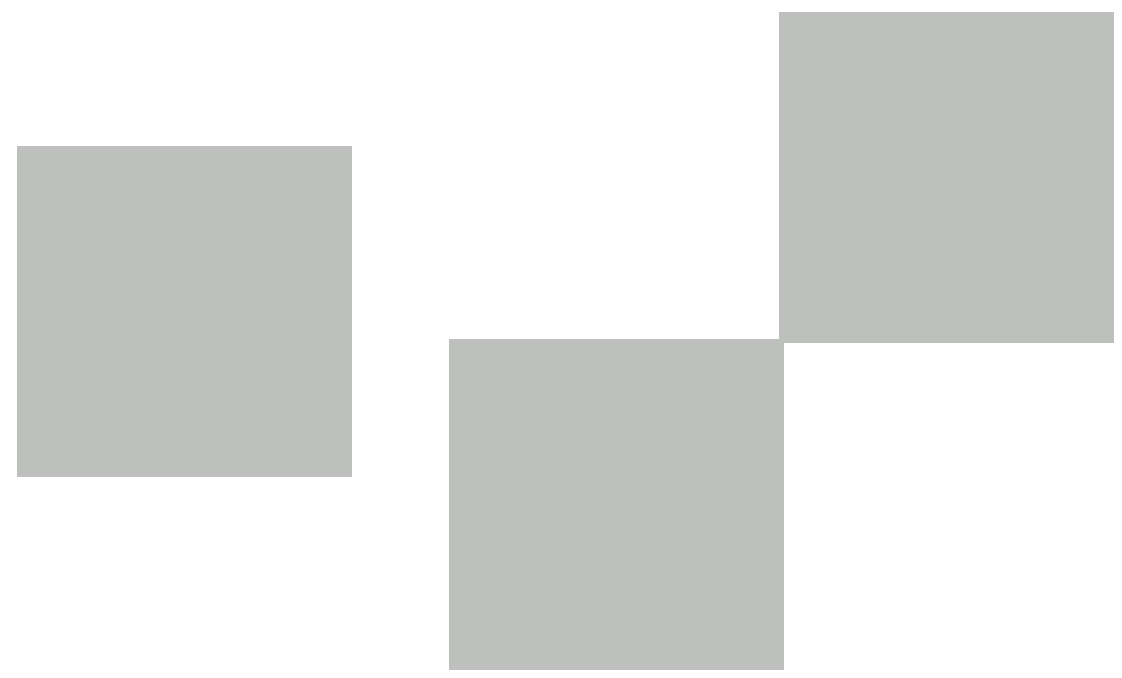

These digital collages contains content that is currently unavailable due to pending copyright approval.

Fig. 0.3-0.13. Collage: 'Fragments of Time'. Digital Collage. 


\section{ACKNOWLEDGMENTS}

I would like to thank my supervisor Daniel Brown for your neverending inspiration, time and wisdom. Thanks for believing in me at times when I struggled to believe in myself.

To my friends and classmates for being the most supportive and positive team; I could not have done it without you.

And finally to my parents for their unconditional love and support throughout my years of study. For listening, for supporting, for motivating, and for being consistently interested. 
Fig. 0.14. Collage: Storing artefacts of Wellington City in Bell Jars. 
Wellington 1893

This content is unavailable.

Please consult the figure list for further details. 
I.

II.

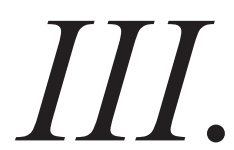

\section{A THEORETICAL FRAMEWORK}

2.1 Introduction: Narrative + Placemaking The Architectural Allegory:

2.2 The Allegorical Architectural Project

2.3 Voices of Allegory
61

62 


\section{$I V$.}

\section{the $C \not D A$.}

Preface

Dreaming of Lost Voices: The Kumutoto Stream Outlet

Dreaming of Lost Voices: The Taranaki Wharf Cut-out

The Lost Map of Time

Unveiling an Artefact of Time

The Bell Jar: An Artefact of Time

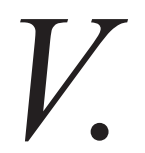

4.1 Précis

4.2 Critical Reflection

4.3 Final Remarks 




Fig. 1.1. Fragment: Through the Portal. Kumutoto Stream Outlet. By Author. 


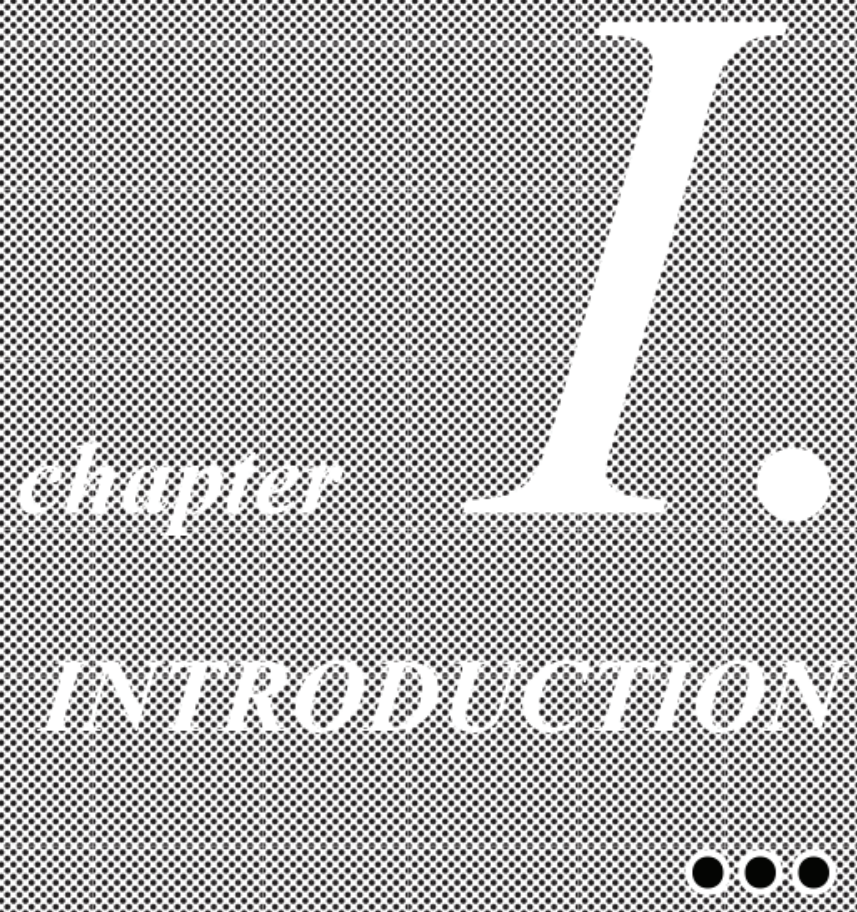




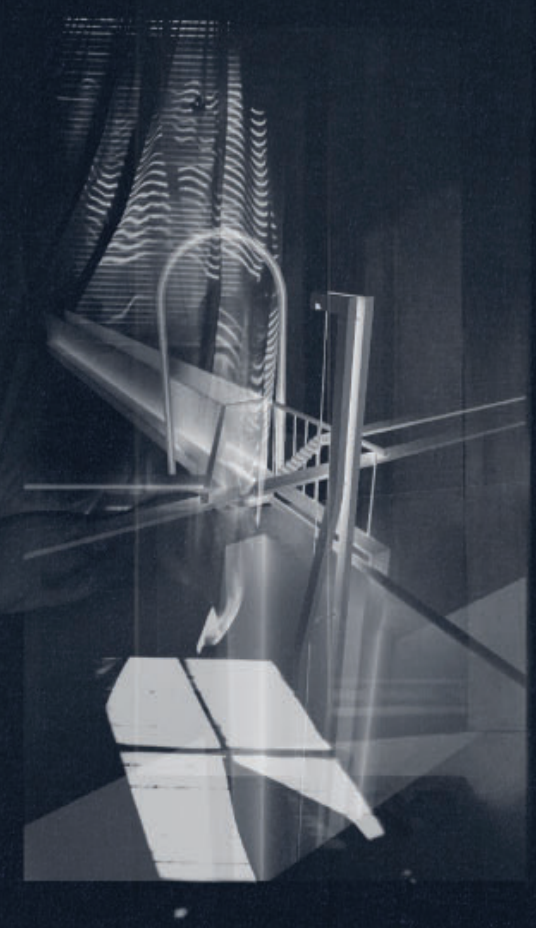

Fig. 1.2. Collage Fragment: Through the portal in a search beyond the veil. By Author 
There are rich layers of stories associated with the history and the identity of any urban site that enable us to associate that site with place identity. These stories represent the voices of a site that are inherent in placemaking. Beneath the urban concrete of Wellington city lies a plethora of lost stories and lost voices, sometimes only accessible as fragments, which should contribute to the rich polyvocal narratives of a site. Recognition of these stories, even as fragments, can enable local inhabitants as well as a wider audience to begin to understand the significance of place.

Heritage stories transform from one time period to the next, creating overlapping layers of a site's identity evolving over time. Each layer, while potentially representing its own unique story, contributes to the metanarrative of a place. This design-led research investigation looks at the problem that arises when essential stories of place are lost when a site is transformed over time. The true story of a site is represented by the hidden layers from previous time periods, which have often fragmented or faded over time. This thesis proposes that lost layers, fragmented stories and faded voices can be reawakened through speculative architectural representation.

"Every image of the past that is not recognized by the present as one of its own concerns threatens to disappear irretrievably" —Walter Benjamin, “Theses on the Philosophy of History”, 247. forgotten roots of the natural landscape. By Author. 


\section{RESEARCH QUESTION This thesis ask:}

How can an allegorical architectural project be successfully used as a critical method to reawaken and unveil lost voices of a place, and generate speculative architectural outcomes that allow these voices to be heard?

Fig. 1.4. Allegorical Drawing Fragment. A threshold to a lost world below. Kumutoto outlet site. By Author.

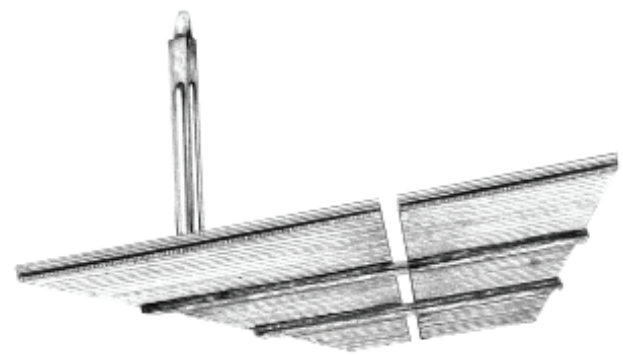



used to generate dreamscapes. Within a dreamscape, the multiple voices of multiple fragments can be heard together, even when they represent stories from different times. When dreamscapes are captured as allegorical drawing fragments, these multiple voices can be heard and retained even when they have partially faded away.

Italo Calvino's Invisible Cities and Alan Lightman's Einstein's Dreams are examples of literary approaches to the allegorical interpretation of fragments. They are effectively re-presenting place and time (respectively) as dreamscapes. By enabling a series of fragmented stories to be heard as one, a richly polyvocal narrative is established that allows the reader to understand the significance of place.

This thesis explores how an allegorical architectural project, drawing from frameworks found in allegorical narrative fiction, can be successfully used as a critical method to help reawaken and unveil lost voices of place, and generate speculative architectural outcomes that allow these voices to be heard. This design-led research investigation proposes to reawaken lost memories of place and bring them to visual life through: 1) mapping the field of imagination 2) collage and the creation of dreamscapes, and 3) allegorical drawing fragments.

The manifestation of memory of a spatial event from the history of the site is idealised through abstraction of the language of architecture... Interpreters, limited by narrative conventions of content ought to be challenged by free associations with symbols and images that determine the objective limits of the architectural language... 
IV. RESEARCH

AIM

The principal Research Aim of this design-led research investigation is:

\section{[RA]: Allegorical Architectural Project}

to explore how an allegorical architectural project can reawaken and unveil lost voices of a place through mapping the field of imagination, collage and the creation of dreamscapes, and allegorical drawing fragments.

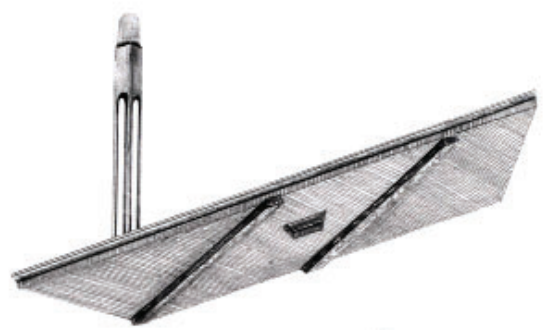




\section{RESEARCH OBJECTIVES}

To address the Research Aim, the principal Research Objectives of this design-led investigation are:

Research

Objective 1
[RO1] Mapping the Field of Imagination: to explore how mapping can be used to generate a foundation (field) upon which multiple sites of the imagination can be simultaneously interrogated as test subjects.

“...mappings discover new worlds within past and present ones ... [T] hey inaugurate new grounds upon the hidden traces of a living context."

- James Corner, 209
Research

Objective 2
[RO2] Collage and the Creation of Dreamscapes: to explore how collage and the creation of dreamscapes can be used to generate speculative architectural outcomes that enable multiple voices over time to be heard at once.

"Assembled, re-cut, realigned, rescaled —collages exist in balanced incompleteness, delicately poised, presented for the viewer to question, to imagine, and to speculate over the completed scene."

—Simon Herron, 98

Research

Objective 3
[RO3] Allegorical Drawing Fragments: to explore how allegorical drawing fragments can be used to generate speculative architectural outcomes that enable voices to be heard, even when they have already partially faded away.

"The artifact in other words, may operate as both active agent and as a means of recordkeeping, occupying a realm which is both 'immediate' and potentially timeless."

-Fred Koetter, "Notes on the In-between", 71 
" THOUGHTS OF AN ARCHITECT

A Manifesto...

duaming

- of the imagination ghost becoming 1 apparitions, outlines, figments.
risplele

They are not diagrams but ghosts. - DEFINITION = - Loul of the dead,

Shrough the partalo into the roid

\section{Tracings are similar to $X$-rays, they \\ penetrate internally. \\ 3. Erasures imply former existences.}

Mapping belon the

- Mere shadow ar Semblame. a brace
Mar

lapping

out foums

and
4. Drawings and tracings are like the hands

of the blind touching the surface of the face

in order to understand a sense of volume,

depth and penetration.

5. The lead of an architect's pencil disappears

RO1: Mapping 1 and interviogation two siter as poutuls to

the inagination

envating

allegonical

fuagmento

as antefacto

(Iiquid densification) the place-site with (drawn away) Metamorphoses.

pracest

PO TAKE A SITE: present tracings, outlines,

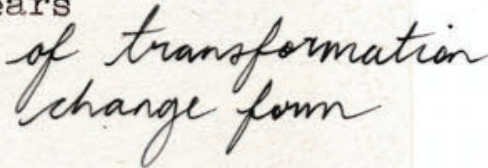

figments, apparitions, X-rays of thought.

Mediations on the sense of erasures.

To draw out by compacting in. To flood

callage-Deramscapes as Construtrion RO2 time.

missing letters and disappeared signatures. Leanaken

To gelatinize forgetfulness." Fongatter Fragments

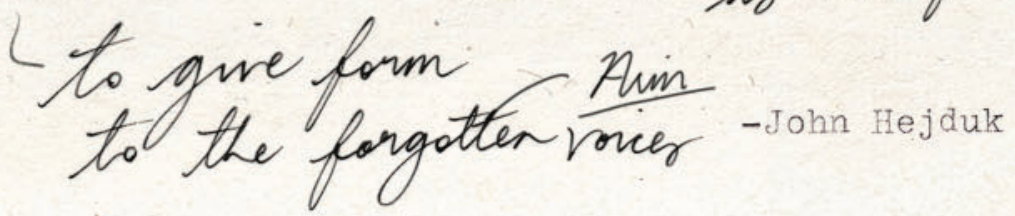

Fig 1.6. Preliminary speculations by author in relation to quote by theorist and architect John Hejduk. (Hedjuk, 1997) 


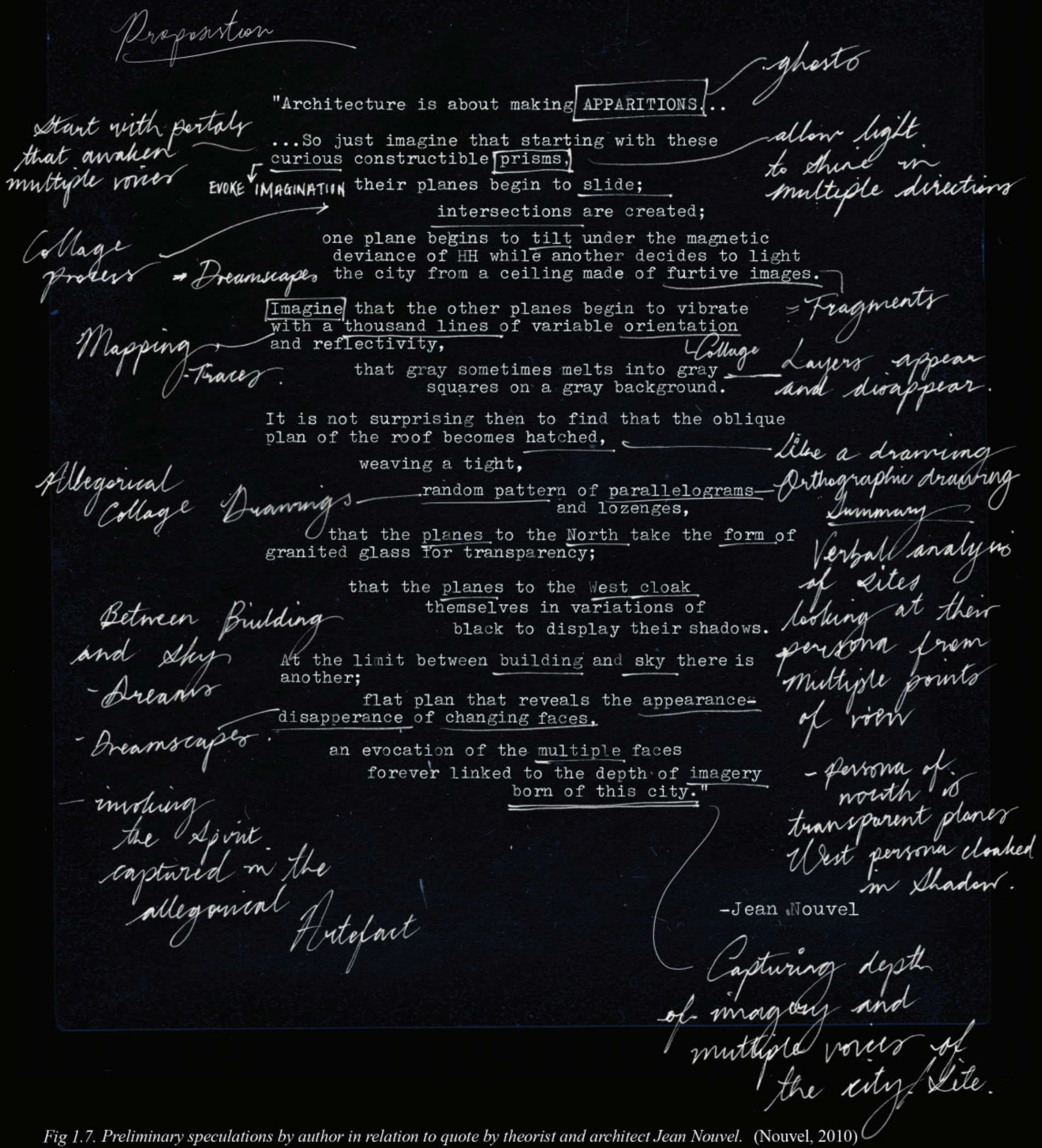



unconscious speculation and questioning - the 'zone' where things concrete and ideas are intermingled, taken apart and reassembled-where memory, values and intentions collide.

This project exists in the realm of the 'in-between'-a field of speculation. Rather than seeking fixed conclusions and a concretised outcome, this thesis posits a series of design explorations through a range of speculative methods. This investigation stems from an understanding of the allegorical architectural project, not a buildable solution to a problem. Instead, it is conceived as a vehicle for critical discourse that weaves visual and textual descriptions to speculate on a speculative architectural project's capacity to reawaken and unveil lost voices of a place through the imagination and generate speculative outcomes that allow these voices to be heard.

In this investigation, allegory is employed as a critical framework to approach this proposition. In an attempt to reawaken and unveil lost voices of a place, this thesis does not propose to represent a literal interpretation of history from limited perceptions of time and place. Instead, it aims to generate outcomes that are 're-presentational' of lost voices and fragments of the past-outcomes that James Corner speculates "do not simply represent a world already in existence, but instead attempts to re-present the world in ways previously unseen, to make the banal appear fresh and the old appear new" (Corner, 181). An allegorical approach to an architectural project facilitates this proposition due to its focus on metaphoric meaning and its call to engage the imagination to see beyond the surface. In her article "The Fall: The Allegorical Architectural project as a Critical Method", Penelope Haralambidou establishes theoretical grounds for the methodological use of allegory in architecture. Two literary works of allegory, Einstein's Dreams by Alan Lightman and Invisible Cities by Italo Calvino, are introduced as allegorical provocateurs and springboards for the imagination-'The Voices of Allegory'. Both are addressed in Chapter II, Architectural Allegory: The Importance of the Story, as an overarching theoretical framework to address the research question and build upon subsequent sections of the thesis.

This investigation is fragmentary in nature. It is grounded in an understanding of a place not as one singular story but as a palimpsest of lost stories, and hidden layers made up of a plethora of voices that have fragmented and faded over time. As Haralambidou writes, "allegory is an experience of the world no longer permanent but fragmentary and enigmatic" (226). Therefore, this investigation as an allegorical architectural project does not merely represent one story or one architectural outcome; rather it re-presents fragments of multiple stories and voices coming together as a collection to form an 'Archive of Fragments of Time'. 
Italo Calvino's Invisible Cities presents 55 fragmented stories of allegorical cities later revealed to be describing only one city-Venice from 55 alternate points of view about a 'place'. Similarly, Alan Lightman's Einstein's Dreams presents a series of 30 fragmented stories of dream worlds, with each tale reinterpreting 'time' from an alternative point of view. Both novels present a series of fragmented stories that, when understood as a collection, enable a richly polyvocal narrative to be revealed. This narrative, however, remains unfinished and open to interpretation, allowing a reader to recognise the significance of overlapping fragments and layers, taking in more than one time and place. These literary works are used as provocateurs for an allegorical approach to an architectural project proposing to reawaken lost voices of a place as fragments that generate polyvocal narratives of time and place when read as a collection.

\section{VII.}

\section{METHODS AND PROCESSES}

The framework for this investigation derives from a form of inquiry where understanding is gained through the processes of design and creation. Literature, theory, and case study views provide a platform for exploring the research question, aim and objectives through design.

This thesis emphasises analysing contextual relationships, engaging generative methods and processes to investigate narratives of place and time. As architectural theorist Jane Rendell proposes in her book Critical Architecture, "In much design research the process operates through generative modes, producing works at the outset that may then be reflected upon later" (Rendell 117). Generative modes allow for unexpected outcomes and findings to emerge from such processes. The research is embedded within the design process, where speuclative architectural theorist Perry Kulper notes "ideas are augmented through an emerging visual field of study that is discovered in the act of constructing [speculative design outcomes]" (59). Adopting this approach allows the investigation to build ideas iteratively and generate a multi-layered design argument, explored and supported through additive findings of each design exploration series.

Every chapter contains its own literature and project review that relates to the unique Research Aim and Objective that is being addressed. Discoveries from these reviews help to establish a robust theoretical foundation upon which relevant design experiments can be built. Each chapter investigates principal authors and precedents that are relevant to the three principal research objectives of the investigation. Throughout the design process, these principal authors and precedents 
are continually interrogated and build upon each other to generate a multilayered theoretical argument. Speculative outcomes are framed and tested in relation to the theoretical findings of the research objectives and the overarching framework of the allegorical architectural project.

Speculative mapping, collage and allegorical drawing are the three main design methods engaged in carrying out the research aim. The term 'design', derived from the Italian disegno meaning drawing, is perceived in this thesis as more than just the drawn line, but as architectural theorist Jonathan Hill emphasises, "the drawing forth of an idea" (6). Knowing is embodied in the act of inquiry, facilitating a symbiotic process of creation and reflection. In this mode the process of making and investigating is as important as design outcomes themselves. For this reason, the entire bound codexthe evolving process as well as the succession of discoveries-is the final outcome. Rather than a singular outcome at the end of this thesis, the design discoveries are presented as fragments of heritage stories, whose voices are brought to life in every chapter.

Speculative mapping is an investigative technique for drawing out forgotten voices and stories hidden in the landscape. It is used in the thesis investigation to generate a speculative field that opens up sites to the imagination. Speculative mapping refers to both the process of diggingrevealing hidden layers-and 'mapping out' contextual relationships that convey stories.

Collage is engaged in the thesis as a technique to explore how multiple voices and fragments of time can be heard at once through the creation of dreamscapes. This investigation engages collage as a digital medium where fragments are cut out of their context and placed into an assemblage or overlaid with other objects digitally.

Allegorical drawing is engaged in the thesis as a method to generate speculative architectural outcomes that enable voices to be heard, even when they have already partially faded away. It is intended that drawing no longer be seen as a means to an end, but as a vehicle for creativity. Engaging allegory in the drawing out of ideas ensures drawings are representational. 
This design research investigation is speculative in nature. The outcome is a speculative archive of fragmented artefacts that invite viewers to witness, through these allegorical artefacts, an urban environment's rich litany of heritage stories before they become permanently lost or displaced. These artefacts take the form of maps, collages and drawings that read as individual artefacts and together as a collection within the archive-this codex of work.

The original heritage conditions of a place often cannot be physically returned to their sites without disrupting the contemporary urban context. As such-and as a speculative and allegorical investigation focusing on mapping, collage and drawing-a buildable architectural outcome is outside the scope of this investigation. Architectural envelope, structure, technologies and costings are outside the scope because of the nature of this investigation as a design-led, speculative research project.

While a vast litany of urban sites contains valuable heritage stories around Wellington, this investigation's scope is restricted to two sites. This restriction is due to the limited time available for the research and the focus and depth of resolution anticipated. By selecting two nearby sites, there is an opportunity to convey a larger meta-narrative about the overall city even within this focused limitation.

งิํำ

This digital collage contains content that is currently unavailable due to pending copyright approval.

Architecture is not a synchronizing phenomenon, but a gradual $u n f o l d i n g .$.

It consists of a sequence of tableaux, associated in time and space.

Like music it is a means of conceiving in time. 
This digital collage contains content that is currently unavailable due to pending copyright approval.

Fig. 1.9. Dreamscape: Layering fragments of time and place of Wellington's Waterfront. Digital Collage by author. 
66

Allowing for leaps and breaks in the space time continuum ...

... time itself becomes visible.

We observe not history already remade

but history in the very process of its remaking." 
THESIS STRUCTURE
CHAPTER I

Chapter I outlines the Problem Statement and Research Proposition and the Research Question underpinning this investigation. It articulates the overall Research Aimoutlining how the thesis proposes to address the Research Question-and three principal Research Objectives that articulate how the investigation plans to address the Research Aim. It outlines the Research Method and Processes, the Scope, the Structure of this investigation, and Site Analysis.

CHAPTER II

Chapter II establishes a theoretical framework for addressing the Research Aim, the Allegorical Architectural Project, interrogating the use of allegory in architecture as a critical method. It establishes an overarching approach to address the research question, aim and all three objectives.

CHAPTER III

Chapter III is divided into three sections, each of which addresses one of the three principal Research Objectives. Each of these three sections contains its own integrated theory and case study review, which is interrogated through research experiments followed by critical reflection.

CHAPTER IV

Chapter IV titled 'CODA' is a series of developed design outcomes that explores the potential of speculative allegorical outcomes to reawaken and unveil lost voices of a place, and capture these voices as allegorical drawings-both as fragments and as collages of multiple fragments upon a field of imagination-that allow their voices to be heard even when they have already partially faded away.

\section{CHAPTER V}

Chapter $V$ concludes the thesis with critical reflections and final remarks. This chapter critically reflects on strengths and weaknesses of the design outcomes in relation to the scope of the research and the research aim and objectives. It briefly reviews the nature of the research problem, why this has been an important issue to resolve through design, and reflects on the capacity of the research investigation to address the issue. It reflects upon how effective the methodology has been; what conclusions can be drawn from the investigation; the constraints and limitations of the findings; other potential applications of the findings; and how this study might advance further in the future, if extended beyond the original scope. 


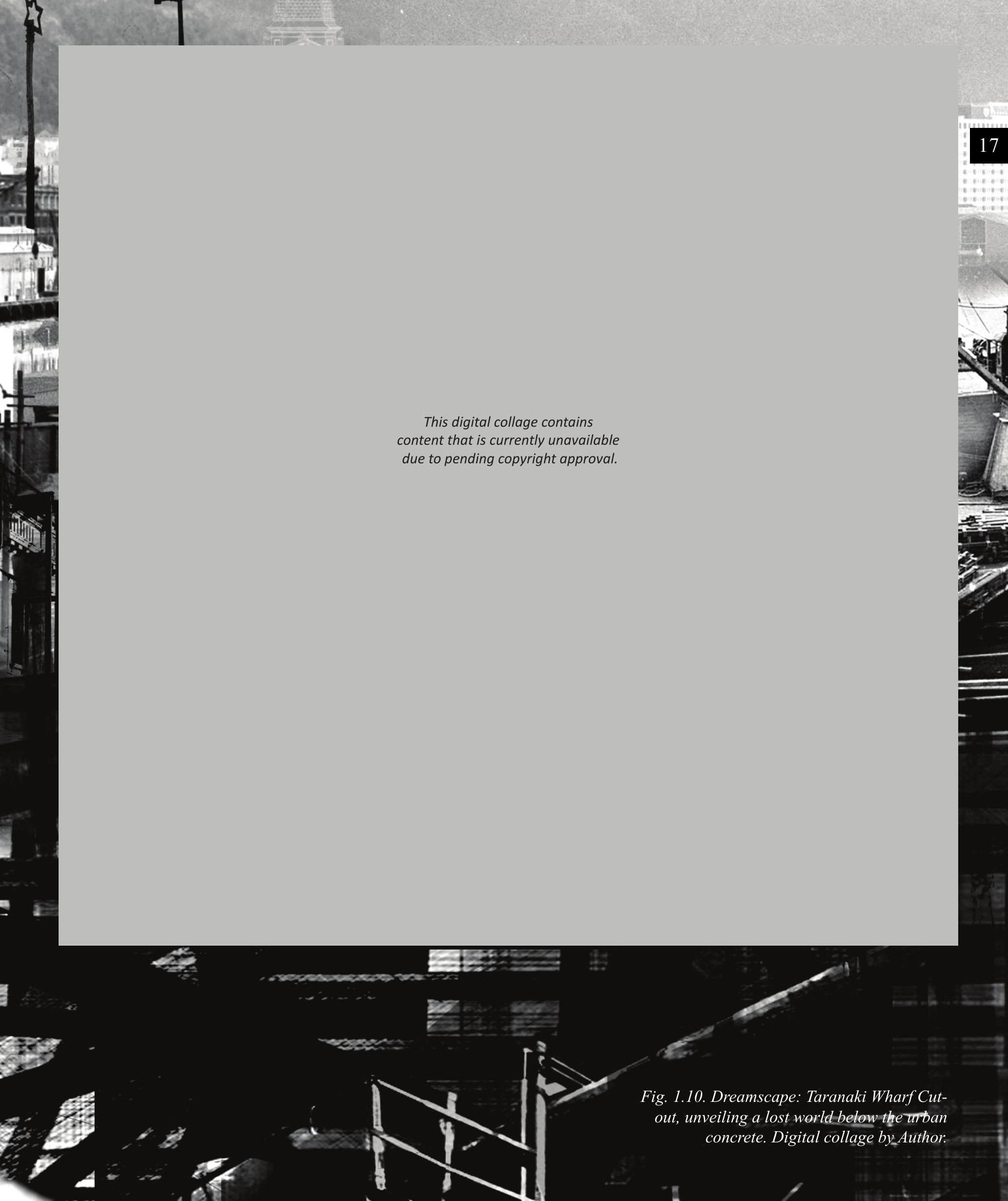


Fig.1.11.Aerial satellite image

of Wellington looking north. 
This content is unavailable.

Please consult the figure

list for further details. 


 THE PLACE}

This content is unavailable.

Please consult the figure

list for further details. 


\title{
SITE
} ANALYSIS

\author{
This section begins by setting the scene. \\ It introduces Wellington City-the 'field' of \\ this investigation, in which the two selected \\ sites, the Kumutoto Stream Outlet and \\ the Taranaki Wharf Cut-out are situated. \\ It presents a background of the Wellington \\ Waterfront's contextual and historical \\ narratives and the two selected sites, setting \\ the contextual scene for this investigation.
}

This content is unavailable. Please consult the figure list for further details. 


\title{
SETTING THE SCERㅌㄹㄹ
}

\author{
This content is unavailable. \\ Please consult the figure \\ list for further details.
}

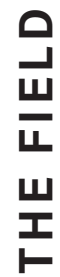

Fig. 1.16. Te Whanganui-a-Tara, Wellington Harbour Pre Colonisation.

This content is unavailable.

Please consult the figure

list for further details.

Wellington-Te Whanganui-a-Tara-is a city founded on the backbone of the landscape. Prior to colonisation of Wellington in 1840, the landscape was adorned by prominent Pā sites and Kainga (village) stretching along its shoreline, surrounded by an array of streams and creeks cascading down the steep slopes of the surrounding topography. Since the arrival of the colonial settlers in the 1840s and the rapid urban expansion that followed, the streams, surrounding bush and natural shoreline, initial vital life sources of the land were destroyed as any available land was quickly claimed for urban growth.

Fig. 1.17. Town plan for Wellington in Petone, 1840. 
23

When colonial settlers first arrived in the harbour in 1839-40, a prescribed gridded settlement was laid out in Pito-one (Petone) (fig. 3.1.5). However, due to the exposed nature of the site, flooding and shallow anchorage the town was relocated in 1840 to the southwestern end of the harbour, where the city stands today. The town plan, the readapted colonial grid, was overlaid upon the landscape cutting through inhabited $\mathrm{Pa}$ and Kainga sites and natural stream paths, clearing bush and mānipulating the landscape to generate a clean slate for the pre-proposed town of Wellington.

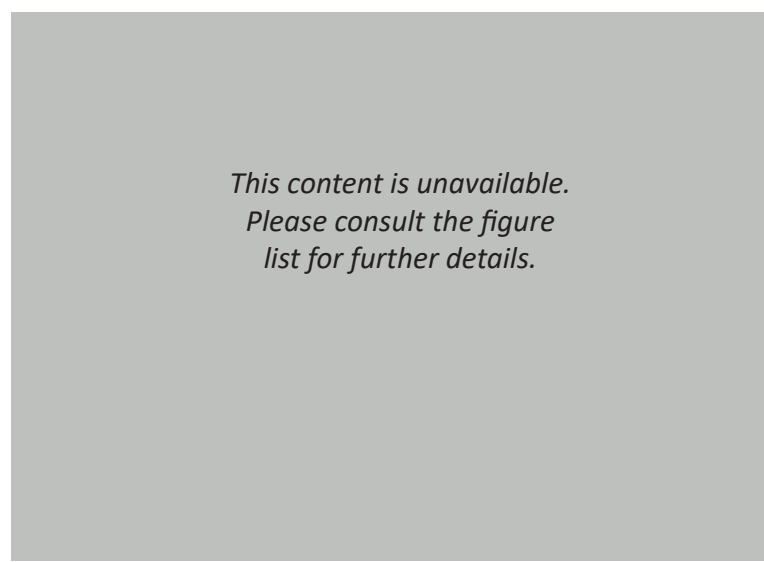

Fig. 1.18. Wellington during early colonisation, 1840.

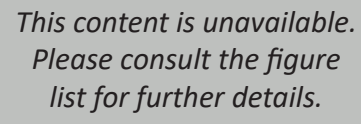

Fig. 1.19. 1840 Map of Wellington Town Plan. 
This content is unavailable.

Please consult the figure

list for further details.

$\stackrel{ }{\underline{u}}$
$\frac{u}{u}$
$\underline{\underline{I}}$

The landscape of Wellington city has changed significantly since the arrival of European settlers in the early 1840 s. The rapid expansion of the city saw a great shortage of inhabitable land to meet the demands of the growing population. As the burgeoning city grew up into the hillside encoarching on the initial planned town belt surrounding the internal settlement, the Wellington Harbour expanded outwards with the addition of 155 hectares through reclamation of land from the sea (fig. 1.21).

Since the 1850s the shape of the inner harbour has been continually reshaped with the shoreline constantly shifting as land has been reclaimed (fig. 1.22). As a result the connection with the natural shoreline of the city has been lost forever.



Fig. 1.20. Historic map of Wellington City streams, 1940.
Fig. 1.21. Reclamation of Land of Wellington Harbour, circa 1925.

The flowing network of five major streams (fig. 1.21) that paraded down the sloping terrain of the landscape were culverted and entombed beneath the urban environment within the stormwater infrastructure network to enable the city free reign to expand. The first to be culverted, the Kumutoto Stream in 1866, signifies the beginning of the decline of the natural ecosystems, lost connections with the natural landscape and the severed spiritual connection of the Māori principle of Mauri, the life giving force of water.

This investigation focuses on the waterfront as the flat stretch of land that has been manipulated, cut up and built up over time. The waterfront represents a continually shifting relationship between the natural and built landscape and the shifting identity of place as the landscape has continually transformed over time. 


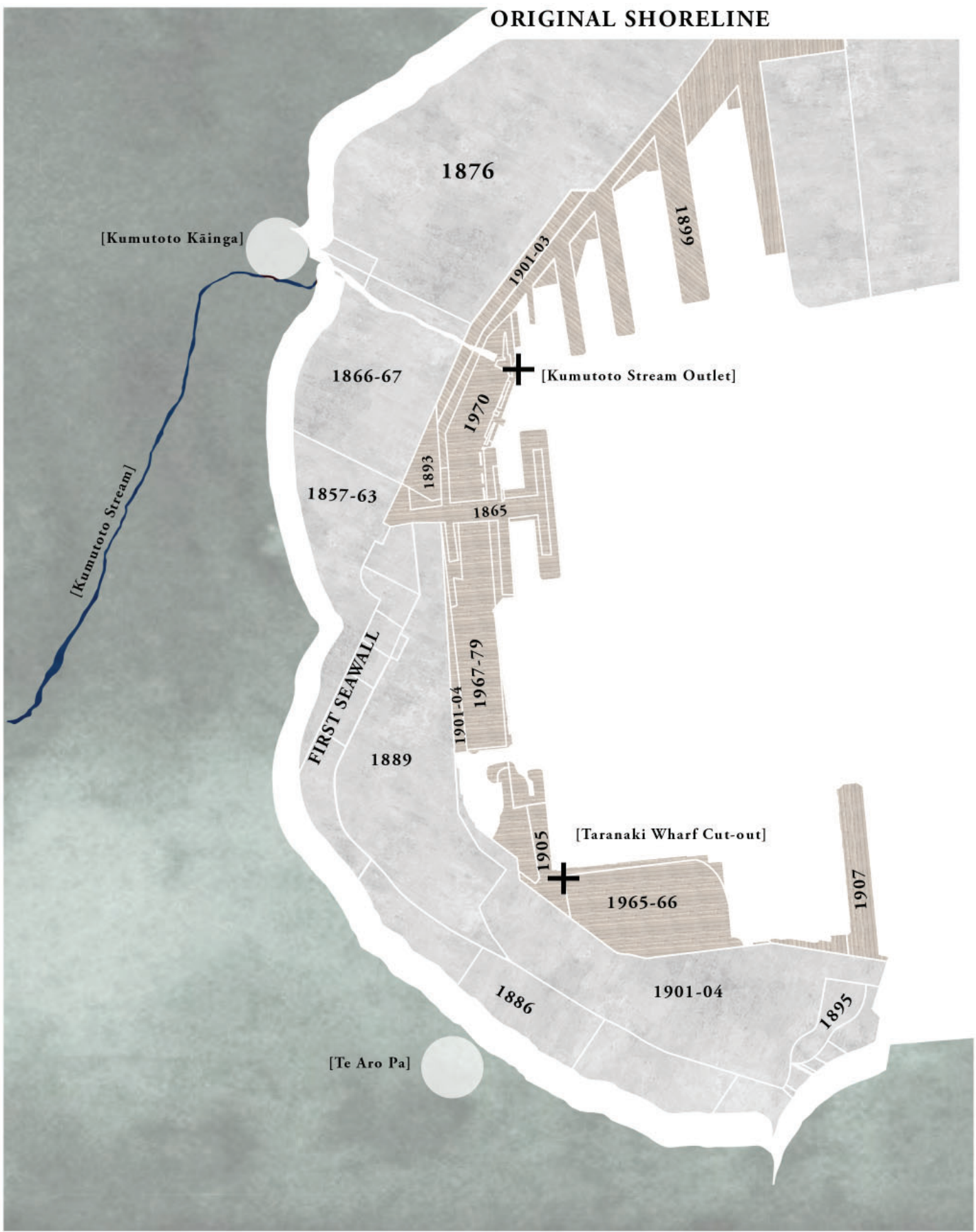

Fig. 1.22. Map of Land Reclamation of Wellington Waterfront. By Author. 


\section{『था SITES (0) 5 IRMAGINATION}

Two neighbouring urban sites along the edge of Wellington Harbour have been selected for this investigation: the Kumutoto Stream Outlet and the Taranaki Wharf Cut-out. Both have their own unique tales to tell. Their tales however, are lost beneath the layers of urban concrete. Both of these sites appear as 'openings' in the concrete where a fragment of the urban concrete has been removed. In this sense, they represent unique sites where we can witness the last remnant of their tales and allow their voices to be heard as fragments. 


\section{Opening Sites to the Imagination}

"One does not impose, but rather expose the site"

Martin Hogue, in his article "The Site as Project: Lessons from Land Art and Conceptual Art", perceives a site as more than a physcial location or empty lot awaiting building and advocates for the reinterpretation of the role of site in an architectural project. Hogue draws on Carol Burn's theories of site from her seminal article "On Site: Architectural Preoccupations", where she asserts that all sites are constructions, built from empirical conditions and the imagination (Burns, 155). Reflecting upon Burn's proposition, Hogue argues that a 'site' is never just found but constitutes an act of making (Hogue, 54).

Furthermore, Hogue draws on artist Robert Smithson who perceives site as the artistic project in itself-the site as project. Hogue summarises Robert Smitherson's understanding of a site as project stating:

Like a palimpsest, any actual site could be seen as a specific set of locations, a variety of narratives, and therefore suggests many possibilities for action (55). But it is also
—Robert Smithson, 47

27

possible to conceive, that the site might be nothing more than the structure of one's experiement. ...Smitherson helps architects to consider the richness of a site outside of its physical properties and features by establishing the importance of ideas and the imagination in site definition (55).

In this investigation, the two research sites are not engaged as physcial locations for architectural interventions, but are rather as sites that embody ideas and important characteristics of Wellington and its transformation over time. The sites are engaged to evoke the imagination to engage with the rich narratives of place that lay beneath the surface of Wellington. These sites are defined as portals to the lost layers below the surface and characters that narrate lost stories of place. Located on opposite sides of the central harbour, this investigation explores how these two sites when placed in a dialogue with one another can reveal an overall meta-narrate of place and the transformation of the landscape as a palimpsest of layers building up over time. 
Fig. 1.23. Wellington City Aerial, 2017. 
This content is unavailable.

Please consult the figure

list for further details. 


\section{KUMUTOTO STREAM

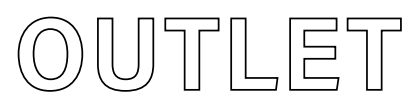

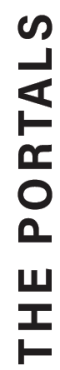

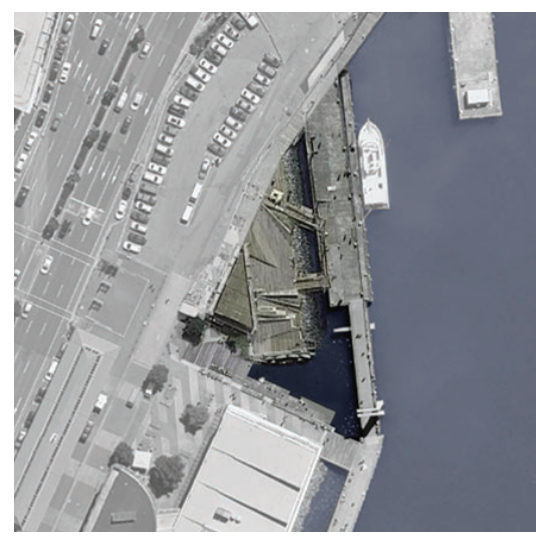

Fig. 1.24. Kumutoto Stream Outlet

The Kumutoto Stream Outlet is the site of the first culverted stream in Wellington. Culverted in 1866, this entire stream has been silenced and has disappeared forever, yet it still survives deep underground within the storm-water network. The Kumutoto Stream embodies the decline of the urban stream, a vital life source of the land prior to European colonisation. The Kumutoto Stream Outlet remained buried beneath decades of urban concrete until 2008 when a fragment of the urban concrete was cut out and removed to reveal the culverted mouth of the Kumutoto Stream as it is thrust back into the sea. This narrow outlet along the Wellington Harbour edge is the last vestigial remnant of the lost tale of the Kumutoto Stream. 


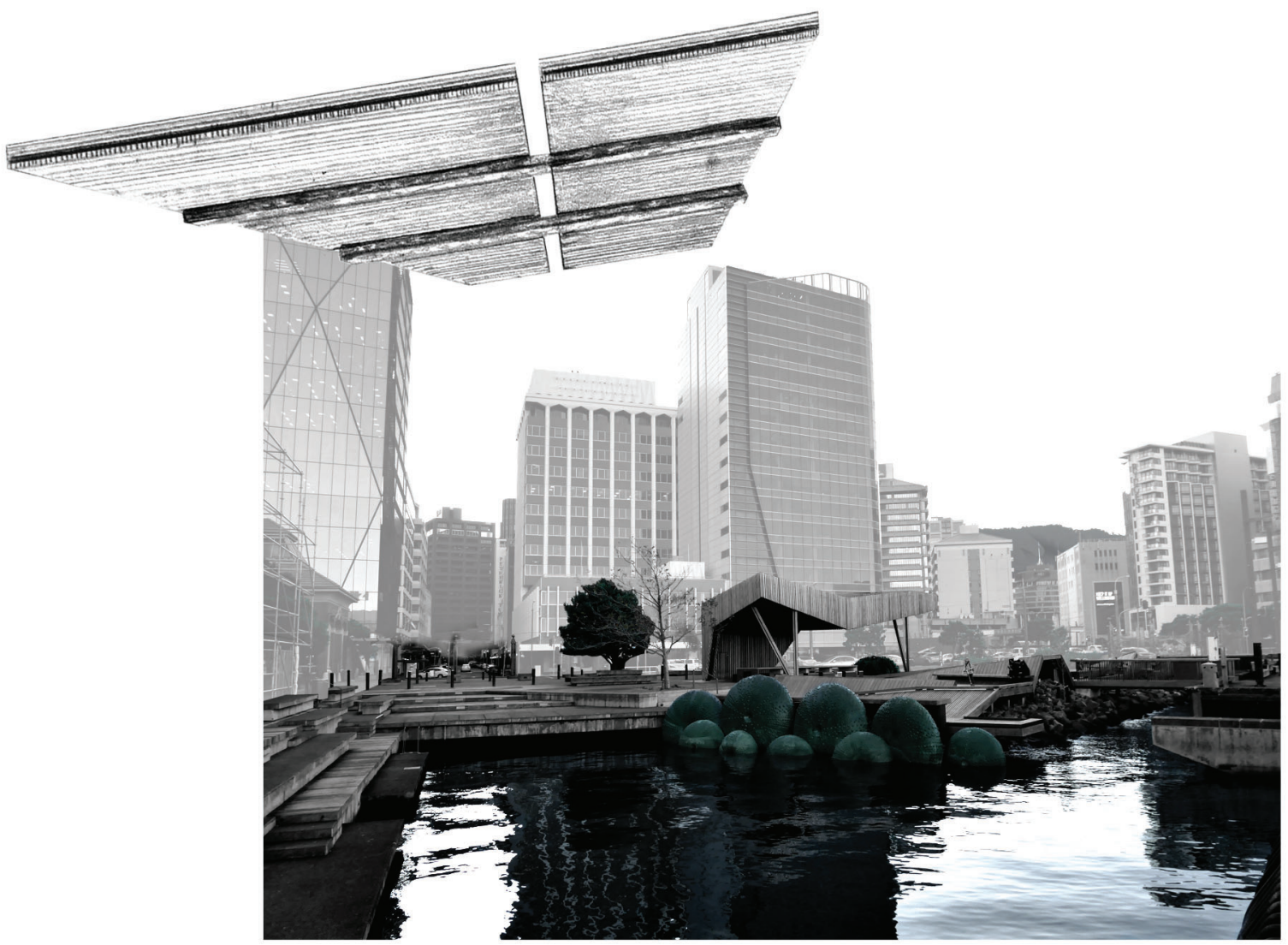

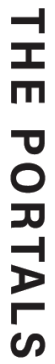

Fig 1.25. Kumutoto Stream Outlet and drawing fragment of the layer of concrete removed from the site to reveal the lost voice of the stream below. Author's own. 


\section{TARANAKI WHARF

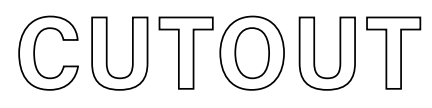

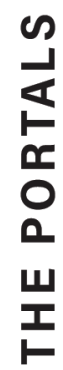

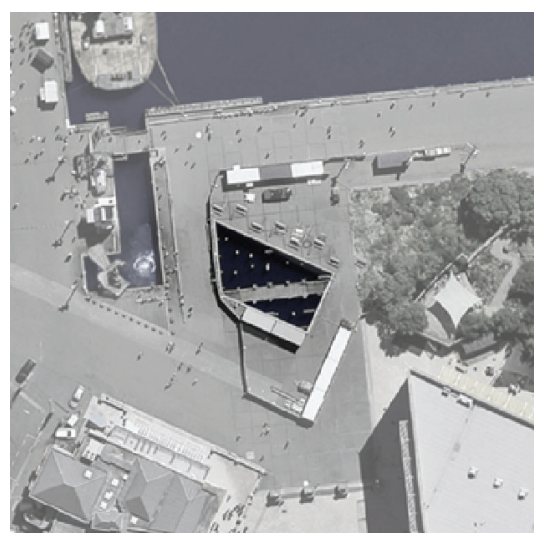

Fig. 1.26. Taranaki Wharf Cut-Out

The Taranaki Wharf Cut-out exposes lost shorelines of Wellington before urban expansion and land reclamation. Wellington's natural shoreline has been silenced and has disappeared forever below decades of urban concrete from the reclamation of land that began in the mid 1800s. In 2002 a fragment of the urban concrete was cut out and removed revealing the lost shoreline and reclamation of land The cut-out provides the last visual connection to the lost landscape below. Revealing the structural pilons of the concrete urban landscape, this site draws awareness to a lost connection between the natural and built landscape. 




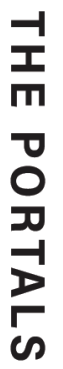

Fig 1.27.Taranaki Wharf Cut-out and drawing fragment of the layer of concrete removed from the site to reveal the lost voices below. Author's own. 


\section{SITE}

GONTEMXS

Fig 1.28. Map of Wellington Waterfront identifying location of selected sites and the path of the lost Kumutoto Stream.

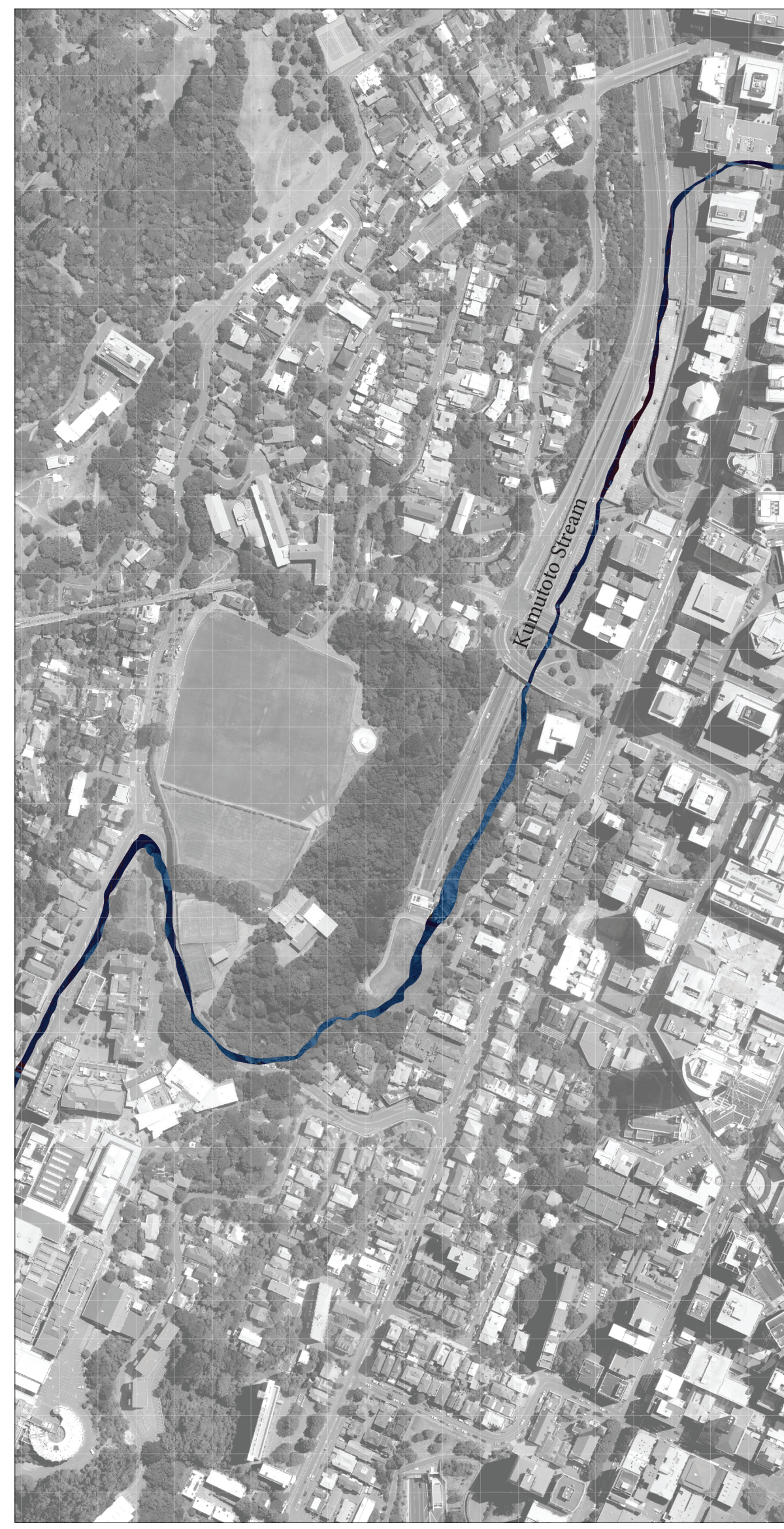


$4=a^{2}=\mathbb{A}^{2}$

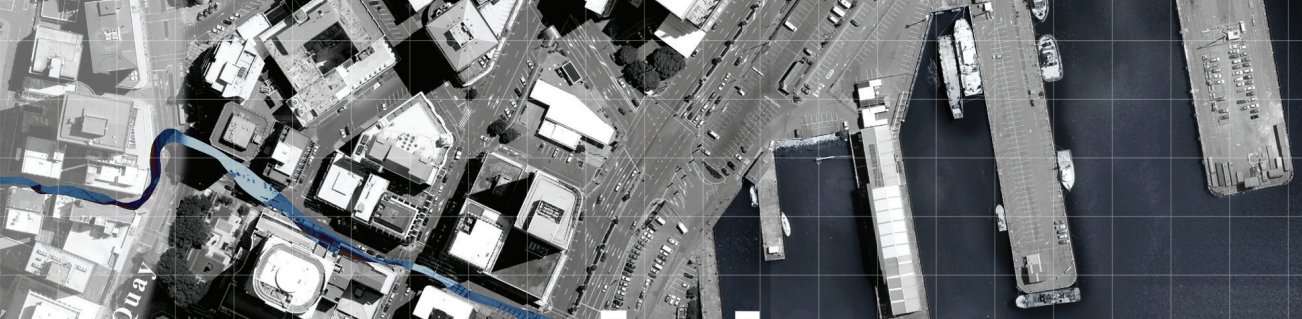

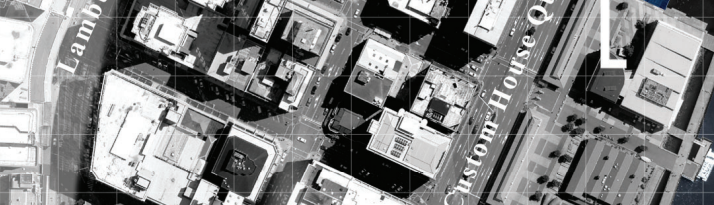

Q



He

1286

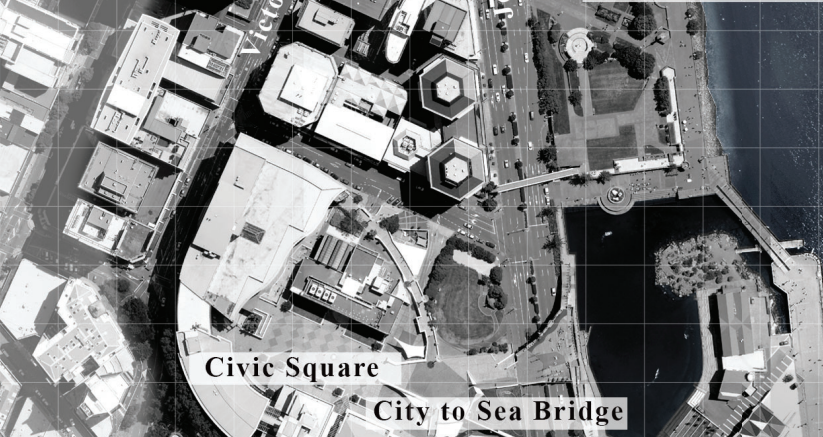

$1<1$ City to Sea Bridge (2.)

$4 x^{2}+x^{1}=1$

- $x$ 1 2 . - cr.tyo

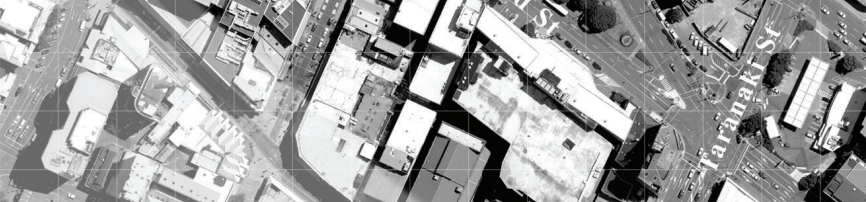

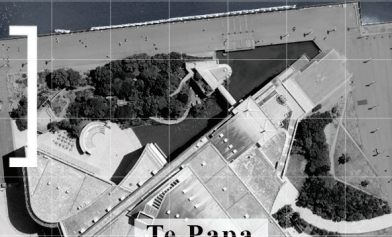




\section{KUMUTOTO STREAM OU⿴囗LET}

\section{SITE [DENTILTY}



Fig 1.29. The Kumutoto Stream Outlet beneath the urban concrete. Author's own.
The Kumututo Stream is lost forever and can never be seen in its original natural state, but its voice can be heard as a fragment-the outlet of its culvert trapped beneath the urban concrete as the stream's water is released out to sea (fig. 1.29). A fragment of the urban concrete has been removed to represent the mouth of the Kumututo Stream, drawing the harbour in and the stream out and tying the waterfront back to the city (fig. 1.31). The bridge across the outlet (fig. 1.32) echoes the presence of historic wharfs and sea walls that once lived in its place. The site represents a collage of fragmented elements that can be interpreted as figurative geometries that represent historic elements and typologies of the site itself and the surrounding waterfront. The current site is represented in this investigation as a character of Wellington that narrates the story of the lost Kumututo Stream.

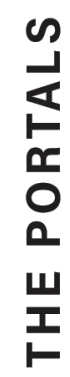



Fig 1.30. Looking towards the wharf opposite the outlet. Author's own. 


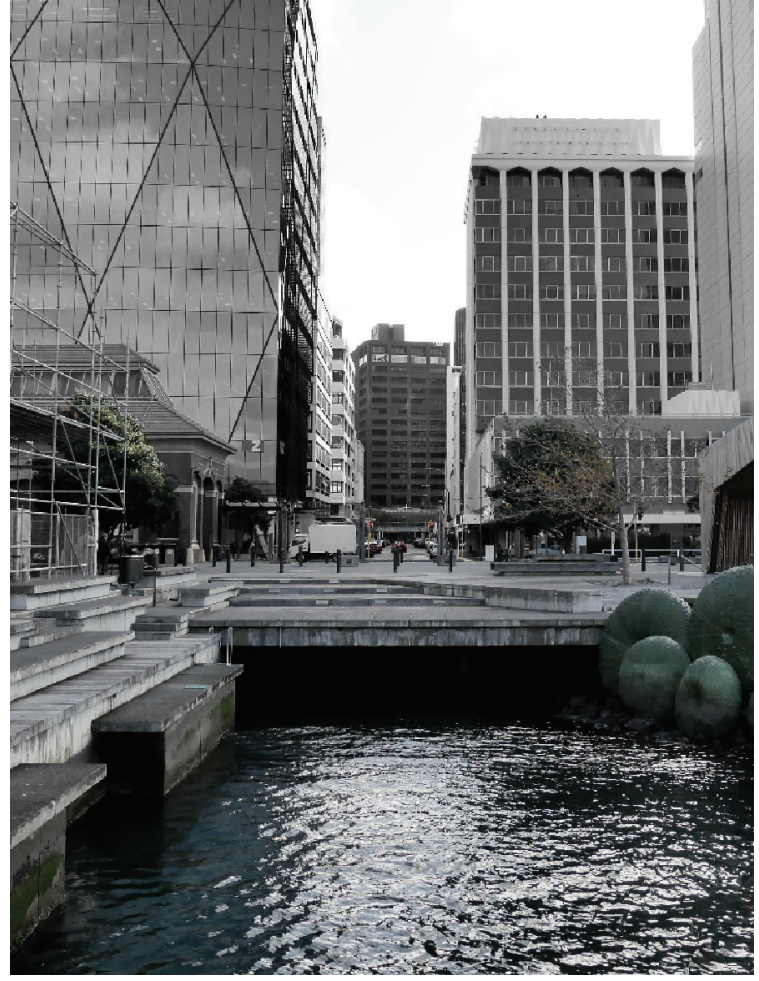

Fig 1.31. Kumutoto Stream Outlet, looking towards Waring Taylor Street. Author's own.

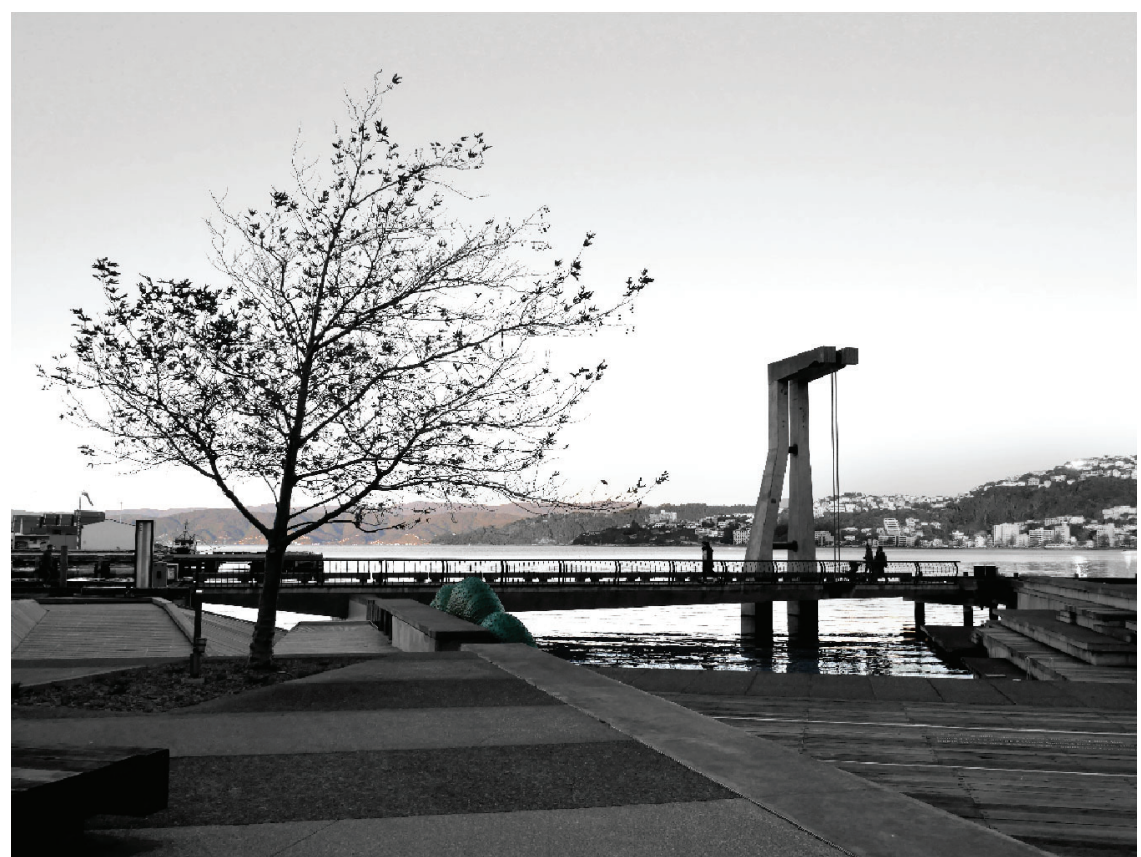

I
m
0
0
0
7
7
es

Fig 1.32. Looking towards the bridge opposite the Kumutoto Stream Outlet. Author's own. 
This content is unavailable.

Please consult the figure

list for further details.
A series of historic images of the Kumutoto

Stream Outlet captures a visual account of the evolving identity of the stream outlet as its location has shifted as land has been reclamed over time. The stream once framed by large numbers of towering native trees now lies buried underneath the constantly evolving built landscape of structures that live upon and surround the stream's lost path.
This content is unavailable. Please consult the figure list for further details.
Fig 1.35. Customhouse Quay, Kumutoto Stream Outlet site, 1905.

Fig 1.33 European settlers inspecting 




Fig 1.36. Aerial view of the city, path of Kumutoto Stream, 1947.
39

고
m
0
0
0
7
7
0

This content is unavailable. Please consult the figure list for further details.

This content is unavailable. Please consult the figure list for further details.

Fig 1.38. Kumutoto Stream Outlet bridge, today. 


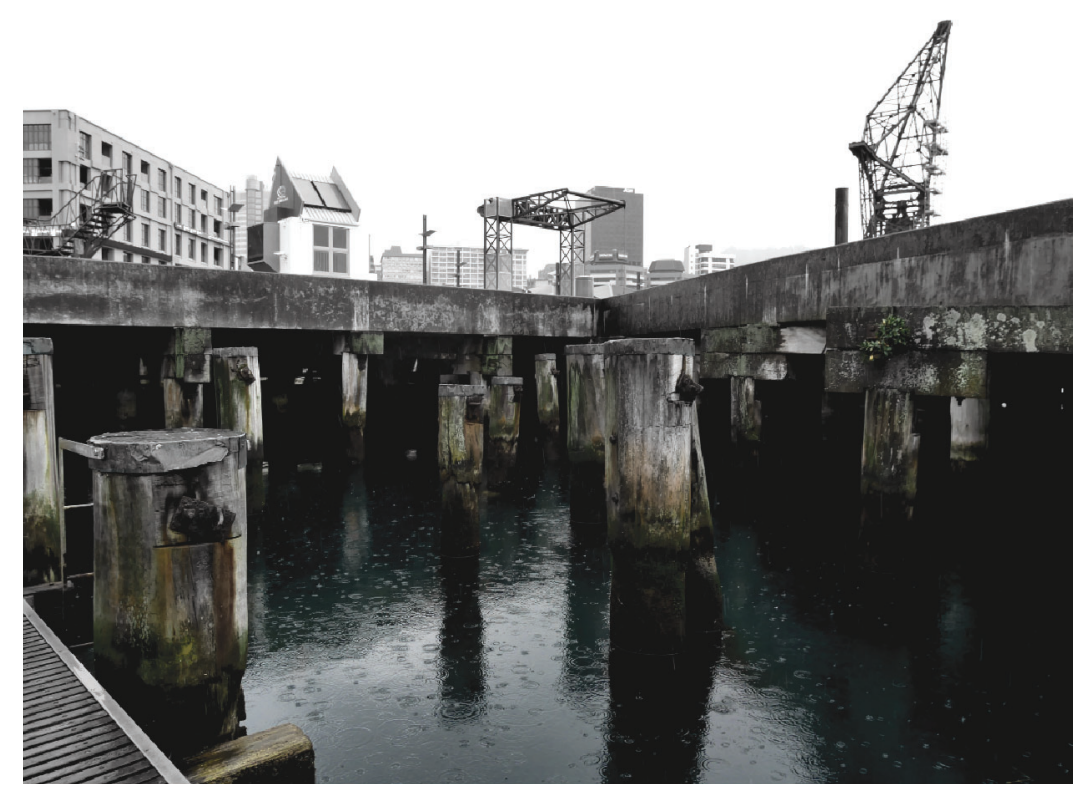

41

Fig 1.43. Taranaki Wharf Cutout, from within the cut-out. Author's Own.

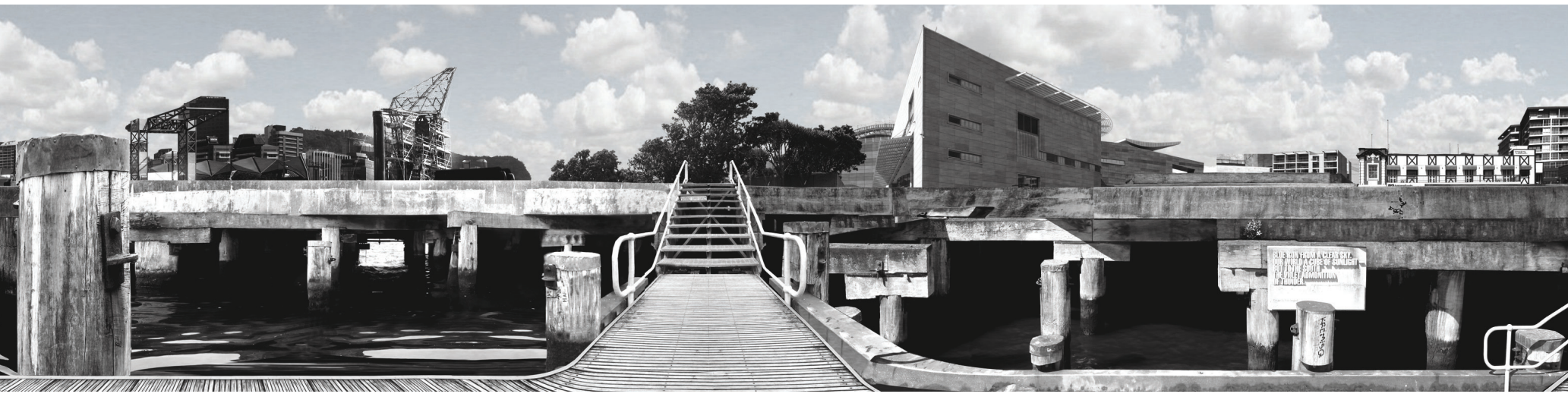

Fig 1.42. Taranaki Wharf Cutout panoramic view from within the cut-out. Author's Own. 


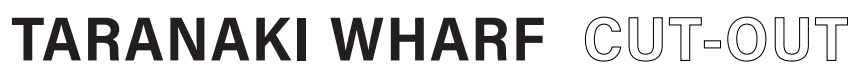

+ CUT-OUT SITE

Fig 1.45. Taranaki Wharf 1956.

This content is unavailable. Please consult the figure

list for further details.

This content is unavailable.

Please consult the figure

list for further details.

A series of historic images of the

Taranaki Wharf Cut-out site and

surrounding Te Aro foreshore captures

a visual account of the evolving identity

of the waterfront and shifting edge

condition as the land was reclaimed

over time.

Fig 1.43. Natural Shoreline of Te Aro

\begin{tabular}{c}
$n$ \\
\hline 4 \\
0 \\
0 \\
0 \\
1 \\
1
\end{tabular}

Flat before reclamation, 1863.

This content is unavailable.

Please consult the figure

list for further details.

Fig 1.44. Te Aro Waterfront, circa 1884. 
This content is unavailable.

Please consult the figure

list for further details.

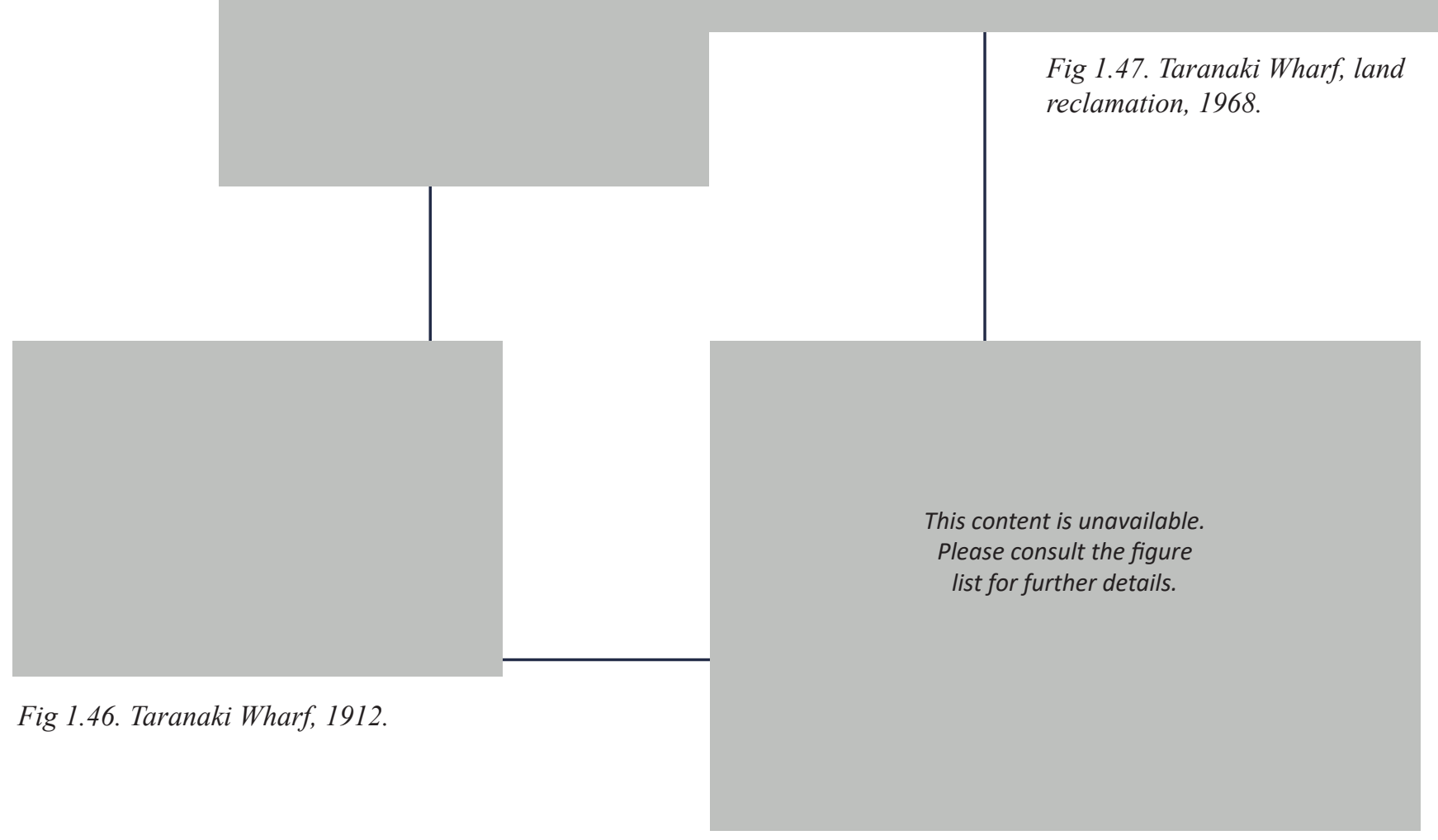

Fig 1.48.Taranaki Wharf Cut-out site, pre cut-out, 1974. 




Fig. 2.1.1. Theory as a notebook of thoughts. 


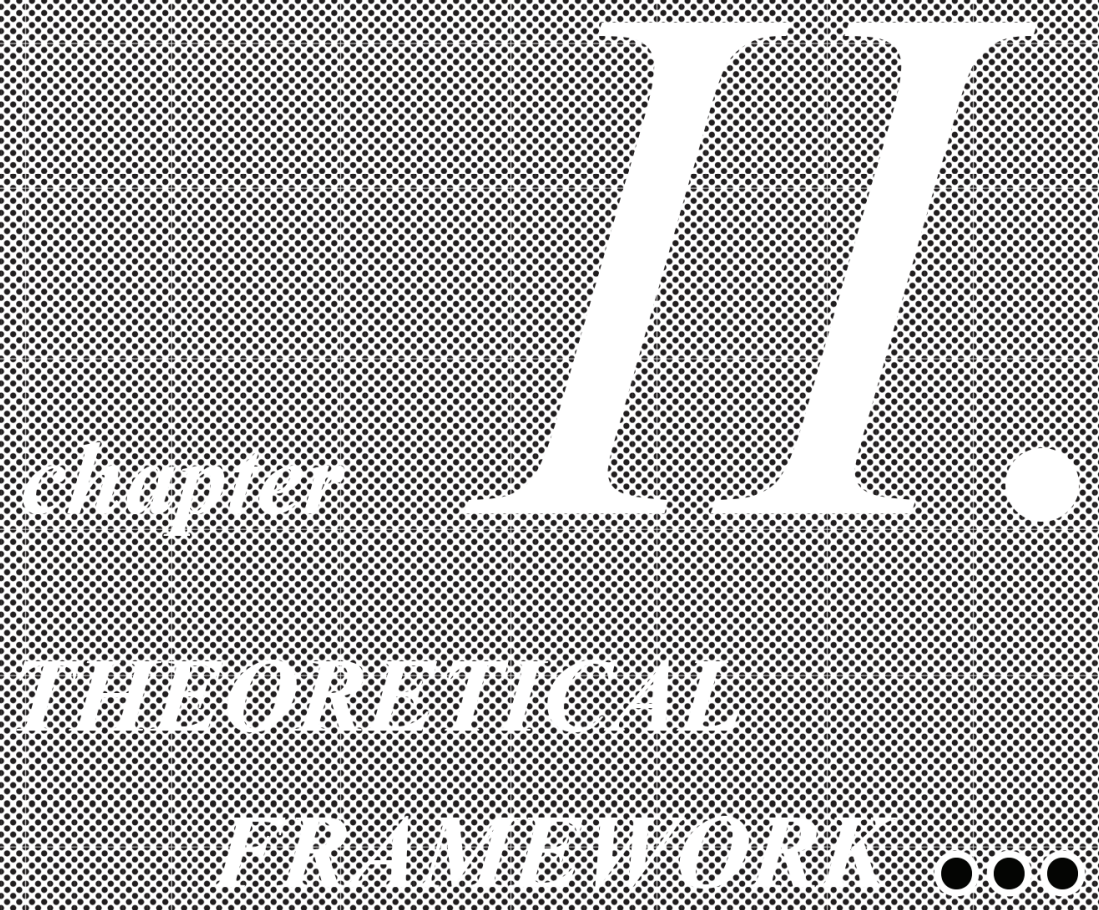



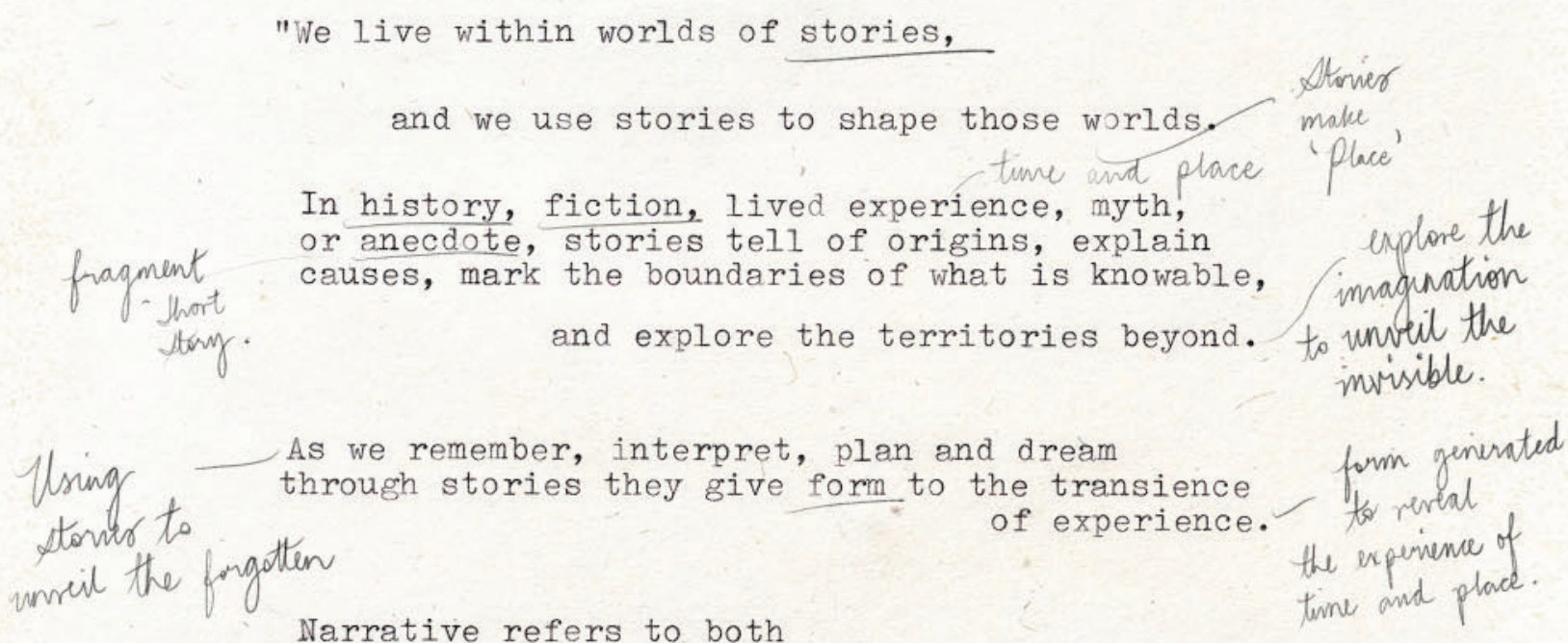

Narrative refers to both

$$
\begin{aligned}
& \text { the story, - the meta-marrative } \\
& \text { what is told, - the furagments of toldoner } \\
& \text { and the means of telling, } \\
& \text { certain meaming } \\
& \text { implying both product and process, form and is prought to life } \\
& \text { The pinocess of forming the } \\
& \text { Whor voice? }
\end{aligned}
$$$$
\text { formation, structure and structuration." and told from }
$$

- Matthew Potteiger and Jamie Furinton, 3 


\subsection{Introduction: Narrative + Placemaking}

There are rich layers of stories associated with the history and identity of any site that enable us to associate that site with place identity. Landscape architects and theorists Matthew Potteiger and Jamie Purinton in Landscape Narratives: Design Practices for Telling Stories write, "every narrative, even the most abstract, allegorical, or personal, plays a critical role in making place" (6). These stories locate us in space and time, offering a greater understanding of the world. Sheila Danko, Professor of Design, in her article "Humanizing Design through Narrative Inquiry" argues:

Narratives ... are a way of making sense of the world around us and our role in it ... [S]torytelling structures perceptions, organises raw experiences into memories, and gives meaning to human experience. (11)

While there is a long history of using narrative in architecture to create designs that tell a story, Danko advocates for the reintegration of narrative as: "a tool for exploring ideas and guiding decisions throughout the various stages of the design process" (13) rather than only as an outcome. Potteiger and Purinton similarly advocate for the use of narrative as a means of critical inquiry throughout all stages of the design process:

As stories sequence and configure experience of place into meaningful relationships, narrative offers ways of knowing and shaping landscapes not typically acknowledged in conventional analysis, documentation, mapping of sites, or even the formal concerns of the design of architecture or landscapes. (Potteiger and Purinton ix)

This thesis engages narrative as a method of understanding, reading and interrogating a placelandscape and/or site-beyond its objective appearance. Potteiger and Purinton posit, landscapes are imbricated with narrative; they intersect with sites, accumulate as layers of history, organize sequences, and inhere in the very materials and processes of the landscape (ix). Potteiger and Purinton further discuss how landscapes not only locate or serve as a background setting for stories, but they are in their own right a changing, eventful figure and process that engenders stories, where traces in the landscape hold secrets and invite interpretation $(5-6)$. This thesis aims to 'open' the landscape to the imagination to reveal these traces and lost layers.

... opening landscapes begin with understanding the site as an intersection of layers of stories connected to other stories. (Potteiger and Purinton, 189)

When integrating narrative thought within the process of design, Potteiger and Purinton argue for the necessity of 'open narratives'-generated from multiple stories shaped by a plurality of voices - in the reading, interpreting and designing of architecture and landscapes (187). This is in contrast to 'closed narratives' that prescribe singular linear narratives from one limited point of view that "silence or displace diverse voices, erase layers of history and complexity of associations, and draw distinct boundaries between [themselves] and the living" (187). Unlike Closed Narratives that remain static and linear, Open Narratives acknowledge "the incompleteness of history, and the dynamics of nature", acknowledging and emphasising the dynamic element of time often neglected in the interpretation and design of architecture and landscape (189).

Rather than prescribing a narrative of place from the outset, this thesis explores means to reawaken and unveil stories as fragments through the process of design, where the greater narrative is shaped by multiple voices and remains open for interpretation. The aim of Chapter II is to establish an overarching approach for addressing the use of allegory in architecture as a critical method for addressing the Research Question. 


\section{Architectural Allegory}

allegory

/'alıg(a)ri/

noun: departing

from a literal use of

words; metaphorical

a symbolic

representation or

narrative

[RA]: to explore how an allegorical architectural project can reawaken and unveil lost voices of a place through mapping the field of imagination, collage and the creation of dreamscapes, and allegorical drawing fragments.

// a critical method 


\title{
2.2 The Allegorical Architectural Project
}

\author{
A Critical Method
}

The Allegorical Architectural Project synthesises design and theory to visually investigate innovative and critical articulation of concepts that are difficult to investigate through traditional design processes. In her article "TheFall:AllegoricalArchitectural ProjectasaCriticalMethod", Dr. Penelope Haralambidou proposes that, "the allegorical architectural project [is] an experimental practice, pointing to ideas impossible to grasp through the profession or in purely discourse-based theoretical investigations" (234).

Based on a theoretical understanding of literary allegory, architectural allegory engages in metaphor to enable a storytelling capacity where meaning is conveyed through enigma and ambiguity to generate duplication of meaning and invite open-ended interpretations (Haralambidou, 226). Haralambidou defines allegory as an experience of the world-not permanent, but fragmentary and enigmatic. In allegory, combinations of memory and object are presented not as a whole, but transformed into signs, both as a technique of allegory and its content (226). Allegory facilitates speculative interpretations of memory and the imagined to play a key role in the conceptualisation and development of complex ideas, and in the case of this research, to act as a provocateur for unique architectural design outcomes to help awaken and reveal lost voices of place. As Haralambidou writes:

The allegorical architectural project can be employed to unravel another piece of work, a site or drawing itself by questioning its underlying syntax: allegorical design reveals an analytical inclination and becomes a vehicle for criticism. (Haralambidou, 225)

Haralambidou conveys her own allegorical design process - an alternative critical practice-through her architectural project, The Fall, the design of an imaginary building, to reveal how allegorical narratives offer critical inquiry into architectural representation, the design process, and theory. In The Fall Haralambidou employs the medium of drawing - the language of describing buildings-alongside methods of collage and speculative mapping, as a vehicle for grasping and developing spatial ideas, questioning underlying syntax within the design process, and revealing an analytical inclination. This thesis engages the allegorical architectural project to critically interrogate the rich narratives of place, and it challenges the ability of architecture to reawaken forgotten layers and stories of 
'place' that lie hidden beneath the urban concrete of Wellington. Due to its critical nature and narrative capability, the allegorical architectural project facilities the possibility of revealing hidden voices and stories of a place beyond a traditional design processes.

Haralambidou provides a theoretical background for allegory as a critical method in architecture and reflects upon five allegorical traits that can be used as tools in the evaluation of the allegorical architecture project.

The key traits of the Allegorical Architectural Project are:

\section{DOUBLE MEANING}

The duplicity of meaning that invites interpretation;

\section{UNFINISHED}

The state of being unfinished;

\section{VISUAL + VERBAL}

The reciprocity of visual and verbal in the production of meaning;

\section{PROGRESS \& BATTLE}

The journey across time, and/or; the conflictopposition between two forces;

\section{FIGURATIVE GEOMETRIES}

The use of figurative elements to denote structural relationship.

This thesis draws on all five traits as contributors to the theoretical framework of the use of allegory in architecture as a critical method. 


\section{DOUBLE} MEANING INVITATION FOR
INTERPRETATION

\begin{abstract}
Allegorical architectural works are structured to be understood in a similar way to an allegorical work of art where meaning is not grasped directly,
\end{abstract}

but through metaphors. Allegory in architecture does not readily convey meaning but uses dualities and overlapping interpretations to generate dual meanings that invite an open-ended interpretation from both the reader and the author.

Haralambidou considers Marcel Duchamp's assemblage, Given: $1^{\circ}$ the Waterfall, $2^{\circ}$ the Illuminating Gas (1946-66), to be a successful work of allegory, because it triggers diverse interpretations, writing: "It is not the artist alone who performs the creative act; the viewers [can] make their own contribution" (231). This active participation in the art form is similar to the way a reader deciphers meaning in literary works; meaning and knowledge are therefore constantly evolving with each reading. As Haralambidou acknowledges, "the work of art is an allegory in receiving, interpreting, but also in making" (230).

Allegorical architecture is an interpretative, critical act, both in the design process and in the reading of works, which encourages poetic imagination to trigger associations, memories, and emotions. Within the Allegorical Architectural Project, the author does not prescribe meaning from the outset, but unveils meaning through the generative process of design: analysis, creation and later reflection, while leaving room for the reader to impart their own meaning.
UNFINISHED

Allegory is often associated with the incomplete, fragmentary and

unfinished. Allegorical architectural projects are unbuilt and occupy the realm of the imagination-a fragmentary, multi-layered and never-ending realm.

Reflecting on her allegorical architectural project The Fall, Haralambidou argues that the true meaning of the project is not revealed through the final series of exhibited drawings and model, but within the pages of 'her sketchbook'-an ambiguous, fragmentary, and often contradictory investigative collection of ideas as drawing fragments and text notes (233). In this thesis investigation, the entire bound 'codex' represents Haralambidou's notion of 'the sketchbook' where the pages reveal the true nature of the research project, not as a finalised design outcome but as a fragmented design process that interweaves text and speculative outcomes to reawaken lost voices of place as fragments, coming together. 
The architecture is the text and the text is the architecture." (Haralambidou 225)

Fig 2.3. The Fall, sketchbook page,

Haralambidou.

This content is unavailable.

Please consult the figure

list for further details.

\section{VISUAL + VERBAL}

American postmodernist critic Craig Owen acknowledges the reciprocity between visual and verbal in allegory, outlined in his article "The Allegorical Impulse: Towards a Theory of Postmodernism", where words are often visual phenomena and visual images are presented as a script to be deciphered (74). In the Allegorical Architectural Project, drawing and text complement each other in the production of meaning.

Haralambidou posits that even a page presenting a constellation of words is a 'written drawing' rather than just text (234). She argues that it is through the configuration and design of both written and drawn parts of a project that the structure of the research is revealed (Haralambidou, 234). Even when a page is mainly a constellation of words connected with lines, it is a 'written drawing' rather than just text, and the configuration refers to the structure of the research, the design of both written and drawn parts (Haralambidou, 234).

The idea of the 'sketchbook' reifies this notion; the notes, fragments cut and pasted, drawings and diagrams can all shape constellations of ideas that shift between writing and drawing, verbal and pictorial or analytical and synthetic (234). 
PROGRESS \& BATTLE

Angus Fletcher in his book Allegory: The Theory of a Symbolic Mode defines two broad categories of allegorical narratives: 'progress', a description of the journey across time, and 'battle', an opposition between two forces seen as a conflict.

Professor of architectural theory Nadir El-Bizzri argues that architecture is never experienced in its totality, but rather is offered through a sequential continuum of manifold appearances in time and space (El-Bizzri, 38). Its visible aspects unfold as we journey through it. 'Progress' is embodied in this thesis as multiple voices of time and place are revealed as fragments through the process of design unfolding as we journey through the archive-the entire bound codex as the thesis outcome.

In this investigation 'Progress' also refers to the transformation of the landscape as a journey across time, generative of rich historical narratives that overlap and intertwine as layers of site identity that contribute to the overall meta-narrative of a place. This trait of Progress acknowledges the prominence of 'Time' as a seminal element in this thesis investigation.

'Battle' in this investigation refers to the dialectic relationship-the 'conflict'-between the built landscape and the natural landscape, and the battle between conflicting fragments of time and place reawakened in this thesis coming together to reconcile their differences.
Haralambidou asserts that allegorical works of architecture can be seen to belong to either one, or both of these categories. These two categories of allegorical narratives provide a foundation for design explorations to build upon.

\section{figurative \\ fig(ə)rativ/}

adjective: departing from a literal use of words; metaphorical
Haralambidou describes allegory as 'Figurative Geometries' where allegorical narratives operate as mathematical equations or geometric principles, which instead of abstract numbers and letters, use abstraction of objects, architectural forms and sites to signify meaning and relationships (231). These equations - the allegory-however, remain abstract and unfinished, as though emptied of their content by the structure that governs them (Haralambidou 231).

Figurative geometries are investigated in this thesis on the two selected sites in relation to: 1) mapping fragments, 2) collage fragments, and 3) allegorical drawing fragments. Figurative geometries are discussed throughout these sections, to explore how analogical thinking has the ability to string fragments together to convey or gain new meaning. 


\title{
The Voices of Allegory
}

\author{
// a provocateur
}

"But what is the past?
Could it be, the firmness of the past is just illusion?"

—Alan Lightman, Einstein's Dreams, 192

"The city, however, does not tell its past,

...but contains it like the lines of a hand". 


\subsection{The Voices of Allegory}

Fictional Literary Context

This thesis engages two fictional literary works, Einstein's Dreams by Alan Lightman and Invisible Cities by Italo Calvino, as allegorical provocateurs for invoking the imagination and discovering new ways to reawaken lost voices of a place.

Professor CJ Lim, in his article "London Short Stories: Drawing Narratives," asserts that the use of literary theory and allegorical literature in architecture can offer inspiration to engage with real and imaginary sites as springboards for imagination (Lim, 102). Engaging literature as a provocateur for architecture encourages critical interrogation and analysis of design and complex ideas, and as Lim argues, restores the symbolic storytelling potential of architecture and place, both in the reading and designing of architecture and the reading of a place beyond its superficial appearance (104).

Quotes from Einstein's Dreams and Invisible Cities thread throughout the investigation as 'The Voices of Allegory' that have been situated into dialogues with one another. 


\section{Einstein's Dreams}

by Alan Lightman

“...time, is an infinite ruler

...time is absolute."

-Alan Lightman, 34

This content is unavailable. Please consult the figure list for further details.

Fig 2.4. Einstein's Dreams by Alan Lightman.
Einstein's Dreams is a fictional collage of vignettes illustrating dreams of Albert Einstein during the year he developed his theory of time. Written through the allegorical framework of dreams, Lightman describes the 29 different perceptions of time as dreams each situated on its own specific day, as if they existed in real life as physical place, rendering time as space. Each world is inhabited by nameless dream figures whose lives are depicted as they navigate the inevitable dictations of the limitations and structures of time. Although the physical setting and structure of time vary from dream to dream, the characters and depictions of life echo a certain familiarityan ultimate quest for meaning and the human relationship with time. Interrogating this relationship, Einstein's Dreams pushes the boundaries of the human connection with the past, present and future challenging perceptions of memory as multi-dimensional. The use of allegory in the visualisation of multiple dimensions allows the reader to reinterpret time, and critically interrogate the implications of time as a nonlinear multi-layered construct, evoking critical perceptions of our experiences and understanding of the places we inhabit. 


\section{"In time,}

Einstein's Dreams is engaged in this design-led thesis investigation as an allegorical framework for reconsidering time and its significance in altering physical sites and landscapes, and how we read and perceive them. Through this generative framework the selected sites are critically interrogated in a nonconventional way to critically draw out more meaningful and unexpected discoveries, with the goal of provoking unique architectural outcomes and experiences in later design stages.
57 there are an infinity of

...worlds." 


\section{Invisible Cities}

\section{by Italo Calvino}

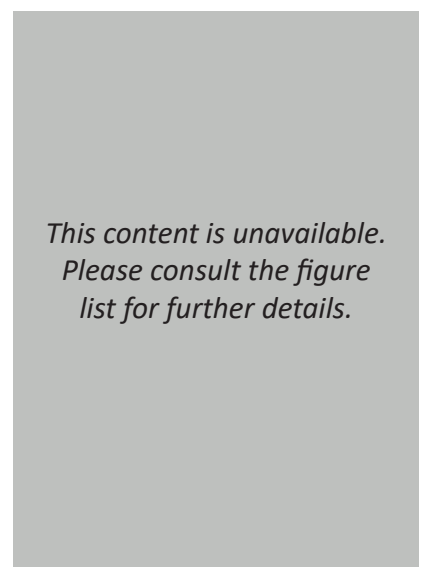

Fig 2.2.2. Invisible Cities by Italo Calvino.

\section{"The city, however, does not tell its past}

\author{
but contains it like the lines of a hand.."
}

-Italo Calvino, 11

Invisible Cities is a collection of fifty-five vignettes framed as a dialogue between Emperor Kublai Khan and Venetian explorer Marco Polo. The Emperor orders Polo to travel the empire and gather stories of cities with which he can be regaled. Polo starts by describing seemingly impossible cities that defy conventional perceptions of place. Polo, however, does not speak the Emperor's language, so uses gestures and objects to communicate. Over time, the Emperor memorizes the meaning of the objects and Polo learns the Emperor's language. Polo's descriptions become increasingly surreal, and the Emperor begins to suspect Polo's descriptions are constructed in his imagination. Polo ultimately reveals he speaks only of his home in Venice from a myriad of imaginary angles.

Invisible Cities identifies that everything from city to object exists as memories, where certain cities change depending on how a person remembers, perceives and experiences them. The identities of these cities are constructed in both the imaginations of the characters who project their personal experiences and desires on them and in the dialogue between them, drawing out undiscovered layers. Calvino is highlighting the notions of subjectivity and multiplicity in the understanding of place. He explains there are as many versions of a tale as there are listeners, "it is not the voice that commands the story: it is the ear" (135). Therefore, in order to begin to reveal the identify of a place through its stories the same stories must be told through a series of different modes and varying points of view.

Polo divides Venice into various categories, including "Cities of Memory," "Cities and Signs," "Hidden Cities," and so on. The cities, however, while categorised, do not evidence a clear pattern of sharing similar themes among each category, but exist as a collage of elements and themes, with a myriad of layers, emphasizing that places cannot be neatly categorised, explained or understood but must be pieced together from fragments and memories. 
"... sometimes different cities follow one another on the same site and under the same name, born and dying without knowing one another, without communication among themselves."

-Italo Calvino, 31
59
Invisible Cities is engaged in this designled thesis investigation as an allegorical framework for reconsidering an understanding of 'place' as multi-layered. Physical sites exist as a myriad of individual identities and voices that alter how we read and perceive them. Through this the selected sites are critically interrogated in a nonconventional way through a range of different techniques to draw out more meaningful and unexpected discoveries, with the goal of provoking unique architectural outcomes that reveal stories of place in multiple different ways retold through different voices.
" Arriving at each new city,

the traveler finds again a past of his

that he did not know he had..."

- Italo Calvino, 28 

61





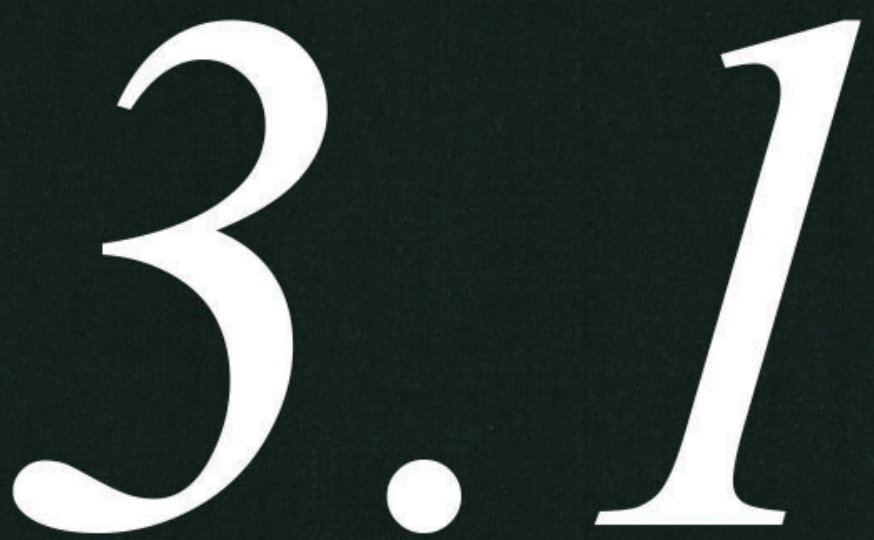

$+$

$$
\text { chace }
$$

"Time and space are dynamic co-existing elements

of landscape; they are ideologically encoded, culturally threaded.

Pieced together in many different ways,
Fragmenty they tell stories - stories of the present that
and may unravel into past, stories not only of now lagery but then, not only of here but there. $\underbrace{\text { SPAL (PLACE) }}_{\text {TIME }}$ (nagments 00 Imagine landscape as a canvas, freshly fragments Imagine landscape as a canvas, freshly overlaid. painted, but with bits of other older paintings showing through, like a pentimento, and with the colours of the world outside the frame seeping in around the edges." 


\section{3}

\section{Mapping \\ the Field \\ of Imagination: Through the Portals}

portal

/'pэ:t(ə)|/

noun: doorway, gateway, or entry to something else
[R01] to explore how mapping can be used to generate a foundation (field) upon which multiple sites of the imagination can be simultaneously interrogated as test subjects. 


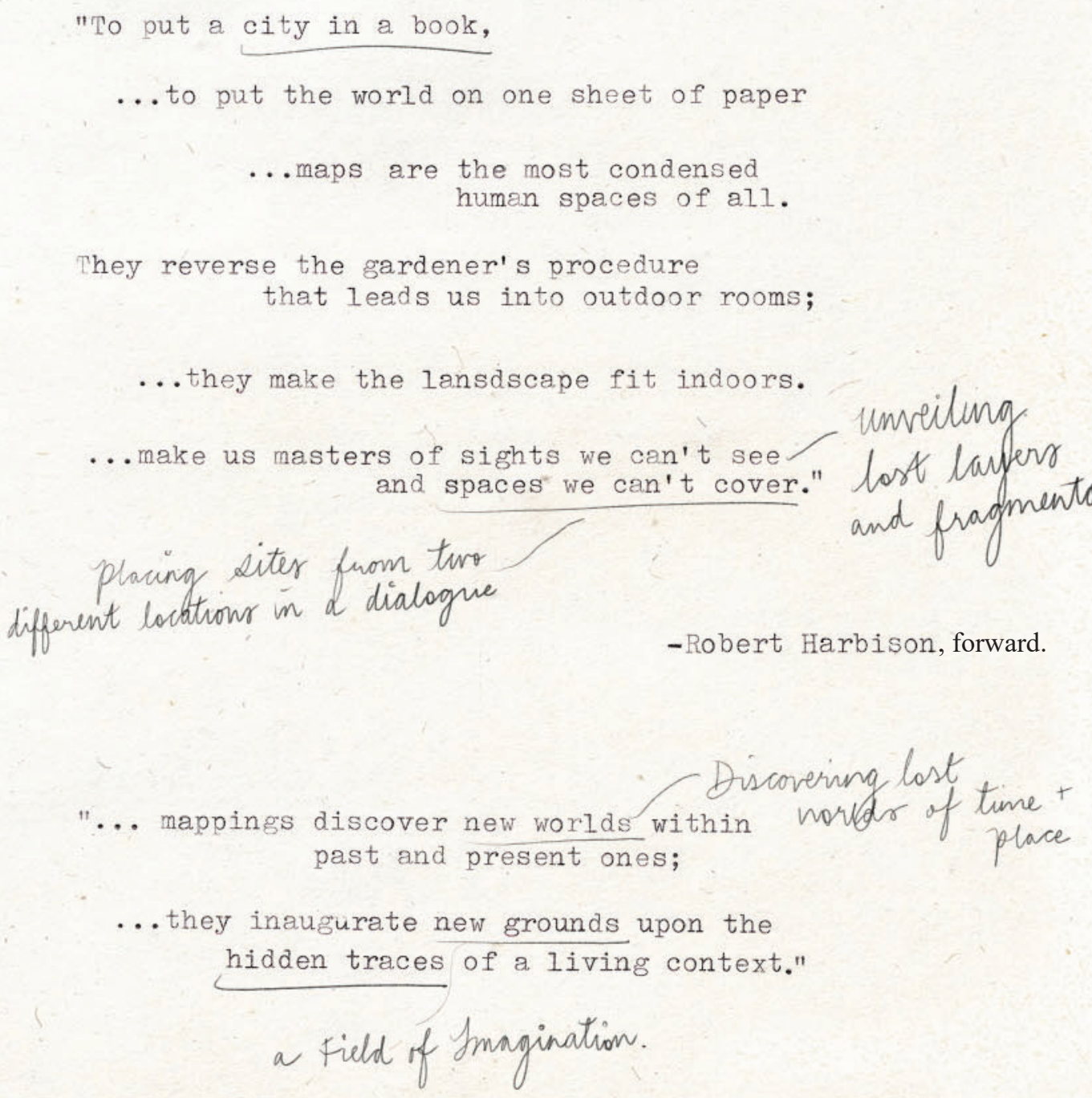

-James Corner, 209

Fig 3.1.2.. Speculation by author of quote by James Corner regarding mapping. 


\subsubsection{Mapping the Field}

"Site" today is a multiplicitous and complex affair, composing a potentially boundless field of phenomena, some palpable and some imaginary. In making visible what is otherwise hidden and inaccessible, maps provide a working table for identifying and reworking polyvalent conditions; their analogous, abstract surfaces enable the accumulation, organization, and restructuring of the various strata that comprise an ever-emerging milieu.

—James Corner, 208

This section addresses Research Objective One, exploring how mapping can generate a foundation (field) upon which multiple sites of the imagination can be simultaneously interrogated as test subjects. It examines how speculative mapping can be used as an investigative technique, to reawaken lost voices of a place by revealing and unveiling lost fragments and hidden layers of the landscape, and to generate speculative outcomes that enable contextual relationships of two sites to be explored simultaneously.

James Corner, theorist and landscape practitioner, in his essay "The Agency for Mapping," advocates for the art of 'Mapping' as a formative process: "first disclosing and then staging the conditions for the emergence of new realities... [as] a process of uncovering multiple layers of information and making them visible through representation" (Corner 216). The aim of generative drawing and mapping for Corner is to uncover what might remain hidden. Unlike conventional mapping methods that trace past conditions through direct appropriation, Corner asserts that contemporary methods should point to the past without directly recreating history.

Alison Bick Hirsch, assistant professor and landscape theorist at the University of California, affirms that the mapping process is by necessity both measured and abstract. Hirsch expresses the analogous nature of mapping in the introduction of James Corner's book of essays The Landscape Imagination, declaring that a map must be more than simply a measured projection of the ground, but must re-present or reterritorialize the world through omissions, symbols, annotations and delineations (Hirsch 25). Hirsch lays emphasis on the operative technique of mapping, in establishing how elements are framed and set up to derive new realities out of existing conditions (Hirsch 25).

Articulating the importance of a framework for the process of mapping, James Corner identifies three essential operations in mapping: 1) the creation of a field, the setting of rules, and the establishment of a system; 2) the extraction, isolation, or "deterritorialization" of parts, fragments and data; and 3) plotting, drawing-out, and setting-up of relationships, or "reterritorialization" of the parts and fragments (214). Unlike traditional mapping, Corner advocates for the speculative nature of mapping to challenge normative practices. Specifically, a field that breaks away from convention is more likely to precipitate new findings than one that is more generic and structured. 
Corner differentiates mapping from 'planning', emphasising the generative nature of mapping that "entails searching, finding, and folding complex and latent forces in the existing milieu", unlike planning that imposes a suggestively "idealized project from on high" (Corner, 212). Whereby a plan proposes a static 'end', the map discloses stages and provides a potential for future discoveries, forms, and narratives to unfold. Acknowledging the generative nature of mapping, Corner argues that "mapping is always already a project in the making" (251).
Corner articulates that a site is "as much bound into time and relational connections as it is to traditional notions of enclosure and "place'" (99). In order to fully examine the identity of a place, mapping must aim to reveal the transformation of a site over time by examining elements of a site from different points in time simultaneously.

Table 1. James Corner's Operations of Mapping (Corner, 94-95)

FIELD

The graphic system with which extracts are organised. The system includes elements such as the frame, orientation, scale and the graphic projection.
Extracts are the things that are observed within a given milieu and drawn onto the graphic field.

They are termed 'extracts' because they are selected, isolated, and pulled out of their original relationships with other things - effectively 'deterritorialized'.
PLOTTINGS

The 'drawing out' of new and latent relationships that can be seen amongst the various extracts and fragments within the field'reterritorializing' extracts.

Structures of Plotting:

- Layering

- Game-board

- Drift

Stage 01

Stage 02

Stage 03

Creation of the Field

Extraction

Plotting

Setting of Rules

Isolation

Drawing Out

Establishment of a System
'Deterritorialization' of parts, fragments and data
Setting up of Relationships, or 'Reterritorialization' of the parts and fragments. 
Alongside his essential mapping operations, Corner introduces a series of 'plotting' structures that provide a useful model for mapping as a creative form of spatiotemporal exploration of a place. This investigation draws on three of these structures: Layering, Game-board and Drift.

\section{LAYERING}

The superimposition of various independent layers upon one another to produce a heterogeneous and 'thickened' surface. When serparate layers are overlaid together, they formulate a stratified amalgam of relationships amongst the parts (Corner, 95-96).

The technique of 'layering' provides a method for how mapping can reveal multiple hidden layers of a site's transformation over time and overlay them to explore how they relate over time.

\section{GAME-BOARD}

Cities are dynamic and multiple; they comprise of a vast range of 'players' and 'agents' whose 'effects' flow through the system, continually rewaorking the variety of urban spaces in any given field. (Corner, 96)

The shared field and graphic map frame upon which various competing 'players' and 'agents' are brought together to work out their differences. Game-board takes individual map frames within which certain conditions are graphically identified and permitted to 'play' and formulate open-ended composite overlays of frames to play out a range of urban futures or issues to convey the plural and interacting nature of the urban 'theatre' (Corner, 96-97).
'Game-board' provides a method for how mapping can reveal fragments of a place and generate a field that allows these fragments to be explored in a dialogue with one another to examine contextual adjacencies.

The third structure of plotting, 'Drift', is explored in the following section, 3.2) Collage and the Creation of Dreamscapes.

\section{DRIFT}

A cognitive mapping of a 'dream-like drift through the city'. A critique of contemporary circumstances from participation within the contours and fabric of the city rather than from the outside and above (Corner, 95).

Mapping provides a working field to explore how landscapes can be 'opened' to the imagination to reveal hidden traces, fragments and layers of forgotten stories. By recognising a landscape as a series of individual fragmented stories located across a wider field, mapping provides a field in which to position fragments in a dialogue with one another to explore contextual relationships. Both Layering and Game-Board are explored in this section to generate a foundation (field) upon which lost fragments and layers of a place from different points in time can be overlaid, and permitted to 'play' in order for their voices to be heard together. 


\section{IRONIC DIVERSIONS}

\section{Mas Yendo}

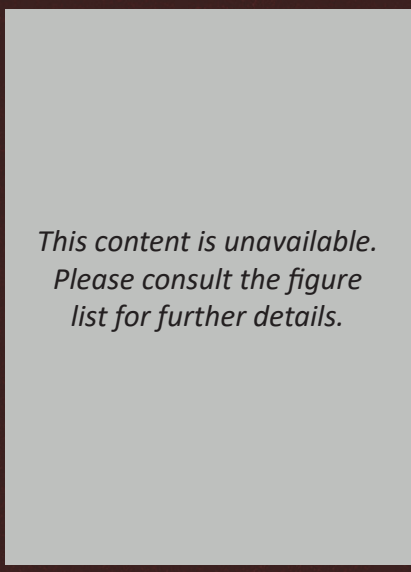

Fig. 3.1.3. Book Cover of Ironic Diversions.
A series of Mas Yendo's experimental architectural speculations, from his book Ironic Diversions are useful case studies for how speculative techniques of mapping can be engaged through the medium of architecture to reveal hidden layers of a site from different times, and explore contextal adjacencies and explore how these layers relate over time.

Henry Urbach, in Mas Yendo's book, refers to Yendo's work as a formulative process of discovery. Referring to his work as 'research', Urbach refers to Yendo's work as "a process of revealing of <<unconcealment $>>$ by which truths are wrested from obscurity and made visible" (Urbach).

Yendo's Ptolemy Institute of Astrology engages mapping across a range of scales to establish a context and orientate the viewer within a 'place' as he scales in and out, moving through 'space' and time-as a 'journey' (progress) across the pages. His work can be interpreted as an example of James Corner's structure of plotting 'Layering', as architectural maps where layers of time are reawakened through the three-dimensional forms built up as layers. Through mapping, or seemingly un-mapping, Yendo reveals a collage of layers through shadow and depth, transforming from two-dimensional to three-dimensional, as if layers of the past have risen and re-established themselves in the present.

Yendo's work engages all three of Corner's 'Operations of Mapping'. The pages of the book can be interpreted as the 'Field'-the graphic system with which extracts are organised and the 'Extracts' can be interpreted as the various mapping frames and varying mapping layers and photographs extracted from the milieu, revealing conditions of the place as they are drawn upon the 'Field' - the page (Corner, 94-95). 


\section{This content is unavailable. Please consult the figure list for further details.}

\section{samarkano ptolemy institute of astrology UL-9010}

\begin{abstract}
Horse and Carriage symbolising going back in time. Where the maps of the second page, reveal layers of history.
\end{abstract}

Photographs of the same site taken from different times, stamping maps in different moments in time.
This content is unavailable. Please consult the figure list for further details.
Removing layers of a site to reveal hidden layers below the surface.
Shadow revealing depth of layers, representing the landscape as a 3-dimensional structure in a 2-dimensional medium. .

This content is unavailable.

Please consult the figure

list for further details.

Fig. 3.1 4. Ptolemy Institute of Astrology,

pages from Ironic Diversions by Mas Yendo. Red Lines: Authors annotations.

This book has no page numbers. 


\section{THE MANHATTAN TRANSCRIPTS}

\section{Bernard Tschumi}

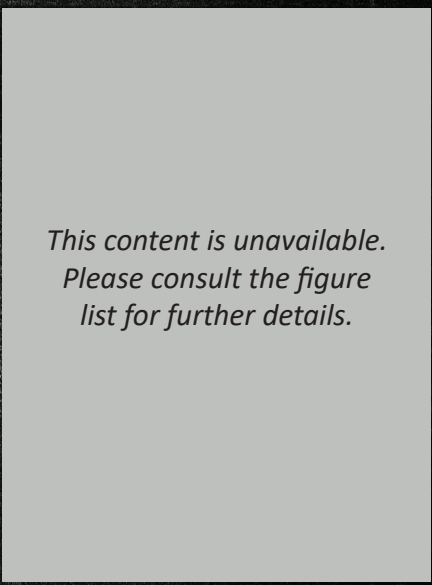

Fig. 3.1.5. Book Cover of The Manhattan Transcripts.
Fig. 3.1.6. Image from Manhattan Transcripts by Bernard Tschumi. Red line and text: author's annotations.
Manhattan Transcripts by Bernard Tschumi is a relevant case study for addressing how lost elements of a place that reveal transformations over time can be reawakened and captured as fragments through the process of mapping.

Manhattan Transcripts engages mapping to capture fragments from within the milieu from multiple sites and orientations to reveal an understanding of a place over time. This map is not presented as a single image. Instead, the map is revealed as a fragmented series of images and symbols coming together as an entire bound codex - the Manhattan Transcripts. Tschumi's codex is the map.

The transcripts for Tschumi aimed to offer a different reading of architecture. Space, movement, and events were presented as independent fragments that stand in a new relation to one another. The conventional components of the architecture are broken down and rebuilt along different axes.

Manhattan Transcripts presents an example of Corner's 'Game Board' structure of 'plotting' where conditions are graphically represented as fragments and individual map frames and collectively presented to allow individual fragments to 'play' to reveal open-ended relationships.

Graphic representations of fragments outline spaces and indicate the movement of what Tschumi describes as "the different protagonists intruding into the architectural 'stage set"' (Tschumi, "The Manhattan Transcripts 1976-1981"). These fragments and individual map frames

'GAMEBOARD’MAP

This content is unavailable.

Please consult the figure

list for further details. 
are arranged in a tripartite model of notation upon the 'Field'-the pages of the codex-to capture space, events, and movement, in order to introduce the order of time into the reading of a city. Presenting conditions through three modes on a collective field allows the viewer to view conditions of a place from multiple points of view and find meaning within the individual fragments and the relationships between them.

The first layer of graphic fragments presents assembled and overlapping fragments exploring contextual relationships between the individual parts, capturing multiple views, conditions and moments of time simultaneously. The second row presents fragments as characters of the city, and the third row presents snapshots of the time, capturing shadow and atmospheric qualities.
THE 'EXTRACTS': Fragments

$\begin{gathered}\text { This content is unavailable. } \\ \text { Please consult the figure } \\ \text { list for further details. }\end{gathered}$
ASSEMBLED FRAGMENTS
This content is unavailable.
Please consult the figure
list for further details.
EXTRACTED MAP FRAGMENTS
This content is unavailable.
Please consult the figure
list for further details.

\section{FRAGMENTS CAPTURING TIME}

Fig. 3.1.7. Image from Manhattan Transcripts by Bernard Tschumi.

71 
"In this world,

... time has three dimensions..."

- Alan Lightman, Einstein's Dreams, 30 


\section{MAPPING THE FIELD:}

\author{
REVEALINGLOST:LAYERS \\ ASFRAGMENTS
}

This series of design research experiments tests James Corner's theory of speculative mapping to reveal and unveil lost fragments and hidden layers of a landscape and to generate a foundation upon which contextual relationships of multiple sites can be simultaneously interrogated James Corner's mapping structures of Layering and Game-board are tested to explore how mapping fragments as figurative geometries-abstracted notations of site conditions - can be used to examine elements of sites from different points in time and place simultaneously. This series explores how Corner's techniques can be used to generate speculative outcomes that enable Potteiger and Purinton's theory of 'opening landscapes' - beginning with understanding the site as an intersection of layers of stories connected to other stories - that can be graphically represented and explored upon a share field (189). 


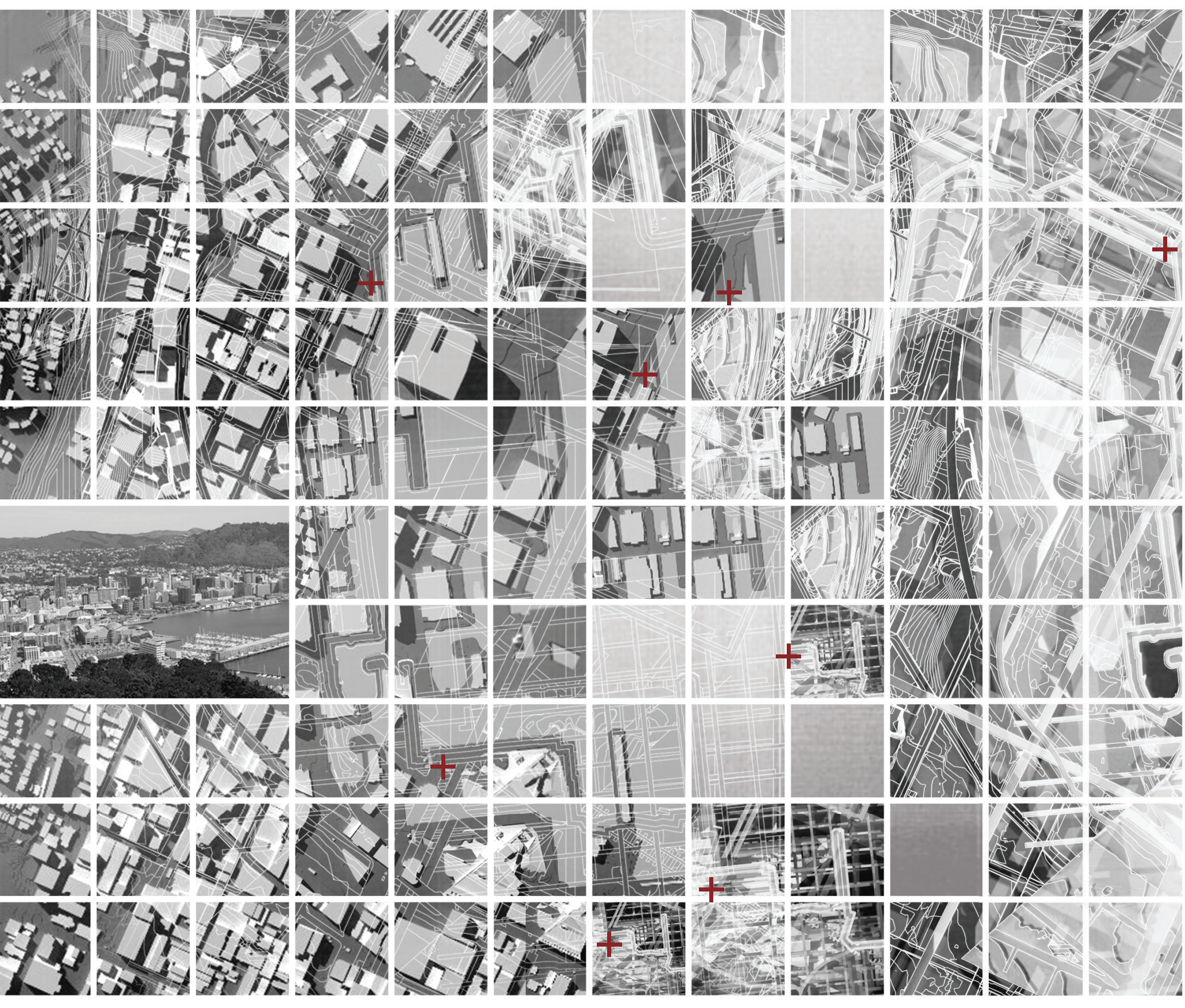

Fig. 3.1.9. Map by author simultaneously representing both research sites: Revealing hidden layers of the landscape as a pentimento.

Two images of the city over time locate fragments of the map in moments in time. The left image, a current view of the city, and the image opposite, a historic image of the city, going back in time as the layers of the urban concrete are removed revealing lost layers of time. 







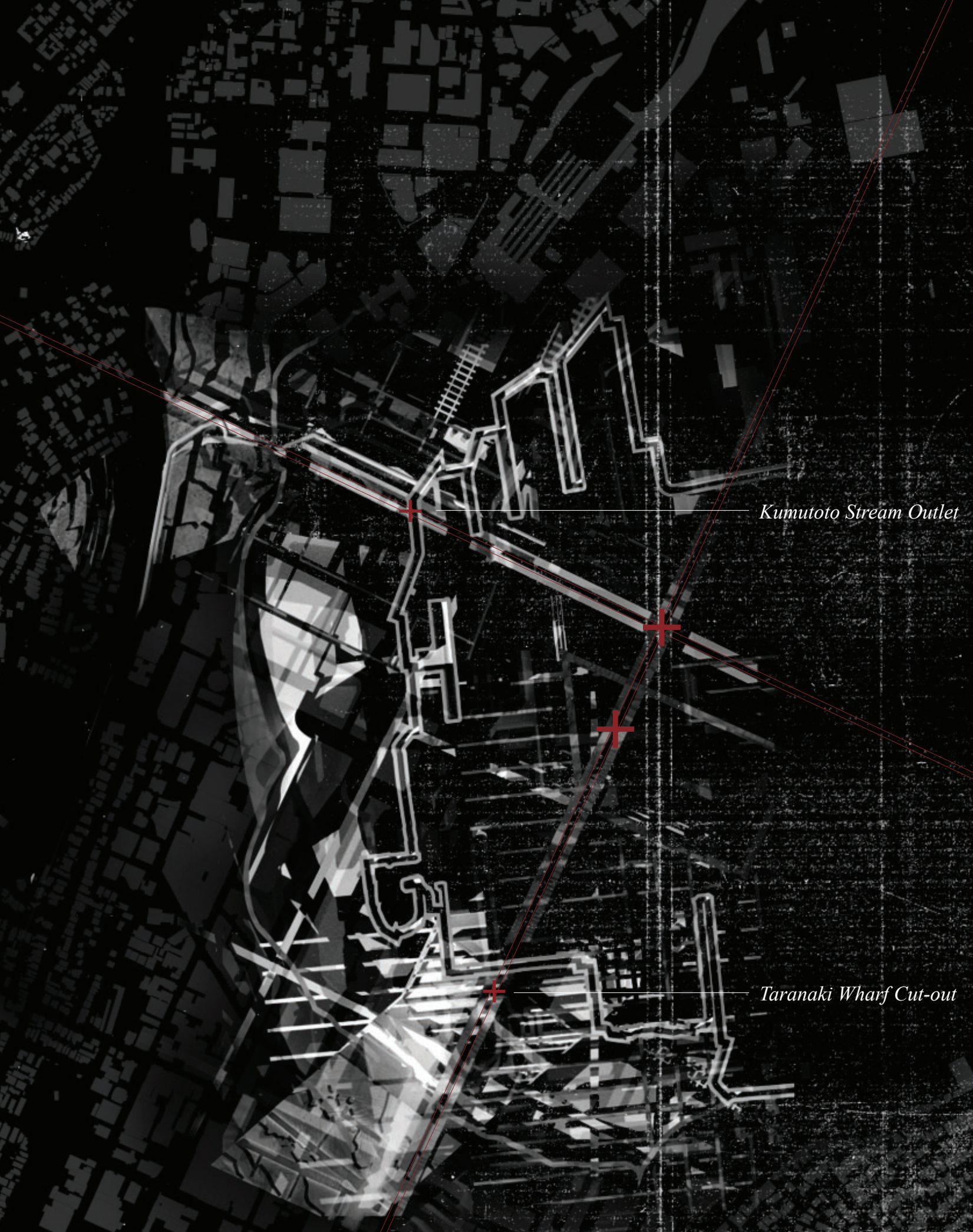

77 
"... time is a rigid bonelike structure ...

...extending infinitely ahead and behind ...

... fossilizing the future" 


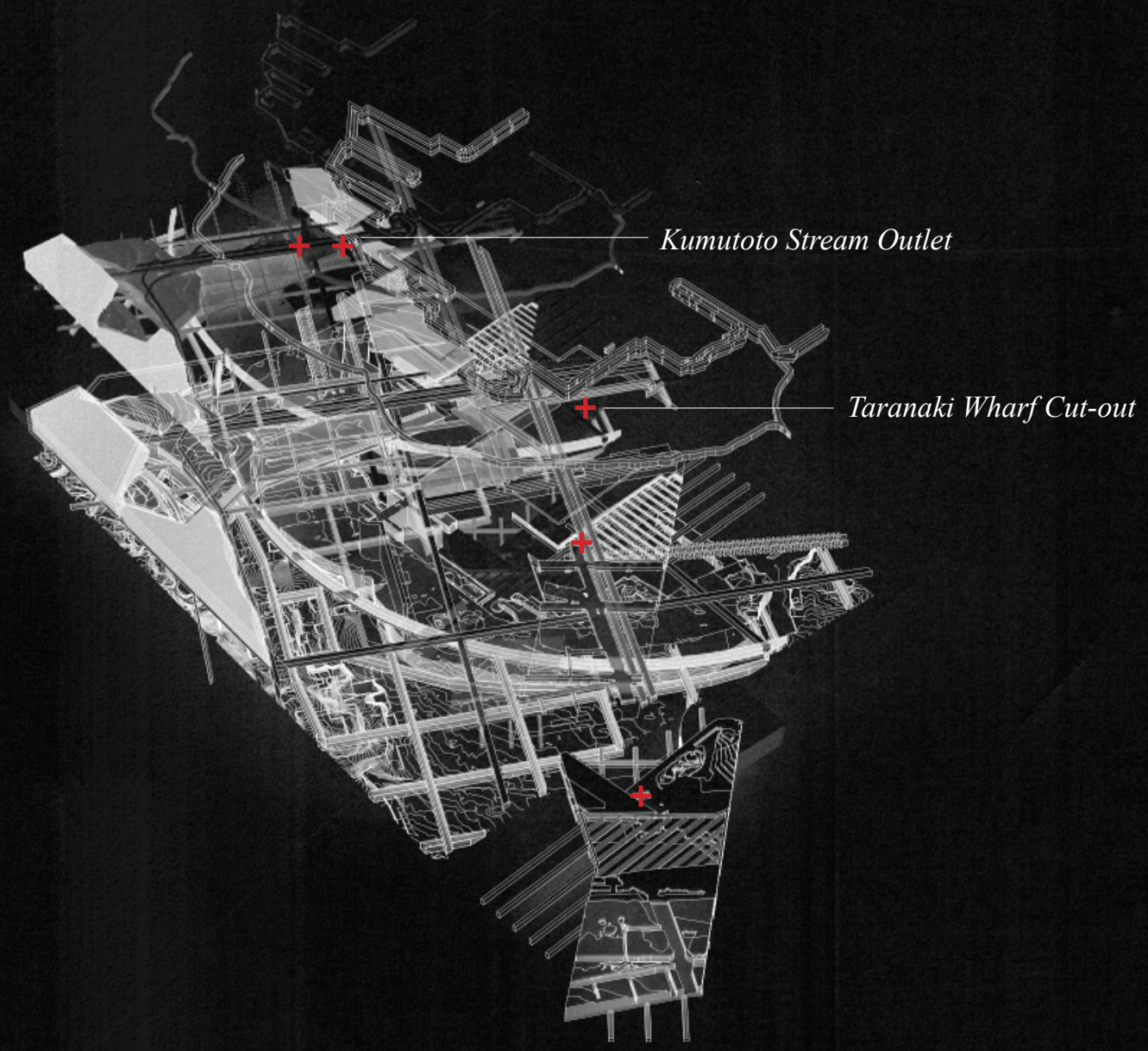

Fig. 3.1.12. Map by author simultaneously representing both research sites: The city as a 'thickened' landscape. Layers of time are overlaid presenting the city as a multilayered structure. Fragments of the landscape are notations arranged on a shared field. Fragments reveal the shifting city grids, reclamation of land and shifting harbour edge. 



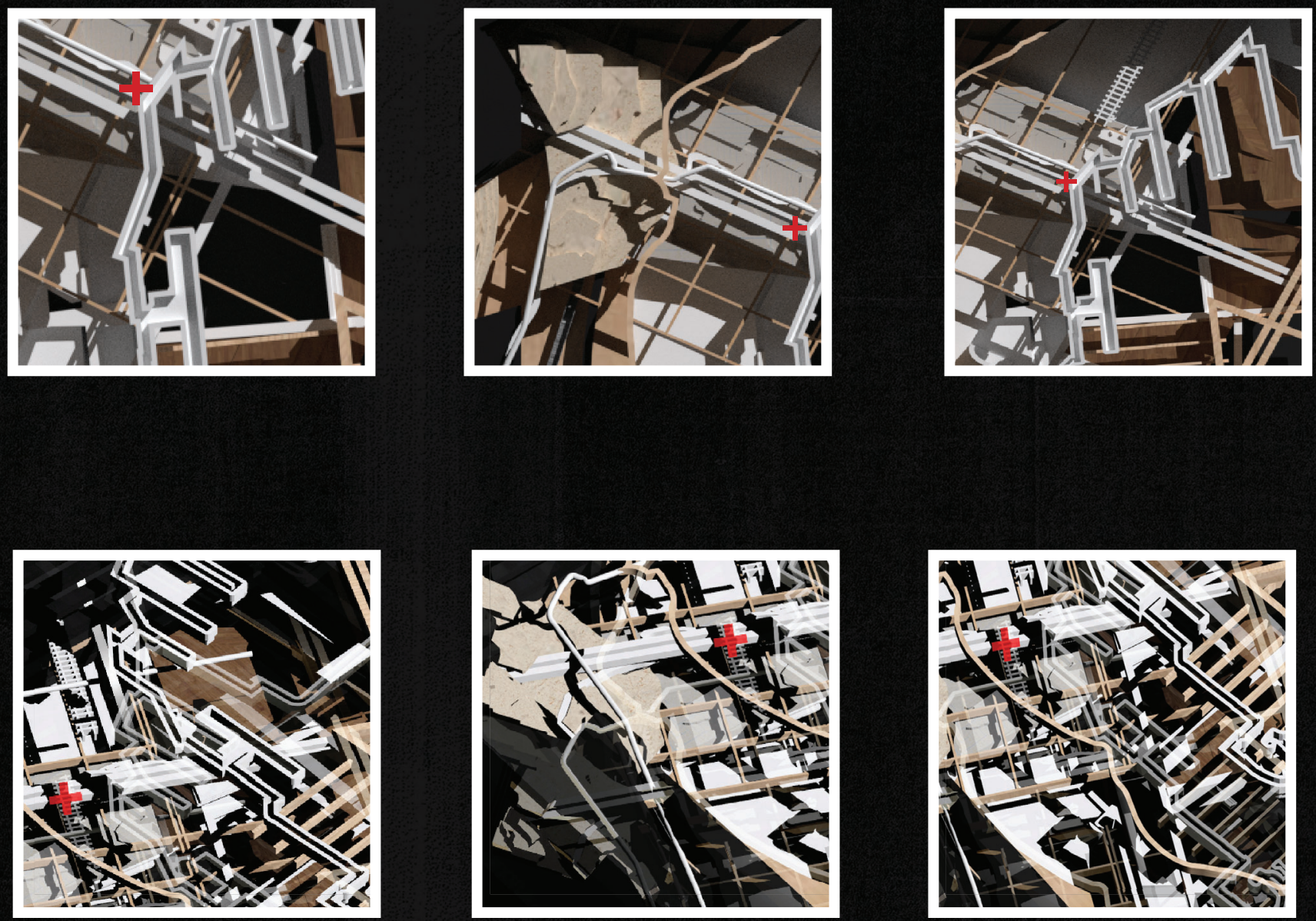

Fig. 3.1.13. Map Fragments: Mapping fragments extracted from the two research sites and surrounding Wellington waterfront from different points in time and place are overlaid upon an imaginary field as a 'game-board' and 'layering' map that reveals the shifting and transforming layers of the landscape that make up the surface of the city. The two sites are drawn out of the landscape and placed in a dialogue with one another as they are overlaid, presented as two openings in the landscape that provide a view into the layers below. 


\section{A VESSEL FOR THE CODEX:} THREE-DIMENSIONAL MAP
A vessel for the codex integrates all the different mapping notions over time from the previous experiments, as fragments that are shifting scale and shifting orientation, layered through time. The box enables the two sites to be seen confronting each other in a dialogue. Pathways are generated across fragments to connect them. This box provides a shared field, a foundation for which multiple sites and contextual fragments can be viewed simultaneously as a 'thickened' surface that enables us to view the landscape as a series of fragments that have shifted, transformed and built up over time.

The layers beneath two opposing harbourside siter, like horirontal yalimpsests, negotiate time and identity pausing and leaping forward, cowverging and separating again. They leave traces upon one another, lach layer calling out in its own voice, relerant to time-their combined vicer a cacophony of fragile civer. - poetce desciption of the vessel
for the codes. 


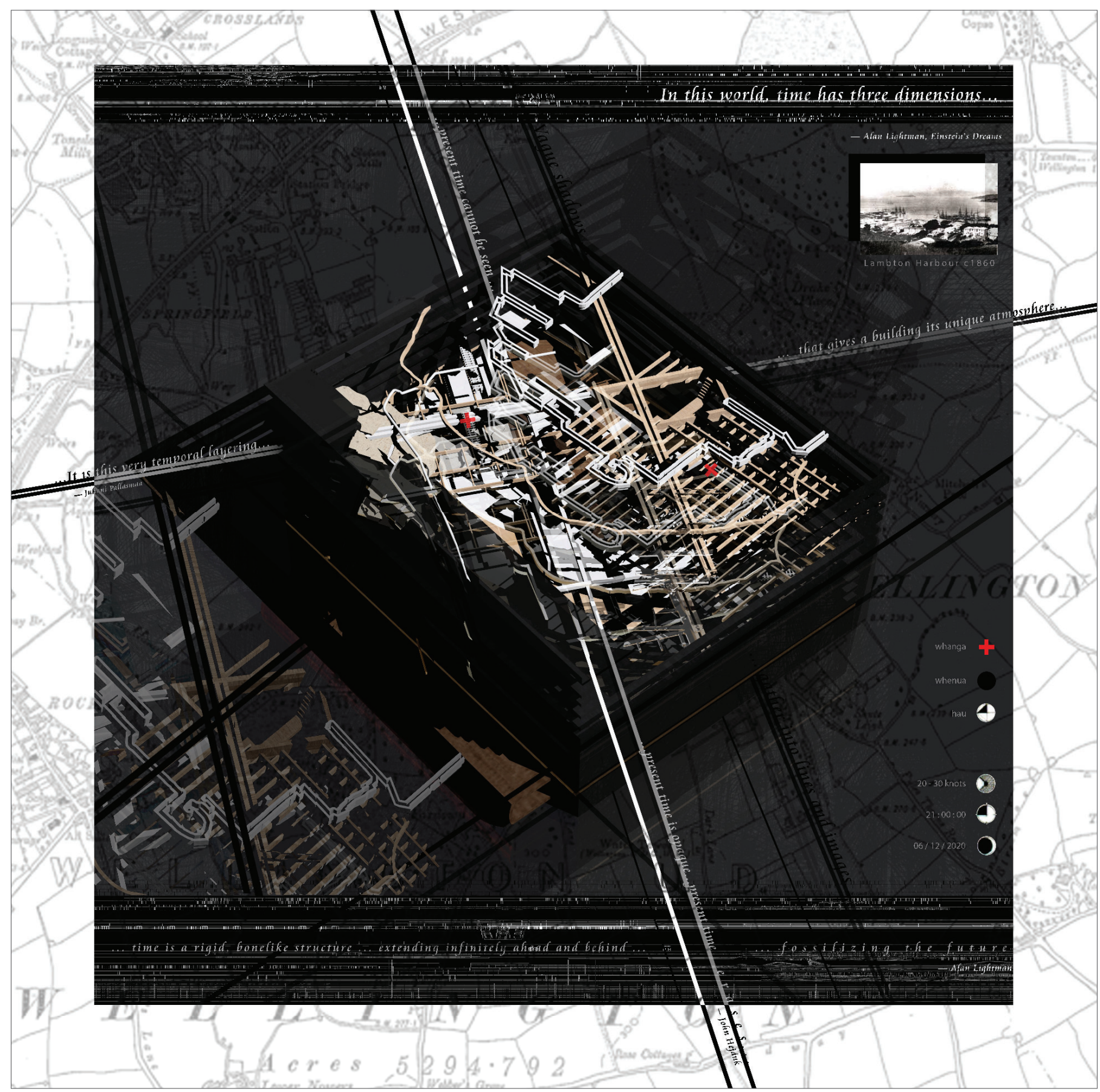

Fig. 3.1.14 Map: Threedimensional map collaging lost layers of time. By Author. 


\title{
CRITICAL REFLECTION
}

\begin{abstract}
Bernard Tschumi, interpreting them through the theoretical lens of key theorist James Corner, in order to generate a foundation (field) of the imagination that represents the layered and fragmented stories of two research sites-Wellington's Kumutoto Stream Outlet and the Taranaki Wharf Cut-out. The objective of the experiments was to situate their fragmented stories into a dialogue with one another.
\end{abstract}

Corner proposes that Layering and Game-board can be used as systems for mapping the field of imagination, where Layering involves the superimposition of independent layers upon one another (95-96) and Game-board involves multiple 'agents' brought together to re-present a range of urban futures and the plural, interating nature of the urban 'theatre' (96-97). The preliminary design experiments were then integrated into a threedimensional 'vessel', conceived to bring together both Layering and Game-board, which resulted in the design outcome seen in Figure 3.1.14.

As an experiment based on Corner's theories, taken together with learnings from the case studies, the experiment in Figure 3.1.14 "A Vessel for the Codex", represents a Game-board conceived through Layering--a three-dimensional mapping of both place and time. This three-dimensional nature of this developed outcome was influenced by Alan Lightman's allegorical narrative Einstein's Dreams. "A Vessel for the Codex" was conceived to represent Lightman's propositions that: "... time is a rigid bonelike structure ... extending infinitely ahead and behind ... fossilizing the future" (159-160) and "In this world, ... time has three dimensions" (30). Simultaneously, it was conceived to represent Italo Calvino's allegorical narrative about place, Invisible Cities: "The city, however, does not tell its past, but contains it like the lines of a hand..." (11). Presenting a map of Wellington as a three dimensional construction of fragmented layers facilitates the 'opening' of the landscape representative of Matthew Potteiger and Jamie Purinton's theory of open narratives discussed in chapter two, the idea that a place is not a permanent or static whole but rather constructed of a constantly shifting array of fragments that shift, transform and add up or fade over time. 
000 




\title{
Collage
}

\author{
and the Creation \\ of Dreamscapes: Into the Realm of Dreams
}

[RO2] Collage and the Creation of Dreamscapes: to explore how collage and the creation of dreamscapes can be used to generate speculative architectural outcomes that enable multiple voices over time to be heard at once. 


\section{COLLAGE}

a technique of composing a work of art by pasting on a single surface various materials not normally associated, with one another, an assemblage or occurance of diverse elements or fragments in unlikely or unexpected juxtaposition.

\section{ASSEMBLAGE}

\section{to reveal voucer} that would othervise

a collection or gathering of things, fragmenftrenting found or unrelated objects

MONTAGE

the technique of combining in a single composition pictorial elements from various ranowo. sources, as parts... or fragments, either to give the illusion that the elements in a canscape belonged together originally or to allow each element to retain its separate identity as a means of adding interest or [meaning] to the composition. 


\subsubsection{Collage, Assemblage, Montage}

... the very role of architecture as frames and settings for human activities turns it into a varying and variously completed entity, an ever-changing collage of activities, furnishings and objects.

—Juhani Pallasmaa, Collage and Architecture, ix-x

This chapter addresses Research Objective Two, exploring how collage and the creation of dreamscapes can be used to generate speculative architectural outcomes that enable multiple voices of time to be heard at once. This chapter builds upon the arguments of critical theorists from the previous chapters to address the research aim of reawakening lost voices of a place and generating speculative outcomes to allow these voices to be heard. Regarding place-making, James Corner affirms,

...the geography of a place becomes known to us through an accumulation of fragments, detours, and incidents that sediment meaning, 'adding up' over time. (Corner, "Drawing and Making in the Landscape Medium”, 167)

Furthermore, landscape theorists Matthew Potteiger and Jamie Purinton, when discussing how 'open narratives' can reveal the identity of a place, argue:
... the past does not lead to the present, nor the present to the past, but rather events are overlaid simultaneously and are open for infinite interpretations. (Potteiger and Purinton 123)

Engaging both these propositions, this section explores how collage (assemblage and montage) can be used as a technique to reveal the identity of a site by reawakening the fragments that have been buried or made to disappear over time, and generate speculative outcomes that recall the stories of a place as open narratives through the layering of multiple voices of time simultaneously.

The collage process refers to the extraction of an object, image or condition out of its context-in time and place-and placing it onto a plane with a myriad of other objects to create juxtaposed assemblages with constructed new meaning. Diane Waldman, in her book Collage, Assemblage and the Found Object, 
"[Collage and] montage works with surfaces and images [where] ... place is created out of fragments distant in time and space."

-Stan Allen, 26

asserts that collage as the temporal layering of fragments from different points in time can compile several layers of meaning: the original identity of the fragment and the history it brings with it and the new meaning it gains in association with the other objects (Waldman, 11).

In her book Collage and Architecture, Professor Jennifer Shields advocates for the use of collage in architecture as a critical tool in the design process. She posits that the collage practice can capture the built environment's spatial and material characteristics, both physical and atmospheric, acting as an analytical and interpretive mechanism (Shields, 2-3). She argues that as a "means of investigating the potentialities of three-dimensional space in a two-dimensional medium, collage facilitates a new conception of space", which "simultaneously engage multiple dimensions of time" (2).
By eluding the logic of time and space, as well as assumptions of scale and perspectives of traditional architectural representation, collage has a multilayered narrative capacity. Juhani Pallasmaa argues that the juxtaposition of fragmented images from multiple points of view and moments in time generates an archaeological density and ability of collage to capture non-linear narratives ("Hapticity and Time: Notes on Fragile Architecture", 3). In the forward of Jennifer Shield's book Collage and Architecture, Pallasmaa writes:

Collage combines pictorial motifs and fragments from disconnected origins into a new synthetic entry which can cast new roles and meanings to the past. It suggests new narratives, dialogues, juxtapositions and temporal durations. Its elements lead double-lives; the collaged ingredients are suspended between their originary essences and the new roles assigned to them by the poetic ensemble. (ix) 
91

All collages tend to have a similar capacity to stimulate our imagination, as if the various fragments, torn from their initial settings, would provoke the viewer to give them back to their original context.

—Juhani Pallasmaa, Collage and Architecture, $\mathrm{x}$

Matthew Potteiger and Jamie Purinton similarly advocate for using collage in architecture and landscape design as a method for both the extraction of narratives from a site, and the representation of these narratives through design, writing:

...these conditions [of collage] offer distinct opportunities for different forms of narratives, such as the gathering of past and present into a synoptic view, parallel or intersection story lines, nonlinear associations, multiple layers of stories and narratives open to participants (Potteiger and Purinton, 10).

Heritage stories of a site transform from one time period to the next, creating overlapping stories and voices of a site's identity that evolve over time. By capturing these stories and voices as both physical and atmospheric fragments of time in synoptic views, collage enables these overlapping stories and voices to be heard at once. The ability of collage to capture multiple perspectives and scales simultaneously enables a site's identity to be interrogated from multiple points of view and in relation to its surrounding context, enabling a site to be understood within a greater meta-narrative of place.

Collages can be interpreted in relation to Haralambidou's concept of 'Figurative Geometries' the mathematical equation that uses the abstraction of objects, architectural forms and sites to signify meaning and relationships. As the overlaying of multiple fragments to present them in new and unseen way, the process of collage demands analogical thinking to piece together fragments to convey and gain new meaning. 
"In the early years of the 20th century, progressive artists abandoned the idea of an objected and static world altogether, as depicted by ... linear narratives Romaining and entered the dyamic experiential reality of lime + dpace opento perception and consciousness that constantly fuses $=$ place
reality and dream, actuality and memory... Marcel Proust, the legeneanseaper-presenting ploce an memonier Open - narratwer Marcel Proust, the legendary observer of time and miltiple stoun told
memory, claimed: 'As there is geometry in space, so fuom a pluralty there is a psychology in time.' The experiential and mental perspective replaced attempts to depict a given

a place ir tatio and unchanging world. Postmodern philosophers, such as of viner but ever. David Harvey and Fredric Jameson ... point but a curious merging of the two physical dimensions: the temporalisation of space (turning spatial dimensions into temporal experiences and units), and the opposite reversal, spatialisation of time... These fusions or reversals are concretised by the fact that nowadays we comnonly measure spatial distances through units of time.



-Excerpt from Juhani Pallasmaa, "Inhabiting Time", 53 


\subsubsection{Collage as Dreamscapes}

Into the Realm of Dreams

93

"Dreams, like cities, shape us and are shaped by us. Architects would have us believe that the edifices that make up the city are immutable and solid, monuments to their designers' immortality. They are not."

—CJ Lim, 2011, 27

This section explores how the allegorical interpretation of fragments can generate dreamscapes that allow multiple voices of a place to be heard together even when they represent stories from different times. This section engages James Corner's operation of mapping and structure of plotting, 'Drift', introduced in section 3.1, as a cognitive mapping technique of a dream-like drift through the city (95). Corner presents 'Drift' as a critique of a place from within the city's contours and fabric rather than from outside and above (95). This section explores how the medium of collage can be used to generate speculative dreamscapes that map 'drift' through the layering of multiple fragments of images of a place from various perspectives and points in time simultaneously.
CJ Lim, architect and professor at the Bartlett School of Architecture, through his speculative works Short Stories: London in two-and-a-half-dimensions, investigates collage's potential to reveal non-linear 'open' narratives of a place through the layering of fragments of multiple points of time and placedrawn from within its fabric-as dreamscapes.

In his article "London Short Stories: Drawing Narratives", Lim argues that the synthesis of allegory, narrative, and collage in the representation of a place can reveal hidden meaning, evoke the imagination, and facilitate critical interpretation of a place to unveil its storytelling potential (102). Lim argues that these kinds of drawing practices in the creation of dreamscapes provide an opportunity to become completely free from the idea of representing a 'true' reality, and that in doing so, "frees us to consider the changes in spatial practices that could be truly transformative" in the understanding of place (212).

This content is unavailable.

Please consult the figure

list for further details. 


\section{SHORT STORIES:}

\section{LONDON IN TWO-AND-}

\section{A-HALF DIMENSIONS}

\section{CJ Lim and Ed Liu}

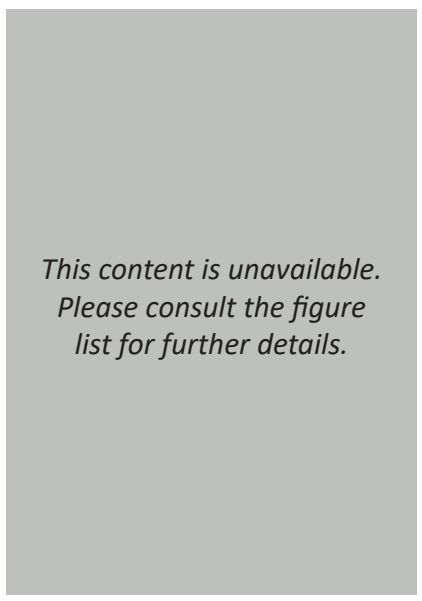

Fig. 3.2.5. Book Cover of Short Stories: London-intwo-and-a-half dimensions

London is a city and cities are alive. They breathe, they grow, they spawn, they die, and they dream. This is London's dream.

—CJ Lim, "Dream Island", 1
Short Stories: London in two-and-a-half dimensions by CJ Lim and Ed Liu combines place and fiction in an imaginative interpretation of ten London sites. It presents a series of provocative dreamscapes that reveal hidden voices and dimensions of place and time that may otherwise remain undiscovered, provoking a reader to engage with the multiple dimensions of London's historical geography that ultimately reveal the identity of a place and its evolution over time (Lim, 104). Lim employs allegorical narratives from literature through the medium of collage to evoke the imagination to re-frame conditions, fragments and well-known epochs of sites and render them in a string of architectural short stories captured as dreamscapes, interpreted as examples of James Corner's mapping technique of 'Drift'. Each dreamscape depicts a site as a collection of dreams and memories located in the liminal territory between fiction and reality. They are constructed from multiple fragments of time and place overlaid to generate a series of non-linear narrative representations of place that challenge traditional static representations of place as individual snapshots of time.
This content is unavailable
Please consult the figure
list for further details.
Fig. 3.2.6. Image from "Discontinuous Cities” by CJ Lim, from Short Stories. 
This content is unavailable.

Please consult the figure

list for further details.

Theallegorical interpretation of a place as fragmented memory opens the possibility of interrogating a place through multiple lenses where the interpretation of a place and its stories are endless. Collage as a representation medium enables an infinite array of fragments of a place across time to be continually reframed, reworked, and overlaid to generate new stories that reveal the never-ending evolution of a place's identity. Lim writes:

We usually expect objects to exist in a singular location, but the elements in a collage or assemblage oscillate between existences like Schrödinger's cat, presenting a flexible vessel in which the reader is encouraged to deposit his or her own historical and cultural montage. (Lim, 107)

In this investigation, Short Stories is a valuable precedent of an architectural representation of place through Invisible Cities' eyes. It is a series of fragmented stories as dreamscapes of place,
Fig. 3.2.7. Image from "The Celestial River" by CJ Lim, from Short Stories.

ultimately, revealed like Invisible Cities, to represent one place from multiple perspectives.

Each dreamscape in Short Stories as a fragmented 'memory' of London is set in a different time period, though not as a literal representation of the historical periods of a place, but rather as a series of stories told through various points of view of time reinterpreted as voices-much like Einstein's Dreams. It represents voices of time that narrate stories of a place, like the voice of the past looking forward towards the present or future or the future's voice looking back towards the past.

His dreamscapes present London in a way that is both real and surreal, familiar and uncanny, to reveal hidden stories and ultimately provoke a viewer to dream, imagine and speculate over their understanding of the significance of time and place. 
But what is the past?

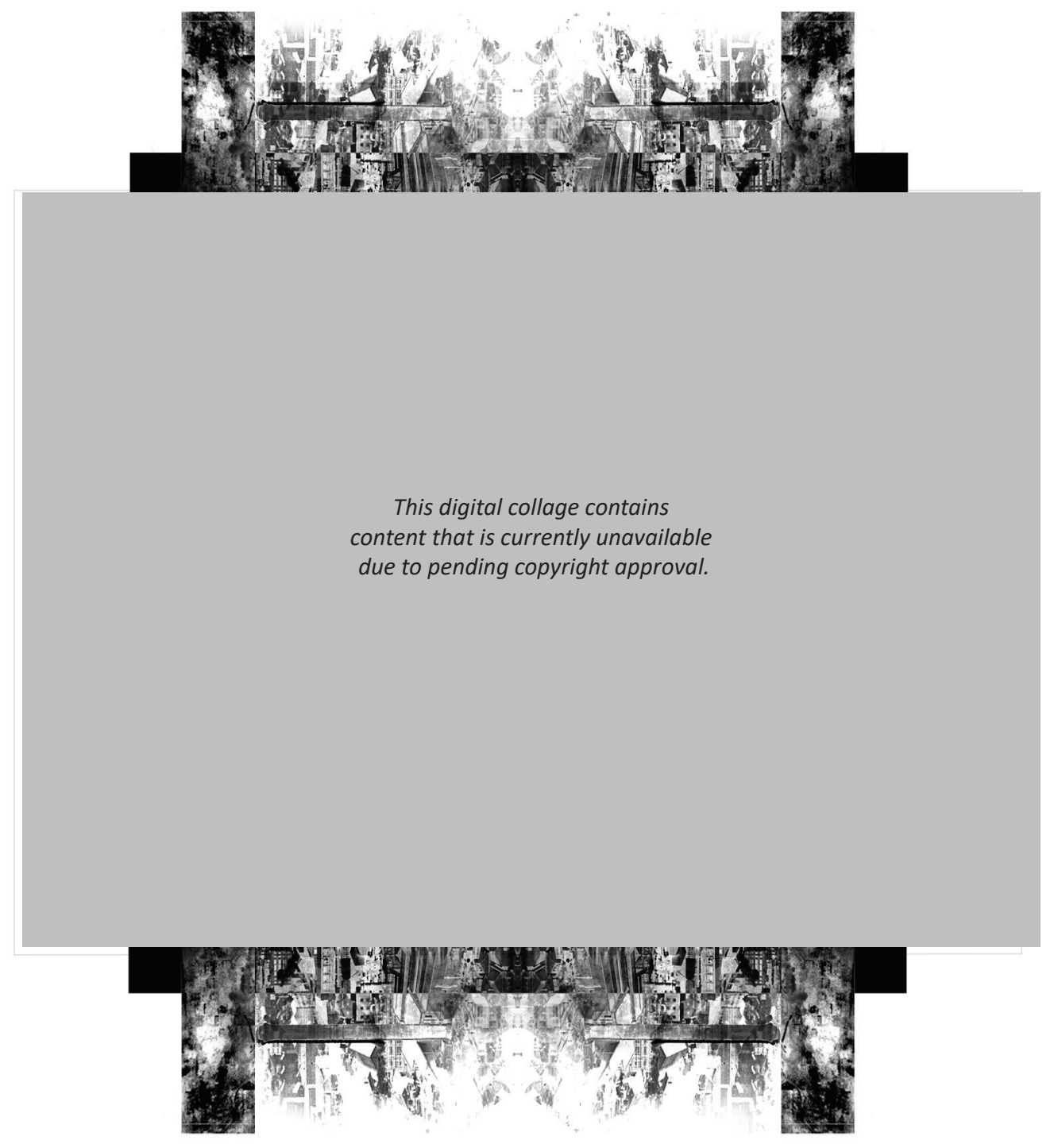

Could it be the firmness of the past is just illusion? 
Could the past be a kaleidoscope,

a pattern of images that shift with each disturbance of a sudden

breeze, a laugh, a thought?

And if the shift is everywhere

how would we know?

— Alan Lightman, Einstein's Dreams, 170

Fig. 3.2.8. (Opposite) Dreamscape: Historical images of Wellington as a Kaleidoscope. Digital collage by author. 
INTO THE REALM OF DREAMS: CAPTURING FRAGMENTS OF
TIME AND PLACE AS DREAMS
This series of design outcomes tests James Corner's structure of mapping 'Drift', a method of mapping a dream-like drift through the city, through the medium of collage. 'Drift' is explored alongside CJ Lim's theory of the integration of allegory, narrative and collage to explore how lost voices of a place can be reawakened and unveiled as speculative collaged dreamscapes that enable multiple voices over time to be heard at once. The following series aims to explore how dreamscapes facilitate a critical interpretation of place and can capture an invisible reality of the city's lost identities and reveal its transformation over time. Extracting fragments from historical images of Wellington and presenting them in both familiar and uncanny ways seeks to provoke a reawakening of the imagination to engage with the multiple dimensions of place and time in ways previously unseen. To draw out hidden stories and meaning from sites as they are viewed from multiple different points of view.

In the following experiements fragments of sites from different times that have never met are overlaid and permitted to speak to one another-generating a dialogue of voices that may have been lost over time or never heard before-ultimately narrating a greater story of the transformation of Wellington over time.

A range of dreamscapes are explored and presented in a collection as fragments, characters that narrate voices, visual journeys through time, and a dialogue of dreams narrated by two characters - the two research sites, as they journey through time and place.

\section{All images in this series are author's own digital collages.}


"The catalogue of forms is endless:

until every shape has found its city,

new cities will continue to be born.

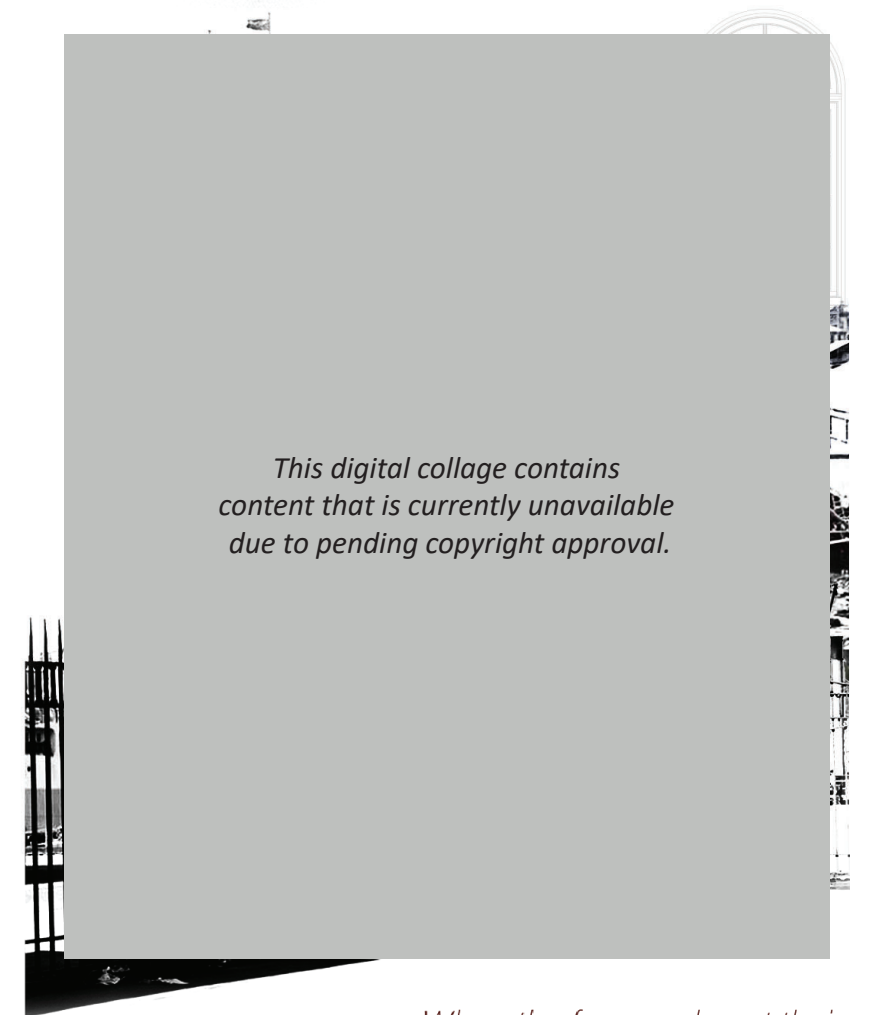

When the forms exhaust their variety

and come apart,

the end of cities begins."

-Italo Calvino, Invisible Cities, 139

Fig. 3.2.9. Dreamscape fragment: The layering of fragments of Wellington's Waterfront construction over time between the two selected sites.

Wellington as with any place is a never-ending construction of layers and fragments adding up over time. With every new construction and alteration of the city, 'new cities will continue to be born' city fragments are added, transform or disappear with each new iteration of the city as an ever-changing collage of fragmented layers (Calvino, 139). 
"In a world where time cannot be measured, there are no clocks...

Events are triggered by other events, not by time."

—Alan Lightman, Einstein's Dreams, 126.

This digital collage contains

content that is currently unavailable

due to pending copyright approval.

\section{DREAMSCAPE}

CAPTURING TIMEAS

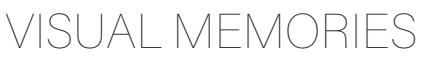

Fig. 3.2.10. Dreamscape: capturing the history of Wellington's waterfront as a continuously evolving landscape.

This dreamscape is a timeline, not a traditional timeline as a written account of events in order next to dates as static time stamps, but as a visual account of history; an evolving landscape that captures the transformation of the landscape as a visual journey across time. While the timeline of events appears linear moving from the past (left) to the present (right), the narrative of events is 'open' - shaped by a plurality of voices in a dialogue, as events overlap and voices become ghosts fading over time. 
101

"In a world of shifting past,

these memories are wheat in wind,

fleet in dreams, shapes in clouds.

Events, once happened, lose reality,

alter with a glance, a storm, a night.

In time, the past never happened."

"Memory's images,

once they are fixed in words,

...are erased.."

-Italo Calvino, Invisible Cities, 87 


\section{THE NARRATORS} UNVEILING SITESAS
CHARACTERS
The following two dreamscapes set out to capture the identities of the two selected sites-the Kumutoto Stream Outlet and the Taranaki Wharf Cutout-by drawing together a series of fragmented voices of the sites over time. These dreamscapes capture the sites as characters that become the narrators of a series of dreamscapes in the following series presented as a dialogue between the two characters.

Fig. 3.2.11. (Opposite) Dreamscape character: The Kumutoto Stream Outlet.

The Kumutoto Stream Outlet in this dreamscape unleashes the voice of the past—-the stream — seeking reconnection and communication with the present. The dreamscape composition reveals the shoreline's shifting edge condition as land has been reclaimed over time; as the edge condition of the land and sea shifts, the outlet's location changes: 1) from the corner of Woodward Street and Lambton Quay, the natural stream outlet's location where the built landscape first silenced the stream outlet, 2) to Customhouse Quay, the reclaimed land shoreline, 3) to the present day where the built landscape permits the stream to be seen meeting the sea.

The natural stream is forever lost and can never be seen as a whole in its original state, but its voice is heard as a fragment - the concrete culvert opening up to the sea. This culvert presented at the bottom of the dreamscape represents how the stream is forever trapped beneath the city's surface. We can only hear a fragment of its voice when the stream is thrust back out to sea. The Kumutoto Stream Outlet is the voice of the natural landscape from the past seeking to be reclaimed from beneath the surface of the built landscape in the present. 


\section{TARANAKI WHARF CUT-OUT}

Fig. 3.2.12. Dreamscape character: The Taranaki Wharf Cut-Out.

The Taranaki Wharf Cutout is the voice of the present seeking reconnection with the past. This dreamscape captures the transformation of the site and its surroundings over time. Various fragments of iterations of the site's identity are overlaid and fade into the background as ghosts surrounding the site as it exists today. The Taranaki Wharf Cut-out is the voice of the built landscape of the present cutting a hole in its surface to release the ghosts of the past, and seeking reconnection with the natural landscape that lives lost in the dark depths below. Fragments of the past that still remain in the present are left unfaded as they have become cemented as the witnesses of the past, as the site has transformed over time. Fragments of the present such as Te Papa and the highrises in the background are faded as they are ghosts of the present that fade as the dreamscape shifts back into the past. 
This digital collage contains content that is currently unavailable due to pending copyright approval.




DREAMSCAPES:



This series explores how collage and dreamscapes can visually interpret a place through Invisible Cities' eyes. As a dialogue between two characters, recalling a journey through cities, presented as fragmented memories ultimately revealing the same city from multiple perspectives. That, when viewed as a collection of fragmented dreamscapes, reveal a greater meta-narrative of place.

Each dreamscape is told from a different point of view of time, as a visual interpretation of Einstein's Dreams. Voices of time narrate the stories of place-The Kumutoto Stream Out-let as the allegorical voice of the past-the lost stream of the past seeking reconnection with the present-and the Taranakai Wharf Cutout as the allegorical voice of the present-a cut-out in the landscape of the present seeking reconnection with lost layers of the past below. Within the dreamscapes, time is not linear or revealing a snapshot of time; rather fragments of various times are overlaid capturing time and place as memories.

The aim of these dreamscapse is to unveil and visually capture the shifting identies of Wellington as they have transformed over time, allowing lost identities of Wellington from the past to be recognised in the present, and visa versa. 
there are an infinity of

$$
\text { ...worlds." }
$$

—Alan Lightman, Einstein's Dreams, 22

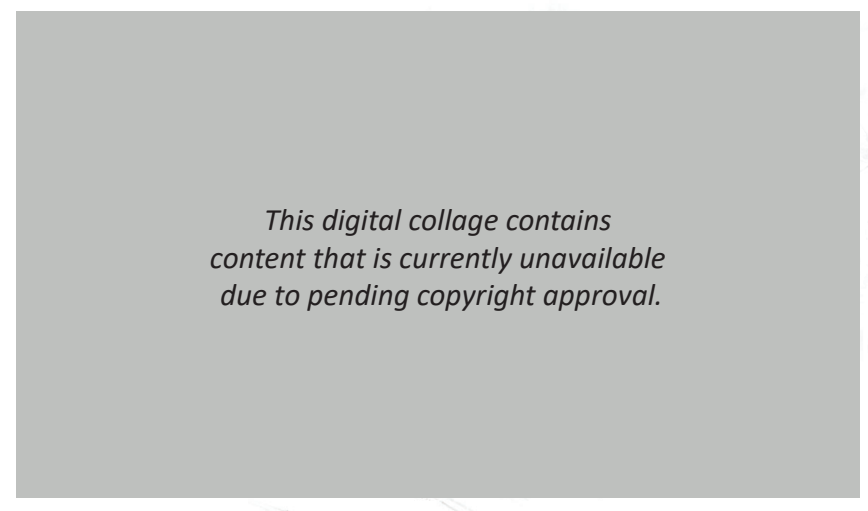

幽

Fig. 3.2.13. Dreamscape Character: The Kumutoto Stream Outlet.
This digital collage contains content that is currently unavailable due to pending copyright approval.

Fig. 3.2.14. Dreamscape Character: The Taranaki Wharf Cut-Out. 


\section{"Arriving at each new city, the traveller finds again a past of his that he did not know he had: the foreignness of what you no longer are or no longer possess ... i. . . . lies in wait for you in foreign, unpossessed places."}

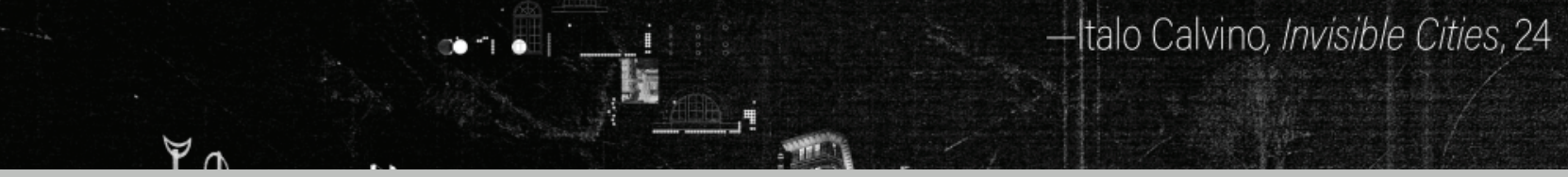

This digital collage contains content that is currently unavailable due to pending copyright approval.

Fig. 3.2.15. Dreamscapes: Mapping the journey through the dreamscapes.

This dreamscape maps the dialogue between the dreamscapes narrated by the voices of the Kumutoto Stream - the pastand the Taranaki Wharf Cutout - the present. It represents a journey through the dreamscapes where the voices of the past and present meet. Presenting the past above the present, presents the past as the voice that lives in the background of the present. It is also present on top of the present as the past has been drawn up from beneath the present to have its voice heard once again. 
"With cities, it is as with dreams: everything imaginable can be dreamed, but even the most unexpected dream is a rebus ... even if the thread of their discourse is secret, their rules are absurd, their perspectives deceitful, and everything conceals something else."

“...perhaps cause lies forever in the past effect in the future,

...but future and past are intertwined."

-Alan Lightman, Einstein's Dreams, 49 
This digital collage contains content that is currently unavailable due to pending copyright approval.

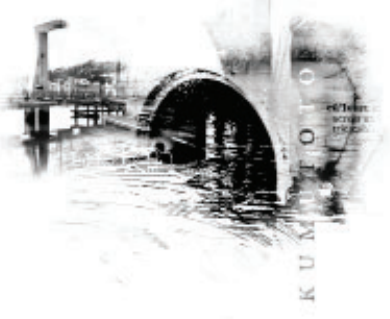

Fig. 3.2.16. Dreamscape: Narrated by the Kumutoto Stream Outlet.

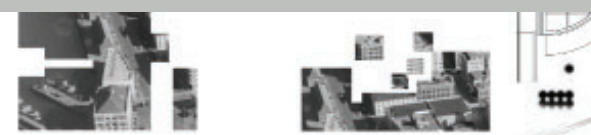

A dreamscape of a city of distant past, the stream's voice only recently silenced, can still be heard as a ghost. As the waterfront land has only recently been reclaimed, the city can still recall memories of the natural landscape. 
- $\circ \circ$

\#: 
This digital collage contains content that is currently unavailable due to pending copyright approval. 


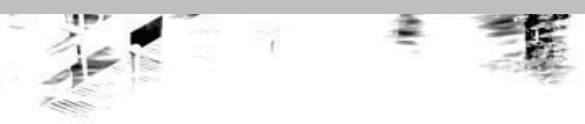

TARANAKI WHARF CUT-OUT

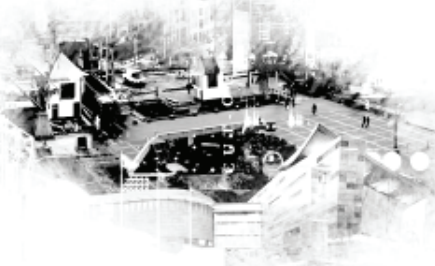

Fig. 3.2.17. Dreamscape: Narrated by the Taranaki WharfCut-out (in the foreground right).

A dreamscape of the present looking back through the ghosts of the past across the harbour to the Kumutoto Stream Outlet site in the background. The present is fragmented. The concrete surface (of the present) surrounding the Taranaki Wharf Cut-out has been removed. It is as if the dreamscape is viewing the layers of history from within the cutout itself. 


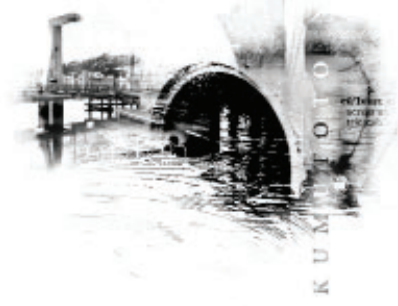

Fig. 3.2.18. Dreamscape: Narrated by the Kumutoto Stream Outlet site (right forground).

A dreamscape of the 'past' (the foreground right) looking towards the present (background) through the layers of fragments of time that have built up as the city has transformed. 
This digital collage contains content that is currently unavailable due to pending copyright approval.

A dreamscape of the 'present' ripping away the surface of the urban concrete to reveal the lost world that lives below. Beneath the surface of the city lie rich layers of lost stories hidden in the darkness below the surface. The cutout is the portal that draws light down into the darkness revealing traces and hints of lost layers below. It reveals layers of time, explored in the following dreamscape series. 
"... the more one was lost in unfamiliar quarters of distant cities, the more one understood the other cities he had crossed to arrive there; and he retraced the stages of his journeys, and he came to know the port from which he had set sail, and the familiar places..."

—Italo Calvino, Invisible Cities, 28

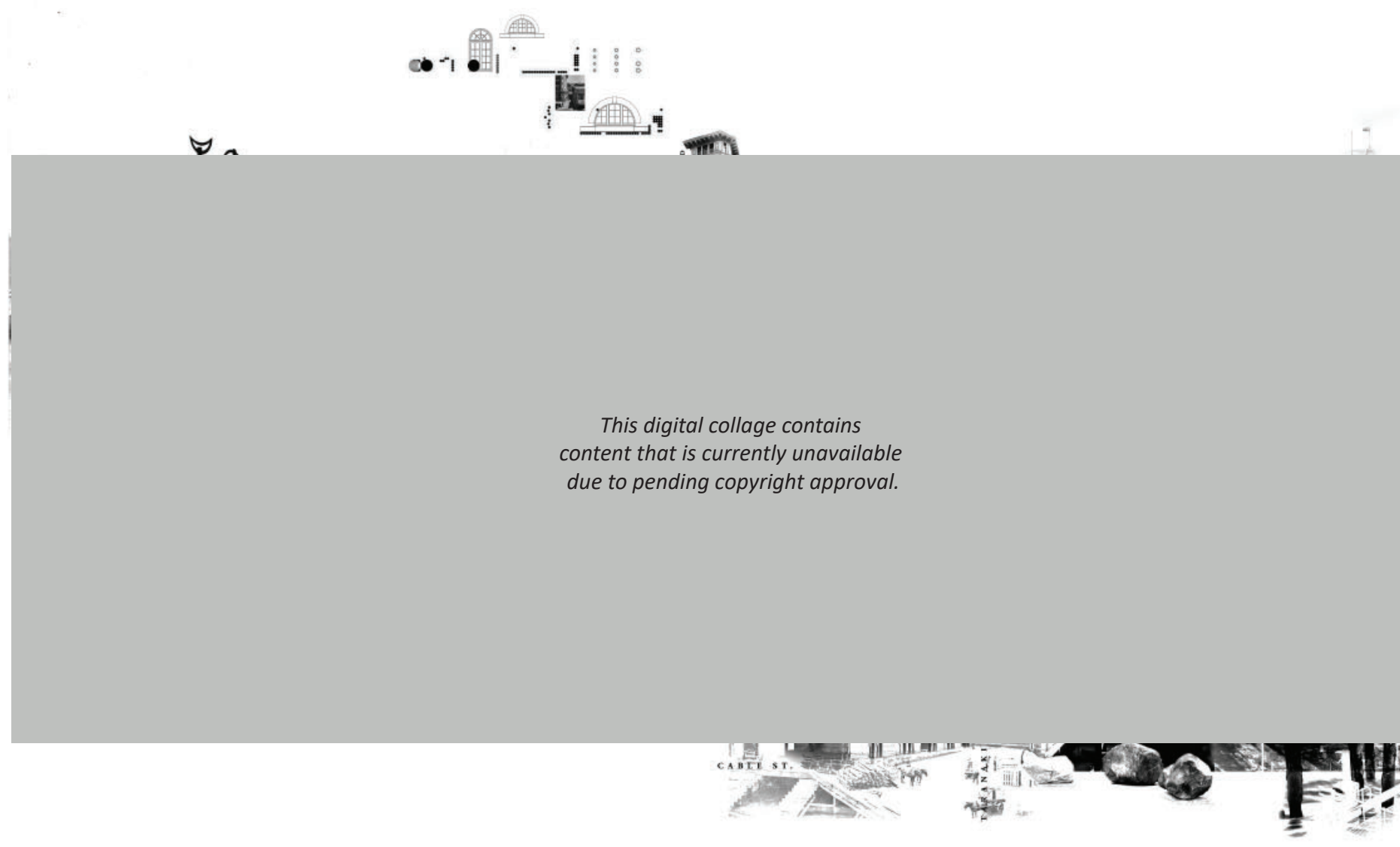

Fig. 3.2.20. Dreamscape Journey: The journey through the dreamscapes retraced.

The journey through these dreamscapes begins with a view of Wellington city that is no longer recognisable by the present. By revealing dreamscapes as a journey through dreamscapes of different layers over time, one comes to recognise these layers are the same place. This reveals the changing identities of place that shift and change as a place transforms over time. 


\section{Critical Reflection:}

These dreamscapes allow multiple voices over time to be heard at once by capturing fragments of time and place as memories narrated in a dialogue. Presented as a journey - a series - these dreamscapes generate a multi-layered meta-narrative of the transformation of Wellington Waterfront over time that remains open to interpretation. While multiple voices can be simultaneously heard over time, certain significant voices become lost in the crowd. The advantages of digital collage over traditional physical collaging is that elements are able to be faded out and overlaid. While fragments in this collage fade out creating spatial and temporal depth, the layering advantages of digital collage could be further interrogated to explore how different fragments when overlaid, speak to each other in different ways revealing different stories and overall voices. This is explored in the following design series. 


\section{DREAMSCAPES:}

\section{LAYERINGTIME}

This series aims to test how the layering of fragments through the technique of digital collage can generate dreamscapes that bring certain voices to the forefront and allow them to be heard above the crowd.

The series takes a range of historical images of Wellington from different points in time and overlays them to generate a dreamscape. This dreamscape portrays a view of the waterfront from the allegorical perspective of the Kumutoto Stream ghost looking across the harbour (over Queen's Wharf, down Customhouse and Jervois Quay) through time towards the Taranaki Wharf Cut-out site in the distance.

The images within the dreamscape are overlaid from four different points of view of time, as a visual interpretation of Einstein's Dreams. They are not presented as snapshots of varying time periods, but as a dialogue between different voices of time, where certain voices of time are heard louder within certain dreamscapes. These design explorations present a view of the city as an evolving pentimento of overlaying buildings and stories that transform, overlap and evolve over time, where varying fragments of layers peel away, revealing fragments of different times simultaneously.

The composition of the images in all four dreamscapes remains the same to explore how the same 'place', when viewed from multiple points of view, can reveal hidden voices and fragments that may not be recognised when viewed from one point of view as a singular representation of place-exploring a visual interpretation of Invisible Cities. This dreamscape aims to visually test and represent an understanding of place as memories, where the stories of a place change depending on the way people remember them. Each dreamscape tells a different story that is ultimately revealing the same story from multiple points of view.

In the following set of iterative experiments, the dreamscape shown on the opposite page will be reinterrogated as fragments of dreamscapes and ghosts of lost fragments, which simultaneously convey multiple interpretations of time and place. 
121

This digital collage contains

content that is currently unavailable due to pending copyright approval. 
Dreamscape fragments: These upper fragments drawn from the dreamscapes below locate and ground each dreamscape in 'place' - a place stamp. They enable a viewer to recognised that each dreamscape is representing the same place from multiple points of view.

The notation device of partial circles below represents the passing of time.

This digital collage contains content that is currently unavailable due to pending copyright approval.
Fig. 3.2.22. Dreamscape: Told from the voice of the past looking towards the present in the distance.

As the layers of place are stripped back to reveal the past's dominant voice, voices of the present and later histories that have been overlaid over time are erased and their voices silenced. The true identity of a place is revealed from the layers of stories and voices that have built up over time. This dreamscape explores the problem that arises when viewing a site solely from a singular voice of history. When voices of the present and later pasts are completely peeled back and erased, does the present recognise itself in a past that is no longer recognisable in the present?
This digital collage contains content that is currently unavailable due to pending copyright approval.
Fig. 3.2.23. Dreamscape: Told from the voices of the past and present in a harmonious dialogue.

When place is viewed as a reciprocal dialogue between varying pasts and the present, the true depth of layers of different times is revealed, ulimately revealing 'open' narratives of place. Exploration of stories does not prioritise one time over the other but rather voices of time are able to speak to each other revealing relationships between fragments of different time that cannot be seen when a site is viewed from only one point in time. The past and present reveal themselves as ghosts oscillating back and forth through time. Through the equitable dialogue of different points of view of time, certain voices are able to be drawn to the forfront and heard above the crowd without erasing or covering layers of different time that lie in front or behind. 
This digital collage contains content that is currently unavailable due to pending copyright approval.
Fig. 3.2.24. Dreamscape: Told from the voice of the present looking back through the layers of the past.

As a place transforms over time, layers of stories and voices become increasingly faded, fragmented and difficult to hear. Voices are compressed and fade into the depths of the thick layering of fragmented voices that have built up over time. Voices become lost beneath the darkness of the surface of the city. This dreamscape aims to explore the problem that arises when viewing a site solely from the point of view of the present. Can lost voices that make up the true identity of place truely be unveiled and freed to be be heard once again?
This digital collage contains content that is currently unavailable due to pending copyright approval.
Fig. 3.2.25. Dreamscape: Told from an alternative point of view of time in which the past does not exist.

This dreamscape aims to explore the problem that arises when layers of the past are lost completely. The Kumutoto Stream-a voice of the past-is lost completely. When the voices the past have been erased, does a place still tell the same stories and can its true identity be revealed? If the past is erased would the same place from the past recognise itself in the future?

\section{"Each time is true, but the truths are not the same..."}


Key to the location of the fragments within the original dreamscape:

This digital collage contains

content that is currently unavailable

due to pending copyright approval.

\section{)}

Extracting fragments of dreamscapes: The aim of these preliminary design experiments is to reveal how the identity of voices change as told from multiple different points of view of time. Using a lost building along a lost shoreline as the voice of the past as an example.

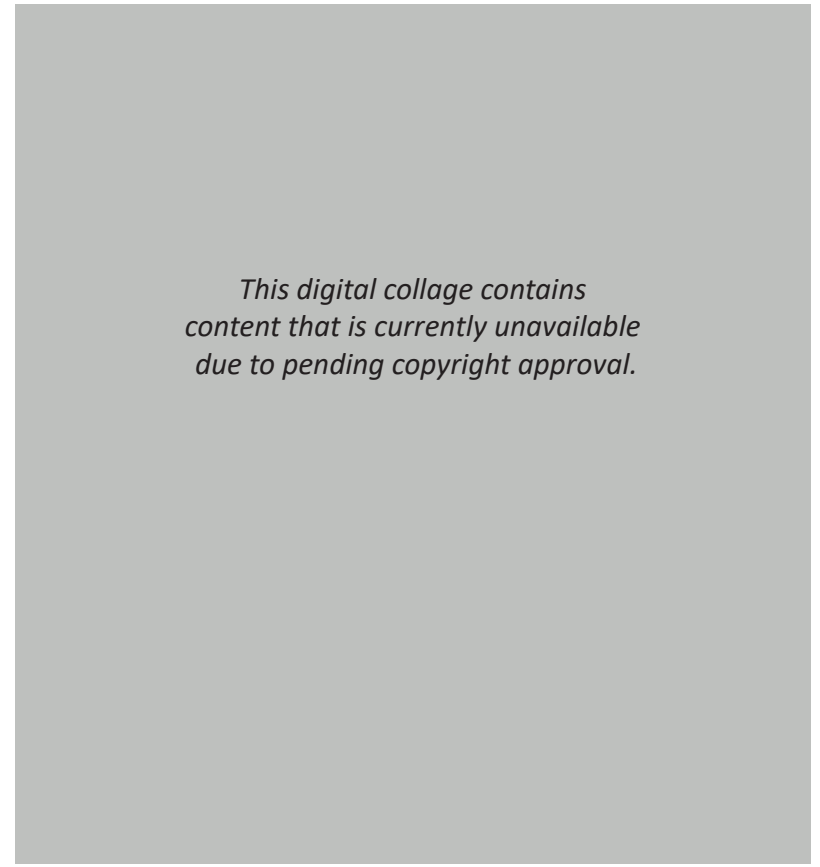

Fig. 3.2.26. Dreamscape Fragment: Told from the voice of the past looking towards the present in the distance.

The voice of the past is whole and opaque; only fragments of other time periods can be seen through. When viewed from the point of view of the past, this voice of the past is silencing voices of the present.

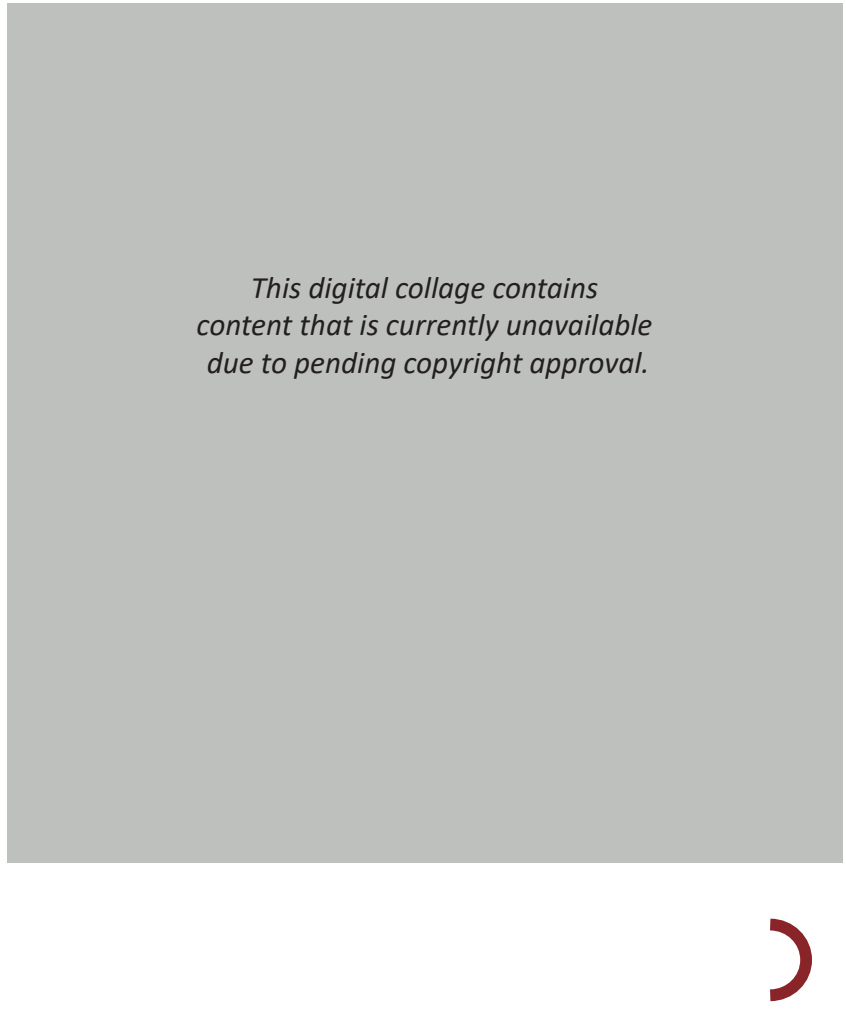

Fig. 3.2.27. Dreamscape Fragment: The voices of the past and present in a harmonious dialogue.

When the voices of the past and present are revealed in a dialogue, the voice of the past can be seen along with a rich depth of layers from other time periods. The layers become transparent ghosts that can be viewed simultaneously. They are free to speak to one another to reveal contextual relationships about different points of time and place. 
“

Suppose time is a circle,

... bending back on itself.

The world repeats itself.."

—Alan Lightman, Einstein's Dreams, 16
This digital collage contains content that is currently unavailable due to pending copyright approval.
This digital collage contains content that is currently unavailable due to pending copyright approval.
Fig. 3.2.28. Dreamscape Fragment: Told from the voice of the present looking back through the layers of the past.

When told from the present, voices of the past remain buried under a thick layer of fragmented voices that live beneath the surface of the present. These voices remain shadowed and difficult to hear.
Fig. 3.2.29. Dreamscape Fragment: Told from an alternative point of view of time in which the past does not exist.

When a site is viewed only from the present, the voices of the past become lost completely. 




\section{GHOSTS OF...}

Fig. 3.2.30. \& 31. Dreamscape Fragments: Revealing how voices of lost landmarks fade over time. The clock tower of Wellington Town Hall was a significant landmark of Wellington in the late 1800s and early 1900s. Its voice was dominant in early visual records of Wellington, until its demolition in 1934. Historical accounts of places often prioritise the archiving of historic monuments and buildings as artefacts, in the retelling of their historic tales of place. The true identity of a place, however, cannot be revealed simply through the collection of these monument; rather these monuments are mere time stamps of certain periods of time in which they lived, that can be used to locate visual accounts of history in moments of time.

This digital collage contains content that is currently unavailable due to pending copyright approval. 
The four dreamscapes are represented in the following pages as stand-alone images to enable a viewer to dive into each dreamscape individually-to discover the rich layers of voices of place that shift as layers of time oscillate back and forth, bringing certain voices to the forefront while others fade away into the background.

By repeating ideas, a viewer can discover lost voices reawakened through the speculative outcomes that may not have been seen or recognised when these outcomes are viewed as a collection. 
This digital collage contains content that is currently unavailable due to pending copyright approval. 
"... even if it was a matter of the past, it was a past that changed gradually as he advanced on his journey, because the traveler's past changes according to the route he has followed: not the immediate past, that is, to which each day that goes by adds a day, but the more remote past."

Fig. 3.2.32 Dreamscape: Told from the voice of the past looking back at the present in the distance.

Fragments of the previous dreamscape have now been reassembled with new fragments upon a larger field. 
This digital collage contains content that is currently unavailable due to pending copyright approval. 
This digital collage contains content that is currently unavailable due to pending copyright approval. 
Fig. 3.2.34. Dreamscape: Told from the voice of the present looking back through the layers of the past.

Fragments of the previous dreamscape have now been reassembled once again with new fragments. 
This digital collage contains content that is currently unavailable due to pending copyright approval. 
Fig. 3.2.35. Dreamscape: Told from an alternative point of view of time in which the past does not exist.

Fragments of previous dreamscapes have now been shadowed and faded, dimmed, prelaced, and re-assembled in new fields of light and darkness, time. 


\section{CRITICAL REFLECTION}

voices in the interrogation of the research sites and surrounding context. In addition to James Corner's cognitive mapping technique "Drift," as a critique of a place within the city's fabric, and CJ Lim's integration of collage, narrative, and allegory from a selection of his case study works, as an approach to break away from a "true" recreation of history to reveal hidden stories, design experiments in this section produced a series of dreamscapes that allow multiple voices and stories of time and place to be heard simultaneously as historic fragments of time and place are overlaid. The objective of the experiments was to capture an invisible reality of the city's lost identities that constantly shift and transform as fragmented memories that when viewed in a collection visually narrate a greater story of the transformation of the research sites and Wellington Waterfront over time.

Unlike the previous section 3.1 mapping that reveals hidden layers and fragments of the landscape from the outset and above through Corner's techniques of layering and game-board, the dreamscapes in this section reveal hidden fragments from within the fabric of the city through Corner's cognitive mapping technique of 'Drift', mapping a city as it is visually experienced as memories. Mapping drift through allegorical dreamscapes, an approach drawn from C. J Lim's case studies, enables both the physical and metaphysical characteristics of the two research sites and surrounding context to be visually captured and represented. Figures 3.2.8-3.2.14 were conceived as preliminary explorations of the ability of collage and dreamscapes to allow multiple voices of time and place at once as collaged fragments, a timeline, and allegorical characters. Figure 3.2.10 presented a timeline that revealed the transformation of the landscape as a visual drift through different iterations of the city, as fragments of both time and place were overlaid as a single dreamscape. Figures 3.2.11-3.1.14 re-presented the two selected sites as allegorical characters that allowed fragments of the sites from different points in time to be viewed at once visually representing multiple dimensions and layers to the sites' identity that may not be recognised in a single snapshot of the site.

The preliminary design experiments were integrated to generate two developed dreamscape series, the first, Figure 3.3.15-3.3.20, "A Journey Through a Dialogue of Dreams", and the 
second, figures 3.3.21-3.3.35, "Layering of Time". The first developed design series was conceived to further engage allegory to represent Calvino's proposition of a city as a series of fragmented perceptions of the city from different points of view revealed within a dialogue between two characters. The two characters in this journey were the two research sites conceived in the preliminary experiments figures 3.3.11-3.3.14 as the voice of the present and the voice of the past. It was conceived to further represent Lightman's proposition that time is not linear, and as a development of the timeline dreamscape, figure 3.3.10, where the journey the overlaying of fragments distant in time allowed different fragments from various pasts and present to be viewed in a dialogue, revealing rich and complex contextual relationships between the past and present. Representing the city as it stands as a complex array on non-linear transforming fragments overlaid simultaneously.

The second developed design series, figures 3.3.21-3.3.35, "Layering of Time", was conceived to further explore the layering of fragments of time and how certain voices of time could be brought to the forefront and allow them to be heard above the crowd. This series of dreamscapes visually revealed how meaning, identity and stories revealed shifts as various layers are reworked and bought to the forefront or fade into the background, like the way the layers of a place that build up over time and fade away shift the understanding of place.

Presenting historical fragments of the two selected sites and the surrounding context of Wellington Waterfront through the method of collage and the integration of allegory to generate dreamscapes allowed multiple fragments of time and place to be continuously reworked to generate varying dreamscapes, allowing different stories to be revealed as each series of fragments is reconfigured. It also facilitated the visual representation of 'open narratives' of the landscape representative of Matthew Potteiger and Jamie Purinton's theory discussed in chapter two, the idea that a place is not a permanent or static whole, rather constructed of a constantly shifting array of fragments that shift, transform, add up or fade over time. 

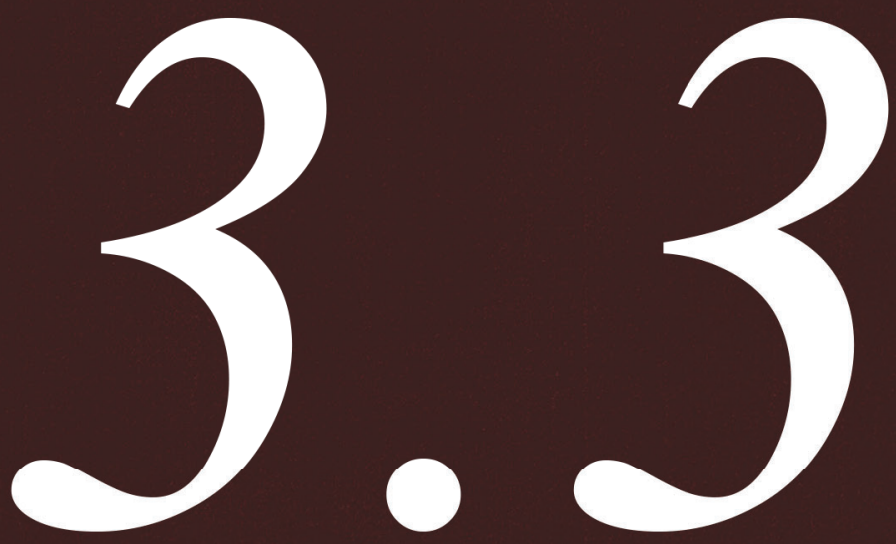

"... ARCHITECTURE.

What is architecture, and can it be held within

a drawing... as well as a building?

It is a synthesis of poetry, fine art, sculpture;

it flows over time like music and its spaces have

Prazeter 3 estabi that capetwrel risual idear form.

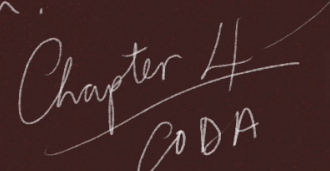

scales (from macro to micro)-and have a denouement, as in film or prose.

One could go on...

000

Above all, architecture is the manipulation of space in all its manifestations.
Space can be both imagined and graphically represented."

$$
\begin{aligned}
& \text { Bringing idear } \\
& \text { to life ar } \\
& \text { draning }
\end{aligned}
$$




\section{Allegorical \\ Drawing \\ Fragments : Manifesting the Artefact}

[RO3] Allegorical Drawing Fragments: to explore how allegorical drawing fragments can be used to generate speculative architectural outcomes that enable voices to be heard, even when they have already partially faded away. 
"A drawing for me is a model that oscillates between the idea and the physical, or built, Drawing of reality of architecture. It is not a step not a procer toward this reality but an autonomous act to of working tonards Single firal outcome anticipate the concreteness of the ideal... but aboun The first markings on a white sheet of paper, exploing the first carvings in stone, the first engravings idear in in metallic plates represent the beginning of risual form architecture, the primal act of construction ar fragmente. towards the realization of an idea. To draw is map the world through signs, locating the absence figurative geometries of the eye. "Tender.
the in insible
visible 


\subsubsection{Allegorical Drawing}

141

To draw architecture ... is ultimately the manifestation of the translatability of a poetic text of metaphors into architectural form."

This section addresses Research Objective 3, exploring how allegorical drawing fragments can be used to generate speculative architectural outcomes that enable voices to be heard and retained, even when they have already partially faded away. To address this research objective, this chapter investigates allegorical drawing as a medium for rendering the invisible visible and the storytelling capability of drawn fragments both as individual fragments and multiple fragments coming together to form artefacts.

Raimund Abraham proposes that drawing can be considered as a model that oscillates between the idea and the physical or built reality of architecture, asserting, however, that drawing does not represent "reality" but instead captures ideas as signs (101). Drawing in this mode is re-presentational; in this investigation, drawing does not merely represent a realistic place already in existence, but instead attempts to re-present stories of place in ways previously unseen.

Architect and theorist Marco Frascari, in his book From Models to Drawings: Imagination and Representation in Architecture, presents drawing as a metaphoric language and a means of architectural imagining. Frascari writes, "architectural drawing is ... wholly based on ... a materialization of fluid, invisible thoughts" (6). The drawing attempts to render visible the invisible (Frascari, 7)
For architectural theorist Neil Spiller, drawing is thinking-formulating and recording thoughts and ideas of the imagination through drawing. In "Drawing as Communicating Vessels", Spiller cites the potential of speculative architectural drawing:

...the explorative, or 'magical' drawing is a site of both understanding and emergence, a repository of information and a 'working' surface on the one hand, and the location of multiple potential imaginaries on the other. (268)

In his article "Architectural Drawing: Grasping for the Fifth Dimension," Spiller depicts drawing as a tool to help find a new, fifth dimension of architecture (the first four being the three spatial dimensions and time). A dimension, he writes, is unable to be explored through design outcomes presenting whole architectures as digitally rendered CAD models. To generate the fifth dimension, Spiller argues, one must consider the 'donegality' of drawing, defined as both the metonymic meaning-a figure of speech consisting of the use of one thing for that of another with which it is associated-and the unique essence, ideas or mood expressed through a story. Spiller argues that it is the 'donegality' of a drawing that contributes to the 'atmospheric chemistry' and helps communicate understandings of place beyond concrete architectural form (Spiller, "Architectural Drawing", 15). 
Spiller advocates for integrating allegory in a speculative architectural drawing to capture ideas and narratives that would otherwise remain unseen in conventional drawing practices as direct representations. He writes:

... [speculative drawing] makes connections that help us see and wonder as they concoct new epistemologies from the fragments around them and echoes in history. (Spiller, "Architectural Drawing," 19)
By engaging allegory in architectural drawing, drawings become metaphors that can visually render lost voices of a place that have already partially faded away, and allow them to be heard once again-voices that would otherwise remain unseen through direct representation of place.

\subsubsection{Allegorical Drawing Fragments}

\begin{abstract}
Allegorical drawing fragments are figurative geometries, defined by Haralambidou as the abstraction of objects, architectural forms and sites to signify meaning and relationships (231). Figurative geometries refers to both the geometric principles, drawing fragments, and the mathematical equations of geometric forms-multiple drawing fragments coming together in different ways to unveil new relationships and meaning that may otherwise remain hidden. An allegorical drawing fragment has the possibility of representing many stories, voices, and layers of meaning, both conflicting and constantly shifting as the identity of fragments transform as pieces are added or taken away.
\end{abstract}

Marco Frascari asserts that drawings must remain fragmentary and unfinished. He affirms that when generating architectural drawings, one must be able to select, discard or further build upon uncovered possibilities (39). Architect and historian Robin Evans, in his book Translations from Drawing to Building posits that drawing fragments have the potential to convey "a constant interplay between the passive portrayal and active remodeling of reality" (21). He argues that perceiving a thing in parts, and by way of the unfolding of a continuum of its manifold visible aspects, engages the imagination in revealing the structural fullness of the form and layers of fragmented stories of a drawing (Evans, 40).

Jonathan Hill, Professor at The Bartlett School of Architecture, in his book Immaterial Architecture, argues for the fragmentary unfinished nature of speculative architectural drawing when telling stories. He posits that 'gaps' in speculative drawings invite interpretation and provoke a viewer to generate meaning through personal interpretation of the fragment itself and as they attempt to conceive a fragment as a piece of an invisible whole (Hill, 161-162). 
The manifestation of memory of a spatial event from the history of the site is idealised through abstraction of the language of architecture."

—Raimund Abraham, [UN]BUILT, 101

Over time, stories of place fragment and fade away as the landscape continually transforms. These lost stories can never be rediscovered in their entirety, but rather fragments of these stories can be drawn as remains and artefacts that allow the voices of lost stories to be heard even when they have partially faded away. Tim Edensor, Professor of Social and Cultural Geography, in his book Industrial Ruins: Space, Aesthetics and Materiality, argues that there is an excess of meaning in the remains, containing a plenitude of fragmented stories that captures the incomplete and open-ended nature of history (140).

Christina Boyer in her book The City of Collective Memory draws on seminal theorist Aldo Rossi's theory of the 'Urban Artifact' defined as elements of the landscape that persist through times of change, or a set of transformations (Rossi, 29). Boyer re-frames the concept of the 'Urban Artifact' as an architectural memory device that reveals traces of previous architectural [and natural] forms that preserve memories of the past (Boyer 31). Peter Eisenman in the introduction of Rossi's book Architecture of the City, declares that the 'Urban Artifact' is not just the physical things in the city, but all of its history, geography, structure, and connection with the general life of the city, acknowledging both the physical and the metaphysical (Eisenman, 4-7).

In this investigation drawing fragments are defined as artefacts that aim to capture fragments of material and immaterial characteristics and stories of place, in order to allow greater stories of place to be recognised even when they can never be seen as a whole or have been lost forever. 
This content is unavailable. Please consult the figure list for further details.

Fig. 3.3.3. Sketch drawing of San Cataldo

Cemetry. Aldo Rossi. 


\section{SAN CATALDO}

CEMETRY

\section{Aldo Rossi}

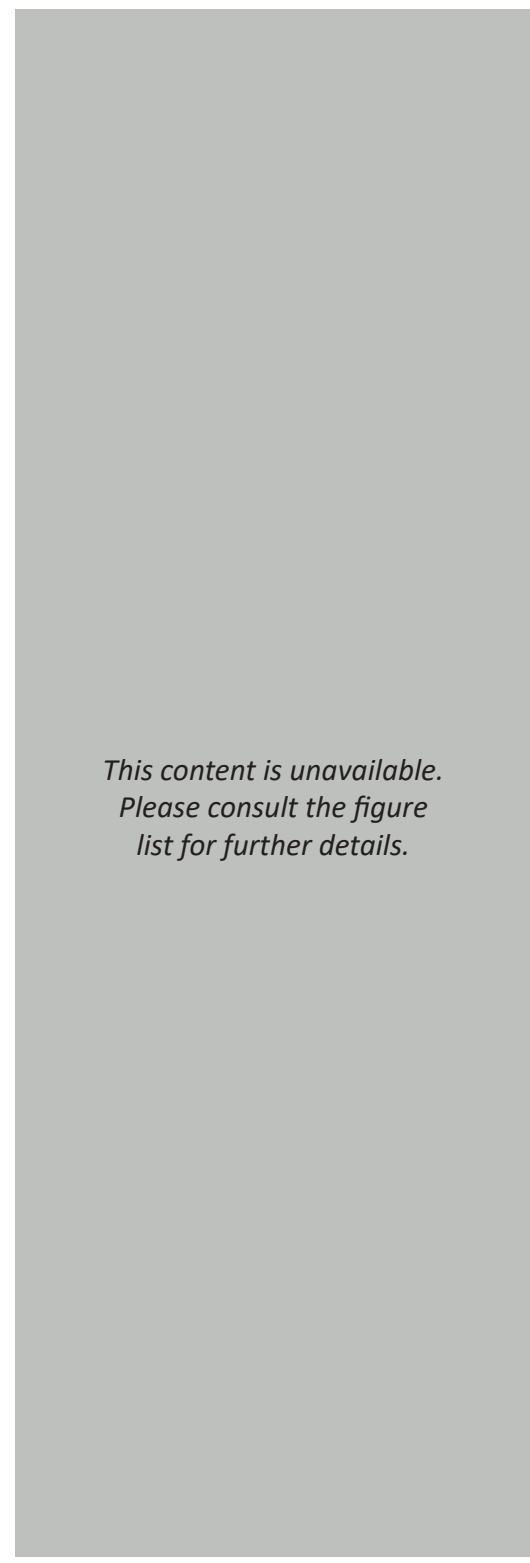

Fig. 3.3.4. Provisional sketches

\& Fig. 3.3.5. Visual montage

of figurative geometries for

the design of the San Cataldo

Cemetry. Aldo Rossi.
Aldo Rossi's San Cataldo Cemetry (1971) is a seminal exemplar of a proposed 'built' architectural allegory generated from fragments charged with symbolic meaning. The Cemetry expresses the use offigurative geometriesthrough its symbolic form as fragmented spatial characters. In creating the cemetery, Rossi draws upon his autobiography of forms he has generated as artefacts and historical symbols to generate an analogical composition of fragments. Rossi's use of figurative geometries denotes structural relationships that call upon history's annals to prompt associations.

Rossi acknowledges architecture as a personal process through which one could understand the complex and contradictory nature of life and a universal source of symbol and meaning (187). In Rossi's sketches of the project, Rossi combines fragments of objects through collage, searching for new associations and relationships between symbols and forms. Both poetic and uncanny, the drawings for the project combine technical and poetic elements. The elements of the cemetery complex are a field of mapped geometric shapes between voids. Figurative elements include: a truncated cone reminiscent of a deserted factory chimney, an image of a ruin, a house with four walls and no roof as a house for the dead, and a series of skeletal passages that represent both body and death. This use of fragmented and collaged figurative elements triggers new meanings and relationships that narrate a collection of fragmented stories.

\section{5}


This content is unavailable.

Please consult the figure

list for further details.

Fig.3.3.6. Vessel of Time. Wellington Reiter. 


\section{VESSELS}

AND

\section{FIELDS}

\section{Wellington Reiter}

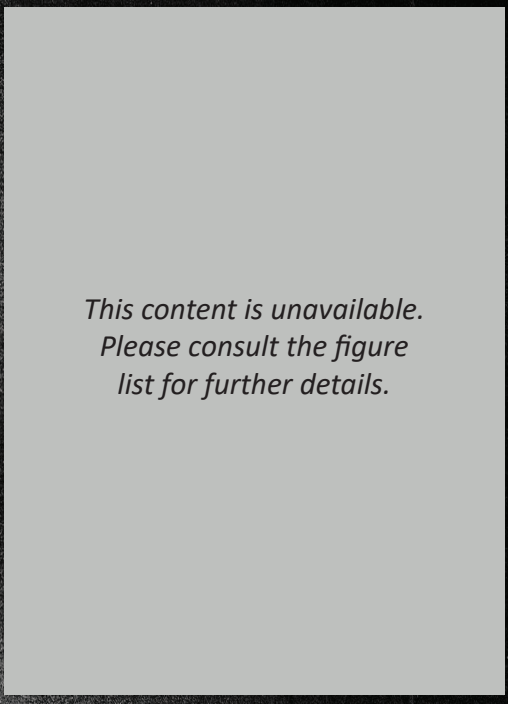

Fig. 3.3.7. Book Cover. Vessels and Fields by Wellington Reiter.
A selection of allegorical architectural works from Wellington Reiter's book Vessels and Fields serves as useful case studies for how forgotten pasts of cities can be derived, represented and reawakened by allegorical drawing fragments, both as individual allegorical characters and fragments that come together as collages and maps.

Reiter engages allegory in drawing as a critical method of questioning ideas, engaging the imagination, and drawing meaning from a place or specific site. He uses allegorical typologies and a syntax of objects to interrogate and animate sites and invoke the past. Reiter's drawings do not simply represent the city; they re-present it, tracing both the physical and intangible. Reiter's typologies include: theatres, arks, gates, islands, bridges, towers, vessels, clocks and fields to create metaphorical characters to tell stories of place and to give presence to overlooked conditions (Phillips, 4). Patricia Phillips articulates in the forward of Reiter's book how typologies oscillate between the imagined or forgotten past and the shifting present and future, and are metaphors to challenge perceptions of time, place, and urban condition (4). She writes how Reiter's proposals are always negotiating fantastic fictional accounts with incisive observation, [disclosing] the restless, transitive characters of cities (Phillips, 4). As characters and stories unfold, intersect and overlap, Reiter's drawings create an atmosphere in which a vivid depiction of the city emerges (Phillips, 4). The drawings exhibited in the book exist somewhere between the real and the imagined, creating an atmosphere that is both familiar and uncanny. Through excavation of presence from absence, Reiter's drawings construct the tangible out of the void and reveal voices of place that would otherwise remain hidden.
VESSEL OF TIME
Reiter's Vessel of Time presents two opposing timepieces positioned together in dialogue. The first timepiece measures time by the upward growth of a tree seen through a transparent cone. The second measures time through the erosion of the solid cone as the site descends to ruin over time. 
ISLANDS

Reiter's drawing OF TIME

series Islands of Time can be interpreted as two opposing sites coming together

in a dialogue to narrate their stories in relation to one another, revealing a greater contextual narrative. These two opposing 'islands' exist on different days, separated by the International Date Line. Each island constructs a bridge toward the midpoint where a table and two chairs are arranged to symbolise their 'meeting'. When these two islands-fragments of different times-meet, time is collapsed. The two sites are anthropomorphised into characters that narrate the story, and can be interpreted as figurative geometries. 
This content is unavailable.

Please consult the figure

list for further details. 


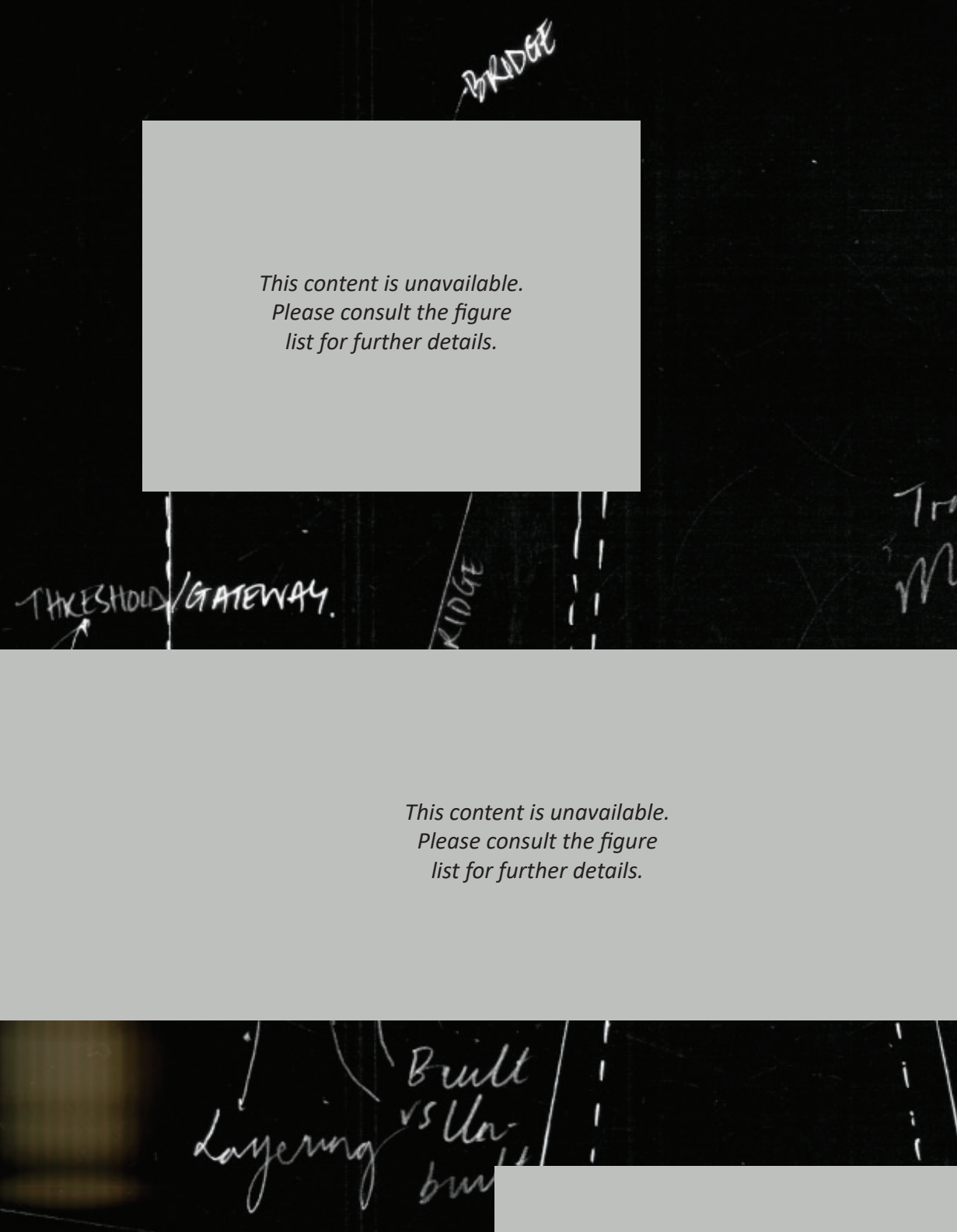

- BELOW

- DARK

- LIGHT ABOVE

Please consult the figure

list for further details.

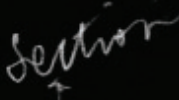

is content is unavailable.

Please consult the figure

ist for further details.

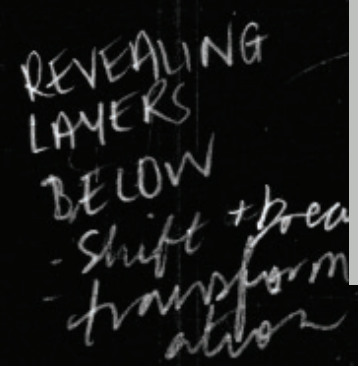

This content is unavailable.

Please consult the figure list for further details. 


\section{ALLEGORICAL DRAWING FRAGMENTS:}

\section{MANIFESTING THE ARTEFACT}

"Architectural drawings are metaphors ... they are a carrying over, a moving of sensory information from one modality, from one set of emotions to another set of emotions.

Thenext series of design-led research experiments tests how the allegorical interpretation of fragments as drawings can tell stories and reawaken voices that have already faded away. As a series of de-contextualised fragments, drawings in this section are interpreted as allegorical characters, artefacts and symbols that engage metaphor to reveal meaning and stories of place. Fragments in this series are conceived as figurative geometries; both as extracted elements from sites and abstracted objects pieced together to explore their storytelling ability and capacity to convey meaning when presented out of context. The series explores how when fragments are placed in a dialogue with other fragments or gaps are revealed, the meaning of the fragment shifts, revealing different stories and hidden meaning that may not be revealed if viewed as a whole.

The allegorical drawings in this chapter generate a foundation for the CODA - the final series of allegorical drawings that integrate collage and mapping with allegorical drawing fragments in the final developed design chapter of the thesis.

\section{All images in this series are author's own.}


Imagine a world in which there is no time.

\section{Only images..."}

- Alan Lightman, Einstein's Dreams, 75

"The eye does not see things

but images of things that mean other things"

- Itato Calvino, Invisible Cities, 13 
An Architecture facade is a Mask. this Mask is dead,

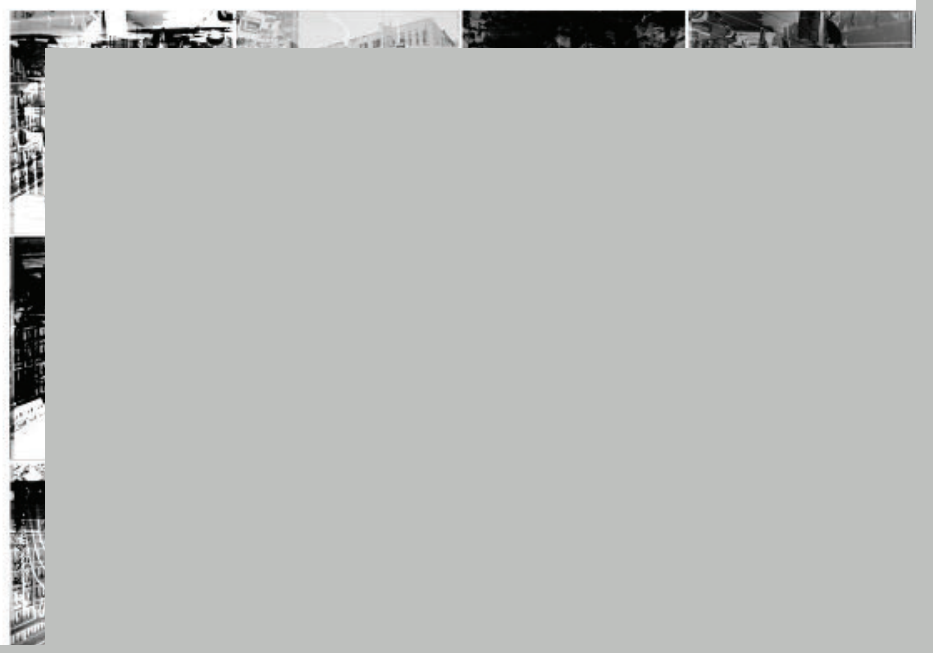

This digital collage contains content that is currently unavailable due to pending copyright approval.

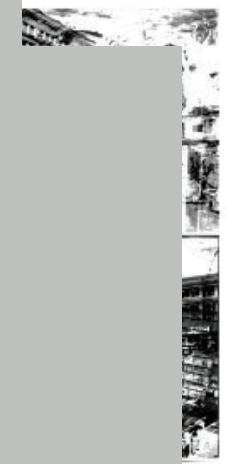

20

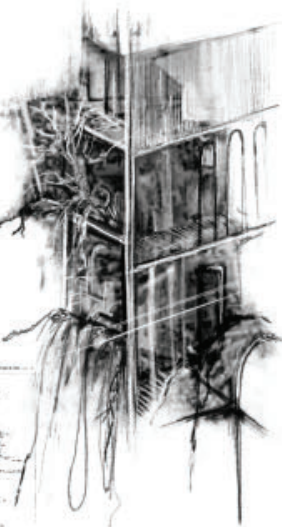

$\frac{1}{4}$

Fig. 3.3.10. Collage: Wellington 'heritage' buildings in 'ruin'. 


\section{EXCAVATING FRAGMENTS:}

\section{COLLAGE + DRAWING}

"Futures not achieved are only branches of the past: dead branches."

-Italo Calvino, Invisible Cities, 29

\section{Destroy thio inaminate
mask and...}

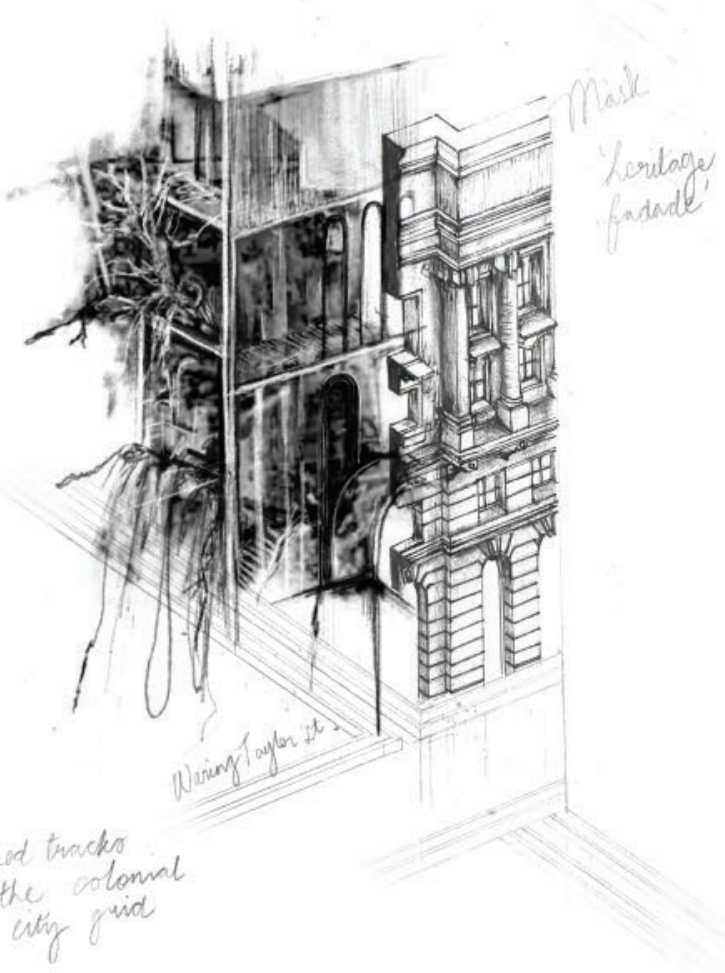

This design exploration is a mediation between digital collage and drawing, exploring how collages can evoke the imagination to extract forms to generate allegorical drawing fragments that tell a story. The collaged fragments are generated from a series of images of buildings in Wellington during their process of demolition, where architecture in this state is perceived as 'ruin'.

A heritage buildings' true identity and historical voices do not live within the preserved facade but within the walls. Beneath the facade's 'mask' lies a collage of various transformations and adapted uses over time. Only in its demolition can we discover all the fragments and layers that construct the building's true identity. The true story is revealed when the heritage 'mask' is removed, unveiling lost voices of identity that lay embedded within. These 'masks' stop time and disguise stories of the future; the mask is a branch of the past: a dead branch.
... a building is alive, living, breathing, growing. Atoring memovier with every of identity... - author's

Fig. 3.3.11. Fragment: Deconstructing a building as a 'ruin'. 


\section{ALLEGORICAL} DRAWING FRAGMENTS:
The natural landscape of Wellington has been destroyed and cannot be returned to its original state. This series of design-led research experiments explores how allegorical drawing fragments can reawaken the natural landscape's voice and allow it to be heard as figurative geometries. It speculates how the battle between stories of the natural landscape. and the built environment can be allegorically represented as individual drawn fragments and explores how the voice of fragments and the stories they tell are altered when fragments are pieced together or as gaps are revealed. 
Fig. 3.3.12. Fragment: The wharf pylons of the Taranaki Wharf Cut-out can be allegorically interpreted as remnants of the trees of the lost natural landscape, cut down and reshaped to form the foundation of the built landscape. Photo by Author.
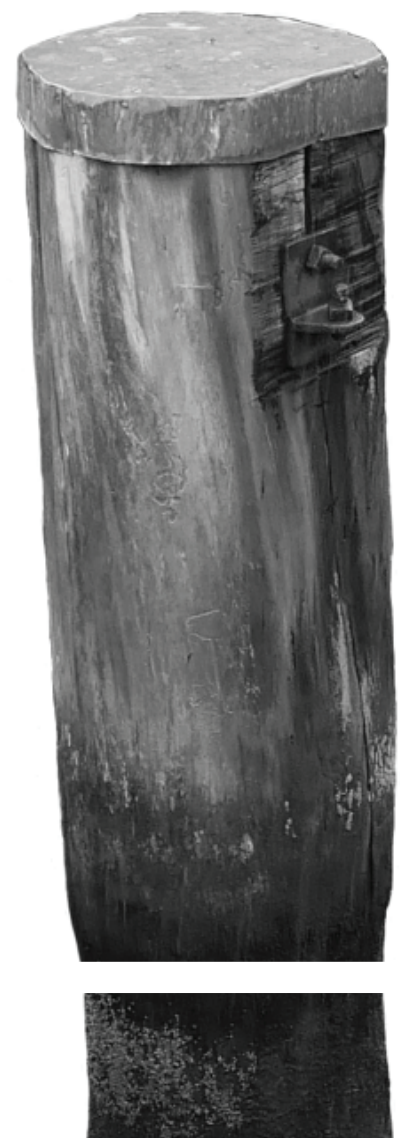


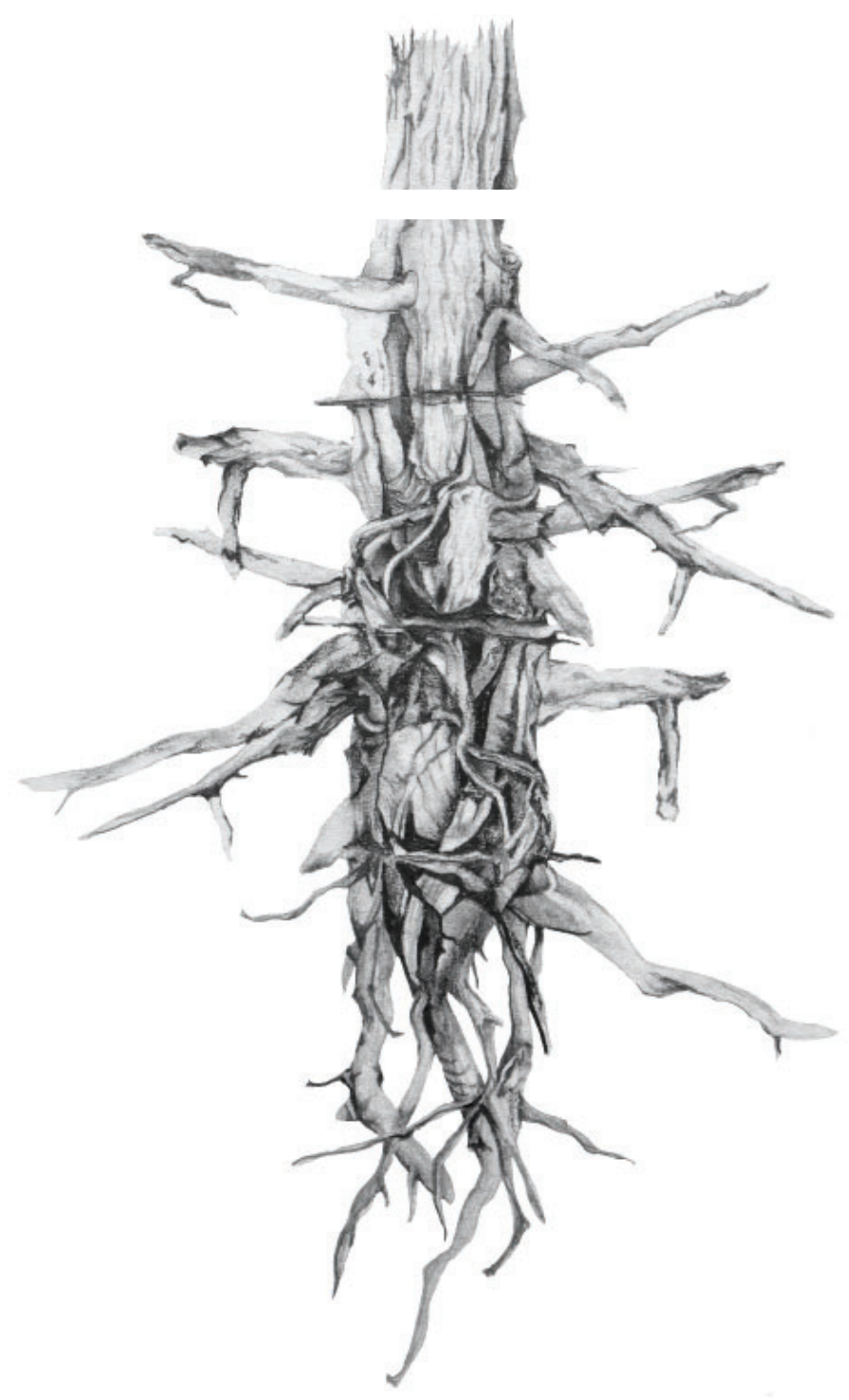

Fig. 3.3.13. Allegorical Drawing Fragment: The roots

An allegorical reinterpretation of the wharf pylon. The pylon as a remnant of the natural landscape where only a fragment of this pylon can be seen. This allegorical fragment reveals that beneath the visual surface of Wellington the roots of the lost voices of the natural landscape live on however cannot be seen and exist as the roots buried beneath the city's ground. Roots can be allegorically interpreted as the voices of the natural landscape that can no longer be seen or revealed without destroying the landscape above. Drawing by author. 


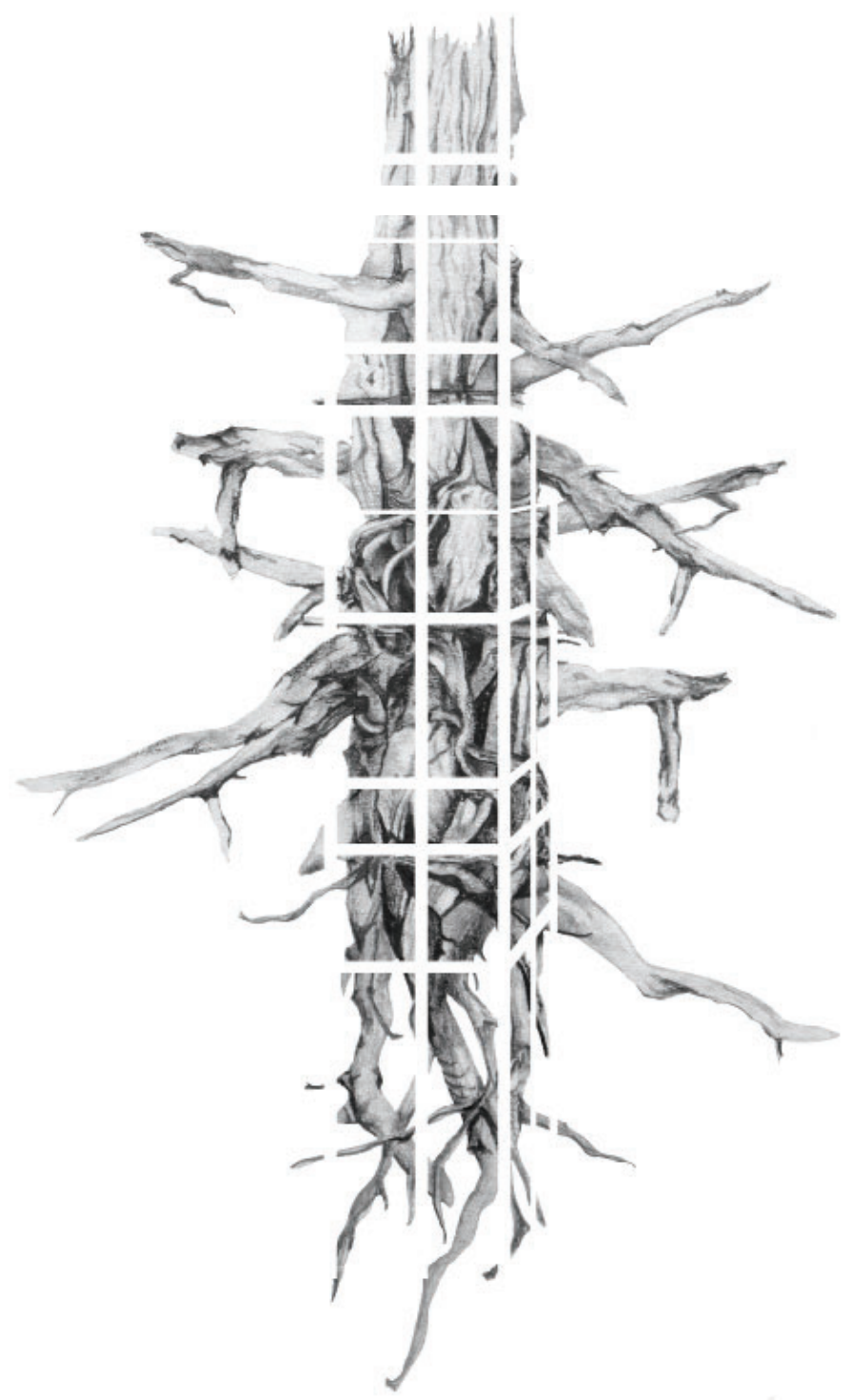

Fig. 3.3.14. Allegorical Drawing Fragment: The roots imprisoned

Imprisoned by the built landscape, the natural landscape's lost voices remain trapped, shaped by the built structure that surrounds them. Revealing gaps in fragments alters the overall story that the fragment has to tell. The fragment retains elements of the same story and voice, but its identity shifts as the story gains another layer of depth that is open to interpretation. Without revealing what is surrounding the roots, the gaps imply that a structure of sorts is imprisoning the roots restricting their growth. Fragments and gaps can tell stories and unveil voices without presenting a completed whole. Drawing by author. 
This series explores how the battle between the natural landscape and built landscape can be allegorically represented as fragments are pieced together. The fragments have their own individual voice and story to tell. Piece these fragments together and they reveal a new story.

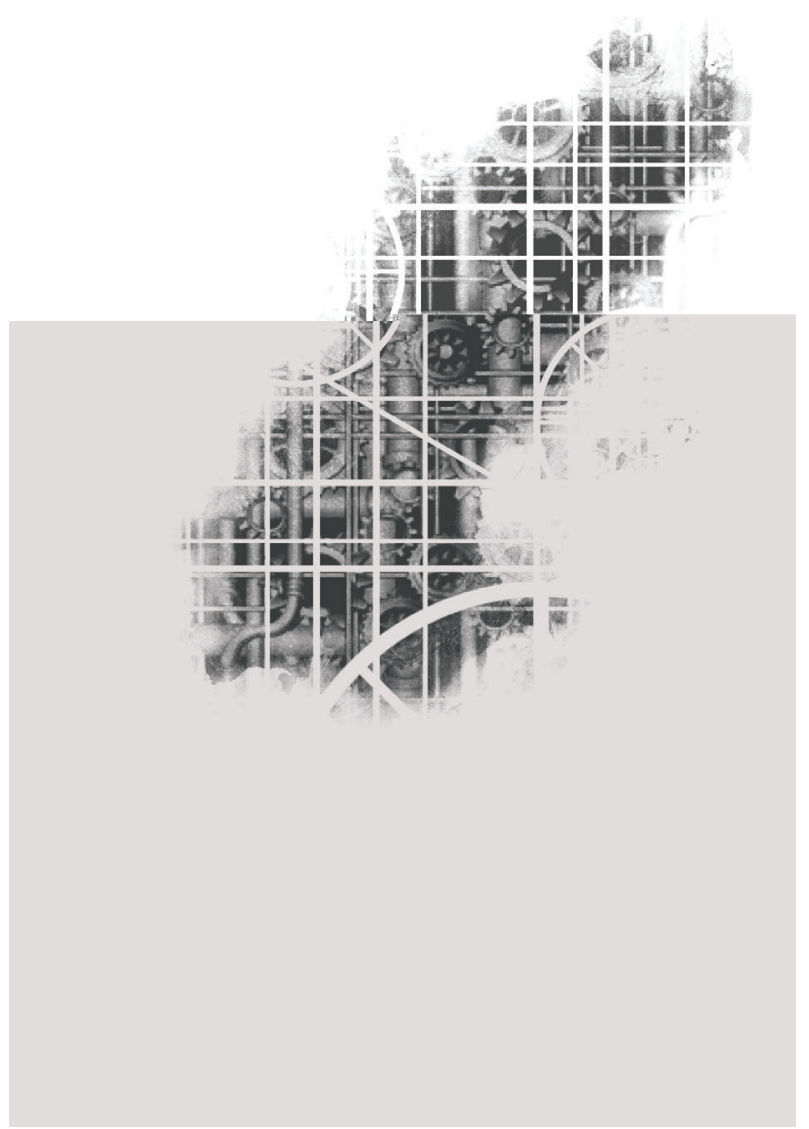

Fig. 3.3.15. Allegorical Drawing Fragment: The built landscape beneath the urban concrete contains the growing network of the mechanical 'roots' of the built city. Gaps in the drawing (the grid) enable the drawing to be located as a layer beneath something else, without revealing what is situated above. Drawing by author.

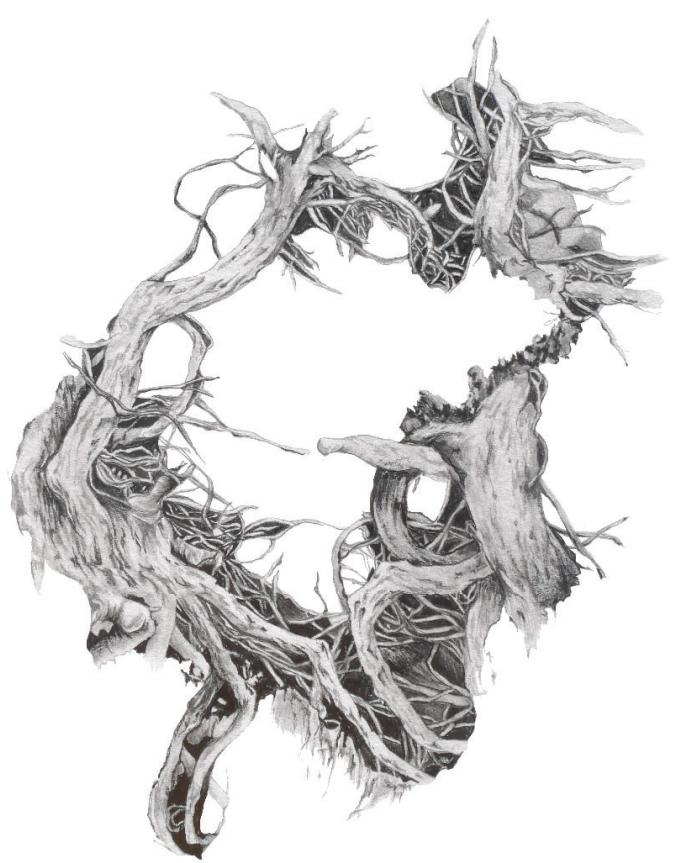

Fig. 3.3.16. Allegorical Drawing Fragment: The roots of the natural landscape are free to grow and change shape. Drawing by author. 


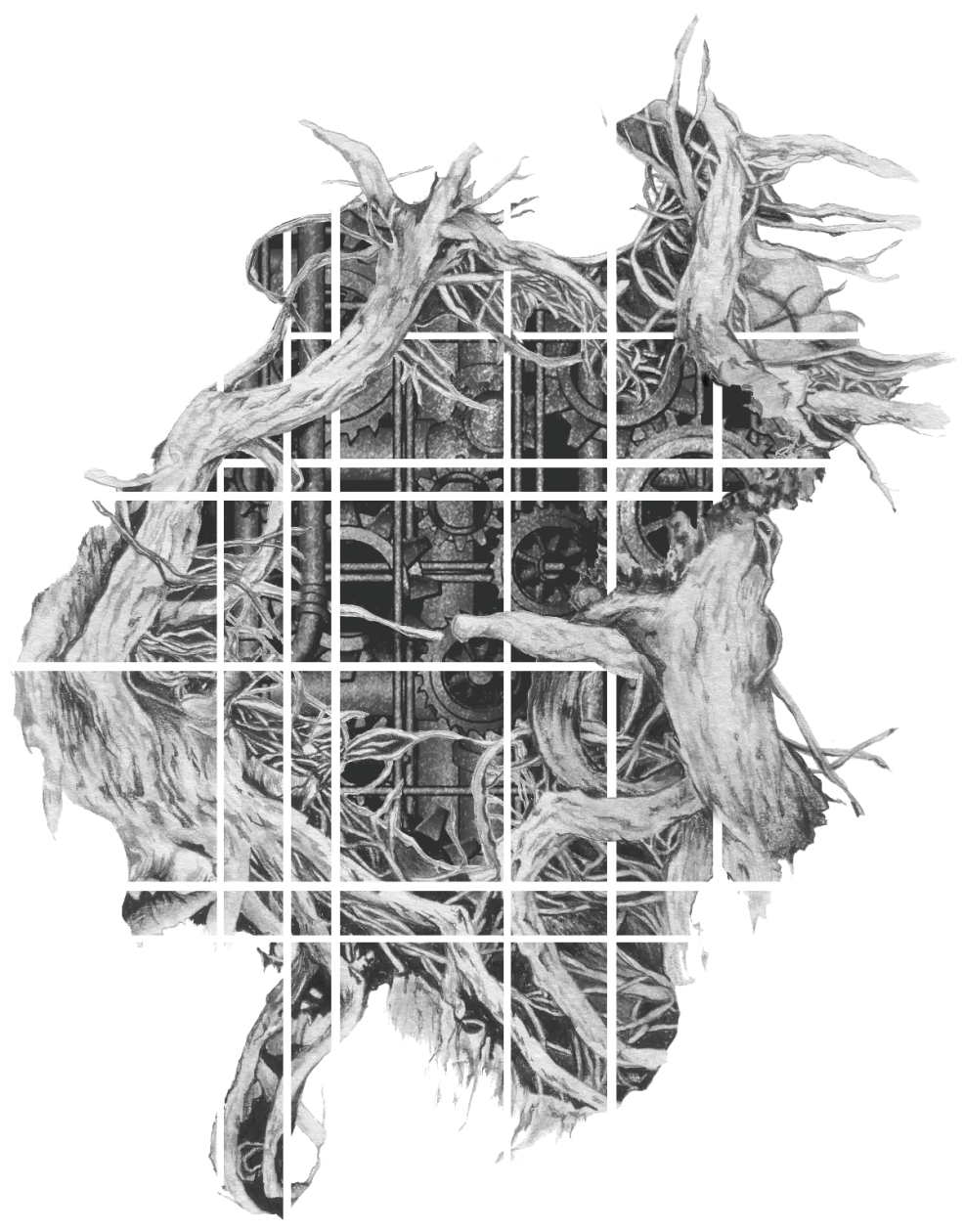

Fig. 3.3.17. Allegorical Drawing Fragment: Beneath the surface of the city the roots of the built and natural landscape are intertwined. The roots of the natural landscape can still grow, however are shaped by the built landscape as the roots thread throughout its layers. Drawing by Author. 


\section{ALLEGORICAL} DRAWING FRAGMENTS:
This series of design-led research experiments explores how the allegorical reinterpretation of sites as characters can convey meaning and elements of their identity. This series takes the two research sites: the Taranaki Wharf Cut-Out and the Kumutoto Stream Outlet, and allegorically reinterprets them as portals that connect to one another. This series further tests the story telling potential of the allegorical interpretation of fragments and how the stories these fragments have to tell alter, or gain new layers of meaning, when positioned in a dialogue with other fragments.

All images in this series are author's own. 
163

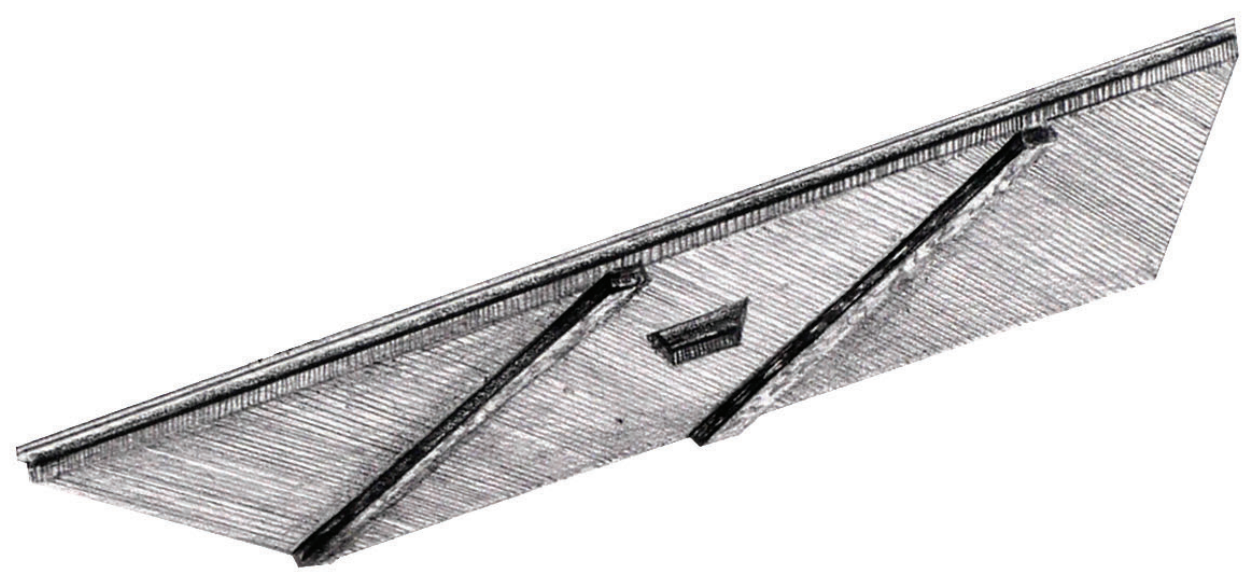

TARANAKI WHARF CUT-OUT

Fig. 3.3.18. Allegorical Drawing Fragment: The Taranaki Wharf Cut-out, removing a layers of the city's concrete. 
Fig. 3.3.19. Allegorical Drawing Fragment: With a layer of the city removed, a bridge across the void presents a portal to a lost world below. While the portal can be seen, the world remains hidden behind a veil. The veil floats open revealing only a trace of what lies behind.






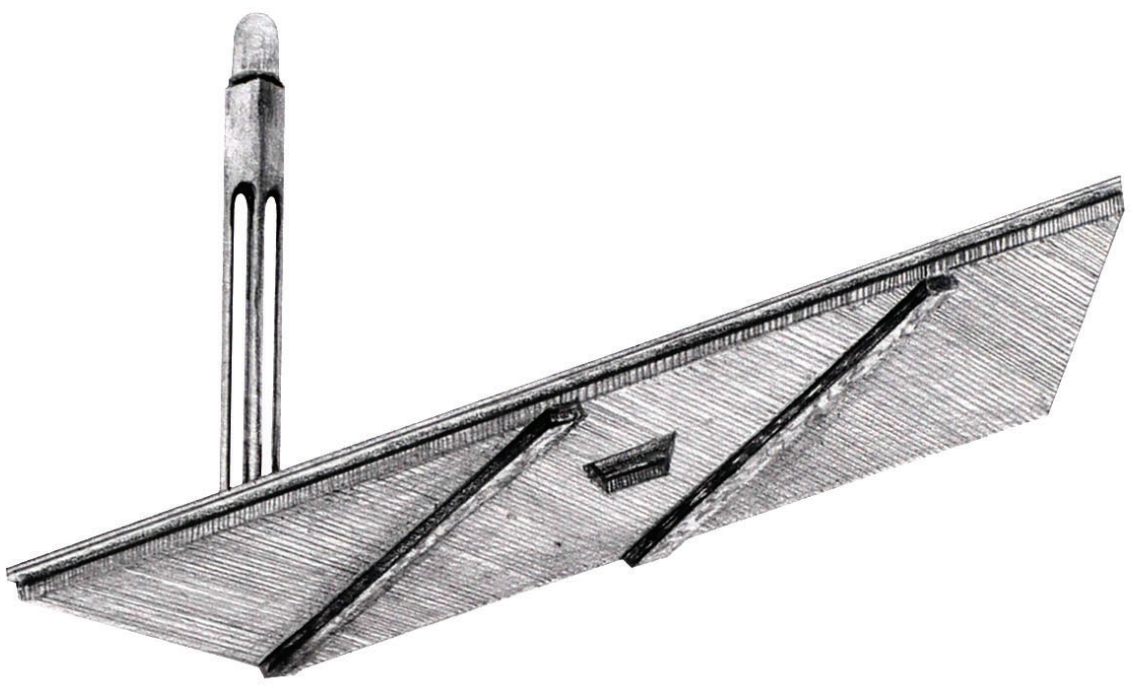

165

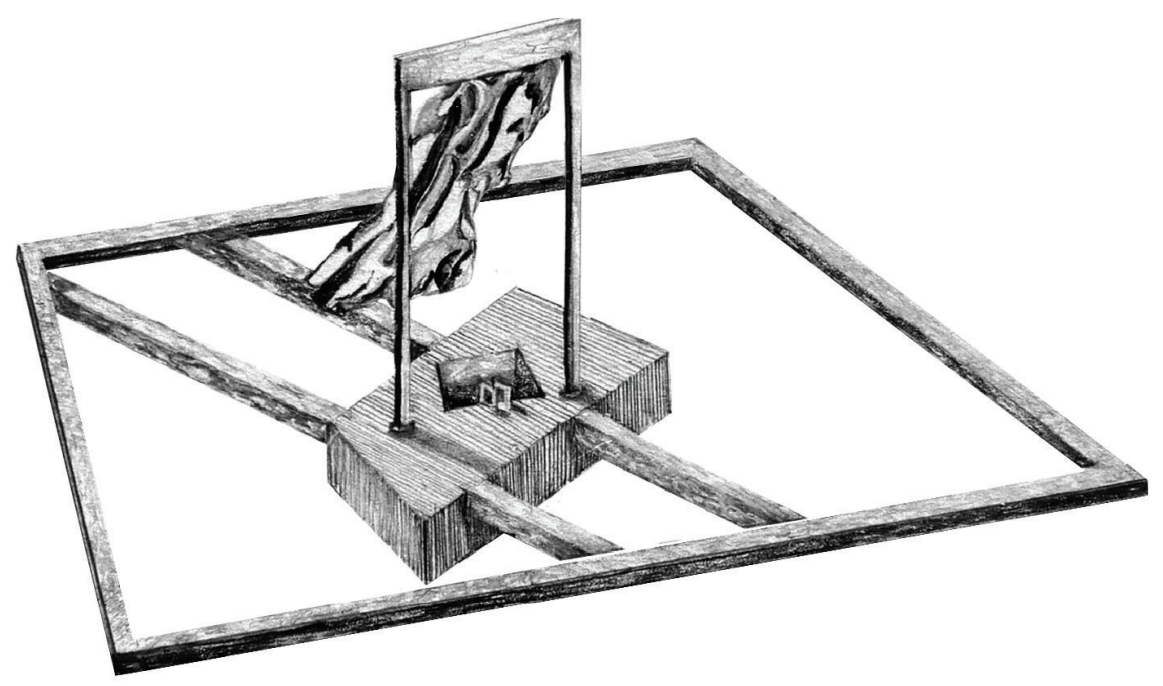

Fig. 3.3.20. Allegorical Drawing Fragment: A monument preserved in a bell jar elevated on a plinth. The preserved architectural monuments of the city are superficially exhibited above the landscape as artefacts of time.
Fig. 3.3.21. Allegorical Drawing Fragment: Above the concrete of the city lives its preserved architecture as superficial monuments-exhibited artefacts of time that claim to reveal the stories of place. The true identity of the place, however, can only be revealed from the voices of the lost world that live below waiting to be unveiled. The Taranaki Wharf Cut-out is the vertical portal to the lost world below. 


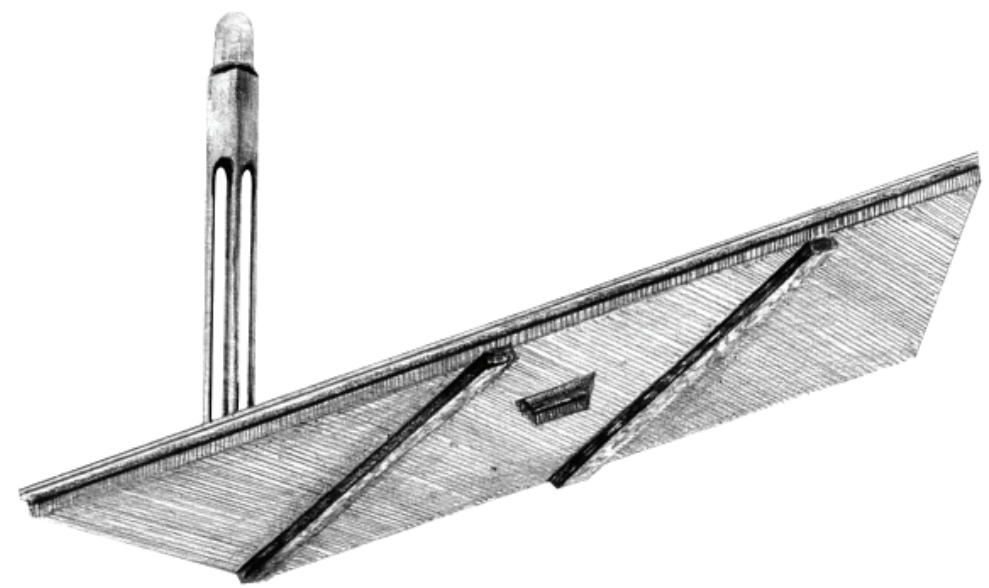

\section{TARANAKI WHARF CUT-OUT}

Fig. 3.3.22. Allegorical Drawing Fragment: The Taranaki Wharf Cut-out, a vertical portal to the lost world below, reveals elements of the structure of the city; the ground and the connection to the natural landscape cannot be seen. This connection is only visible in the lost world below.

The reintroduction of abstracted elements of site - the stairs and the wharf pylons enable the allegorical character to be recognised as the site itself. When fragments are curated and placed together they can reveal the story of a whole while still only being presented as fragments. 


\section{KUMUTOTO STREAM OUTLET}

Fig. 3.3.23. Allegorical Drawing Fragment: There is a continuous bridge around the waterfront that connects the Taranaki Wharf Cut-out with the Kumutoto Stream Outlet.

The Kumutoto stream entraped in a pipe entering out from beneath the surface of the city. 

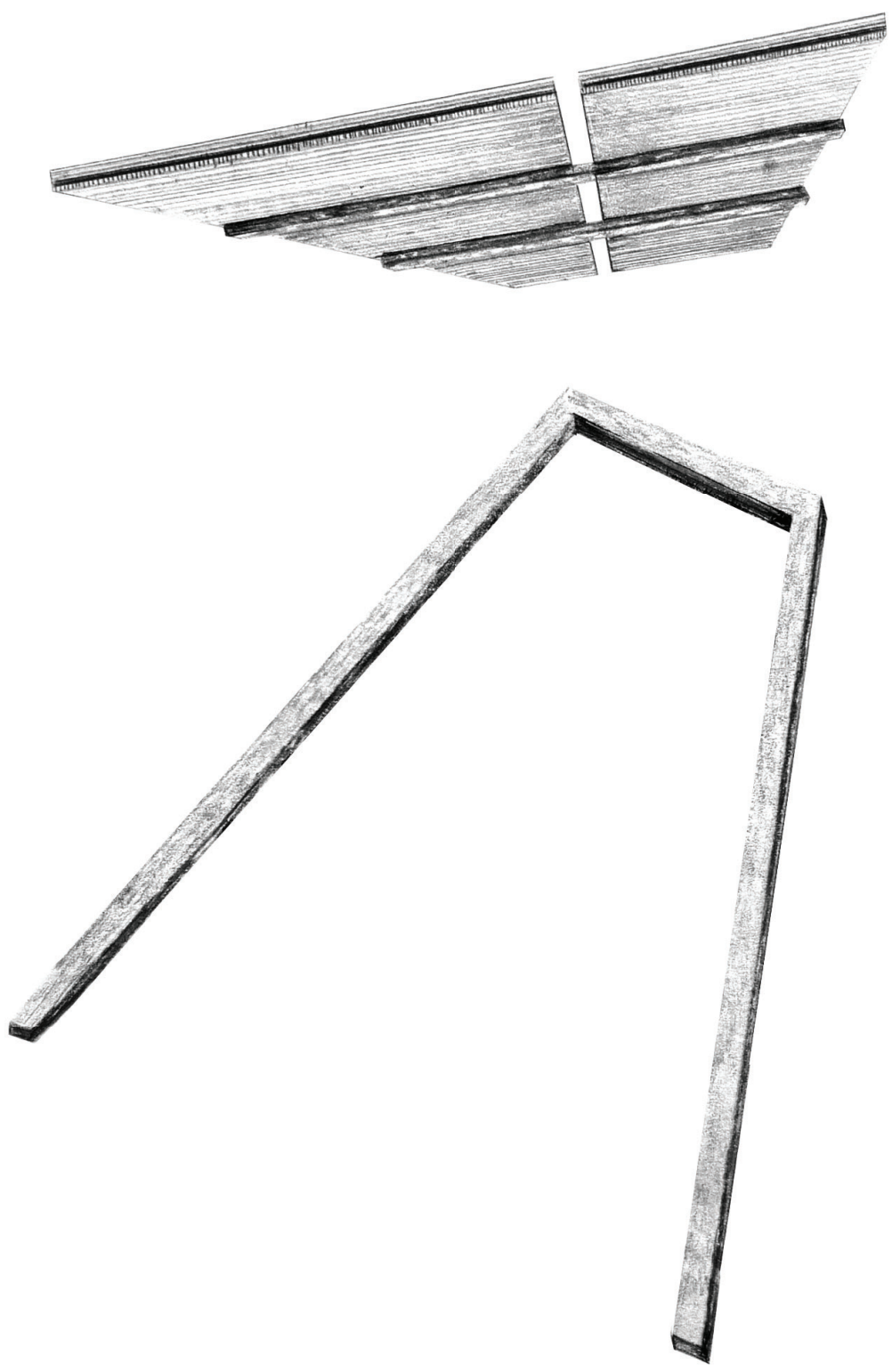

\section{KUMUTOTO STREAM OUTLET}

Fig. 3.3.24. Allegorical Drawing Fragment: The Kumutoto Stream Outlet removing a layers of the city's concrete.

(Right) The preserved architectural monuments of the city are superficially exhibited as artefacts of time. 

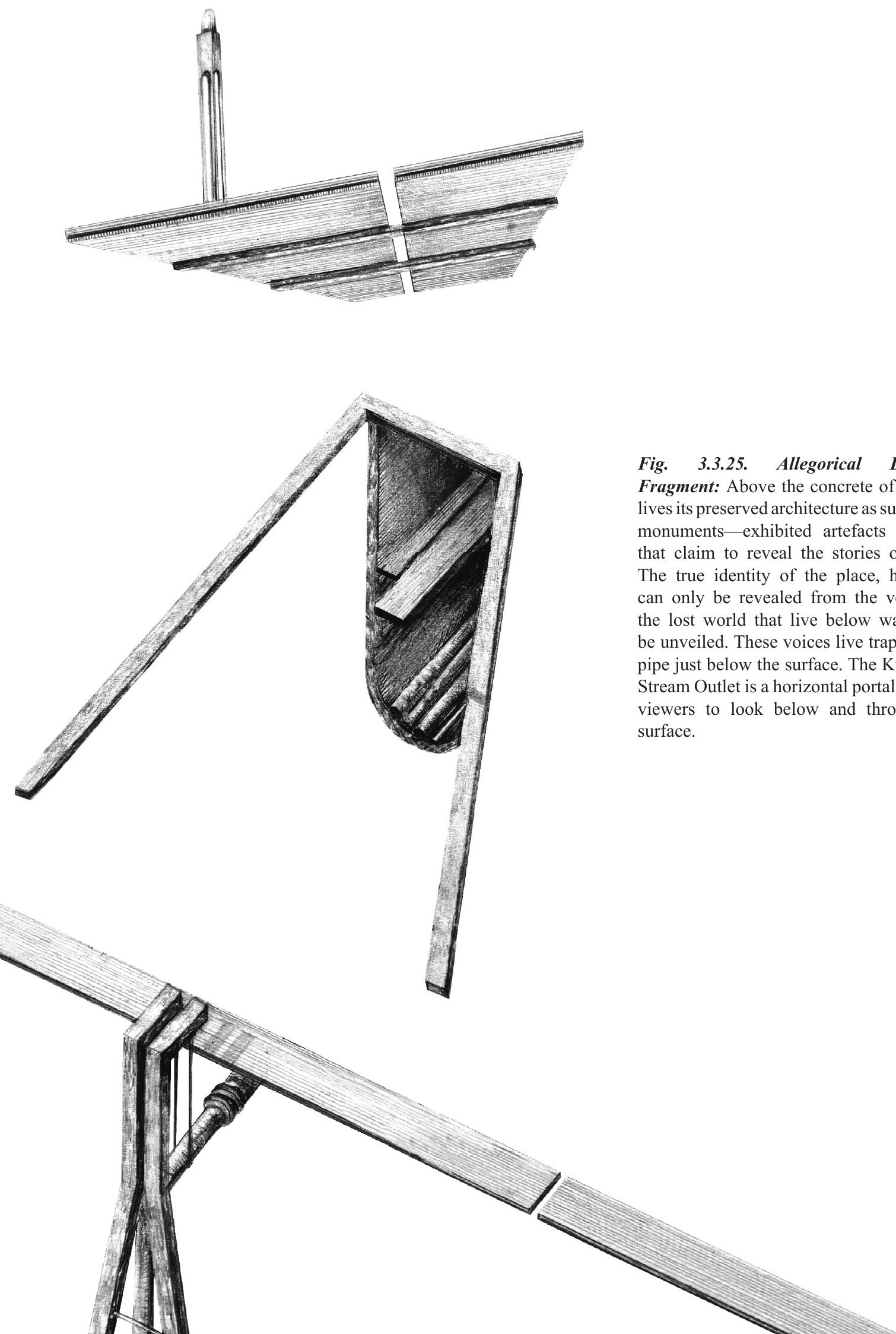
Fig. 3.3.26. Allegorical Drawing Fragment: The Kumutoto Stream Outlet is a horizonal portal into the lost world that lives trapped within a pipe. While the portal can be seen, the world and the voices that live within it remain veiled. The veil floats open, revealing only a trace of what lies below.

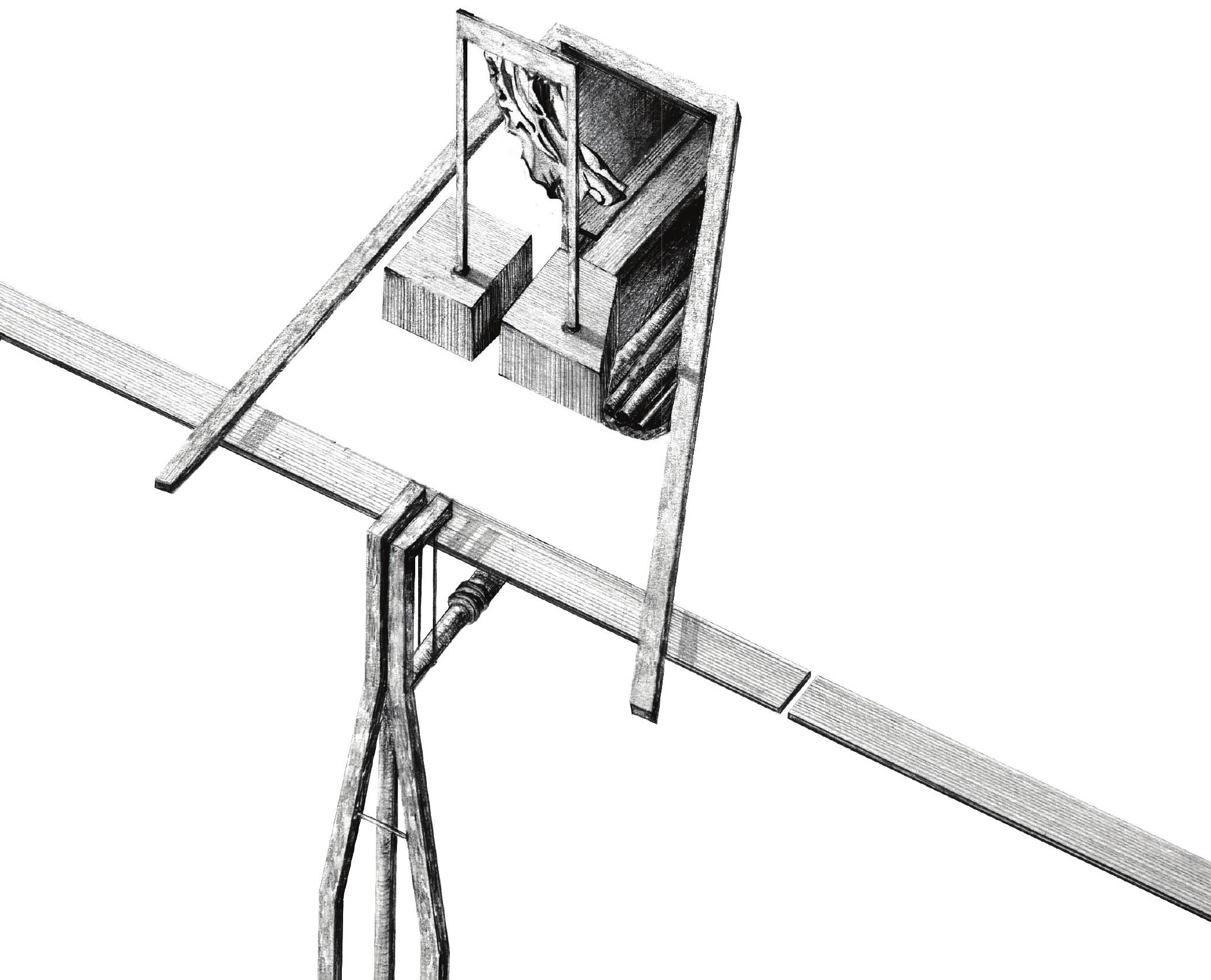




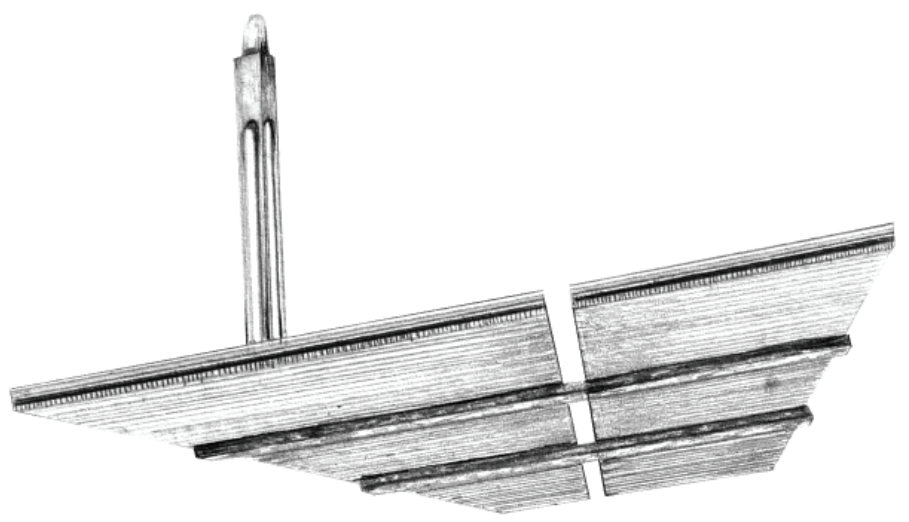

\section{KUMUTOTO STREAM OUTLET}

Fig. 3.3.27. Allegorical Drawing Fragment: The Kumutoto Stream Outlet. Elements from the site such as the steps down to the water and the concrete platforms are identifiable features of the site that add a familiar element to an uncanny re-presentation of the site as an allegorical character.

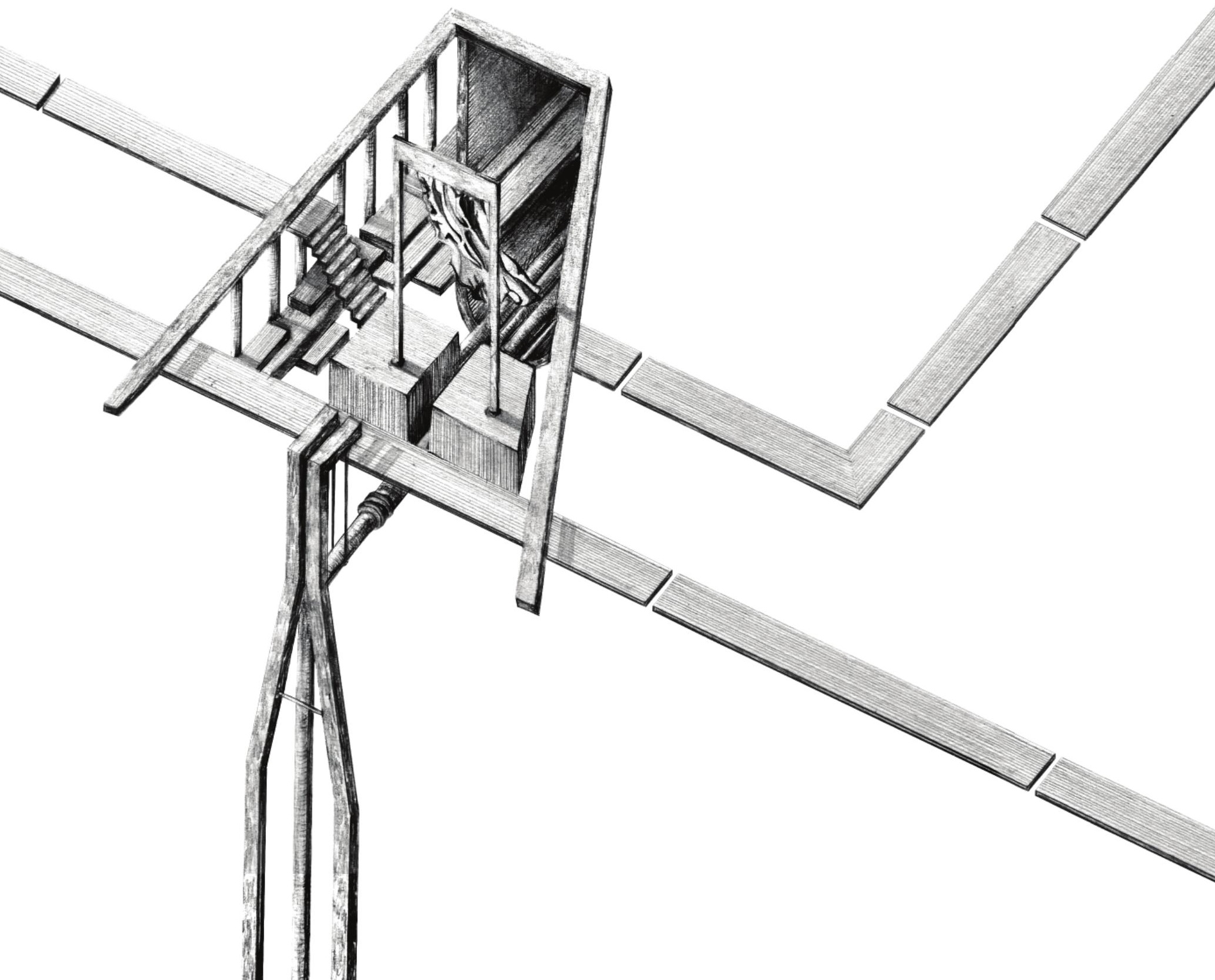


Fig. 3.3.28. Allegorical Drawing Fragment: The portals of the lost world.

The two sites are positioned in a dialogue with each other. These drawings draw from the map box, fig. 3.1.14, and the notion of mapping fragments of sites together to allow them to speak to one another and reveal contextual relationships.

\section{TARANAKI WHARF CUT-OUT}



\section{ALLEGORICAL DRAWING FRAGMENTS:}

This next series of design-led research experiments presents a series of allegorical drawing fragments as figurative geometries of key elements of the identity of the Wellington Waterfront and the two research sites. These drawings explore how the abstraction of elements of sites and architectural typologies as figurative geometries can allow lost voices and identifiable elements of place to be heard without direct re-creation. These fragments are established as characters that will be used in the final developed design chapter, CODA as fragments of a dreamscape.

All images in this series are author's own. 
Fig. 3.3.29. Allegorical Drawing Fragment: Wharf Typology. The wharves of Wellington are the backbone of the built landscape of the waterfront. This wharf typology drawing is presenting the wharves as the 'spine' of the waterfront. The curved structural elements allegorical represent the 'structural ribs' of the wharf and the surface of the reclaimed landscape of the waterfront.

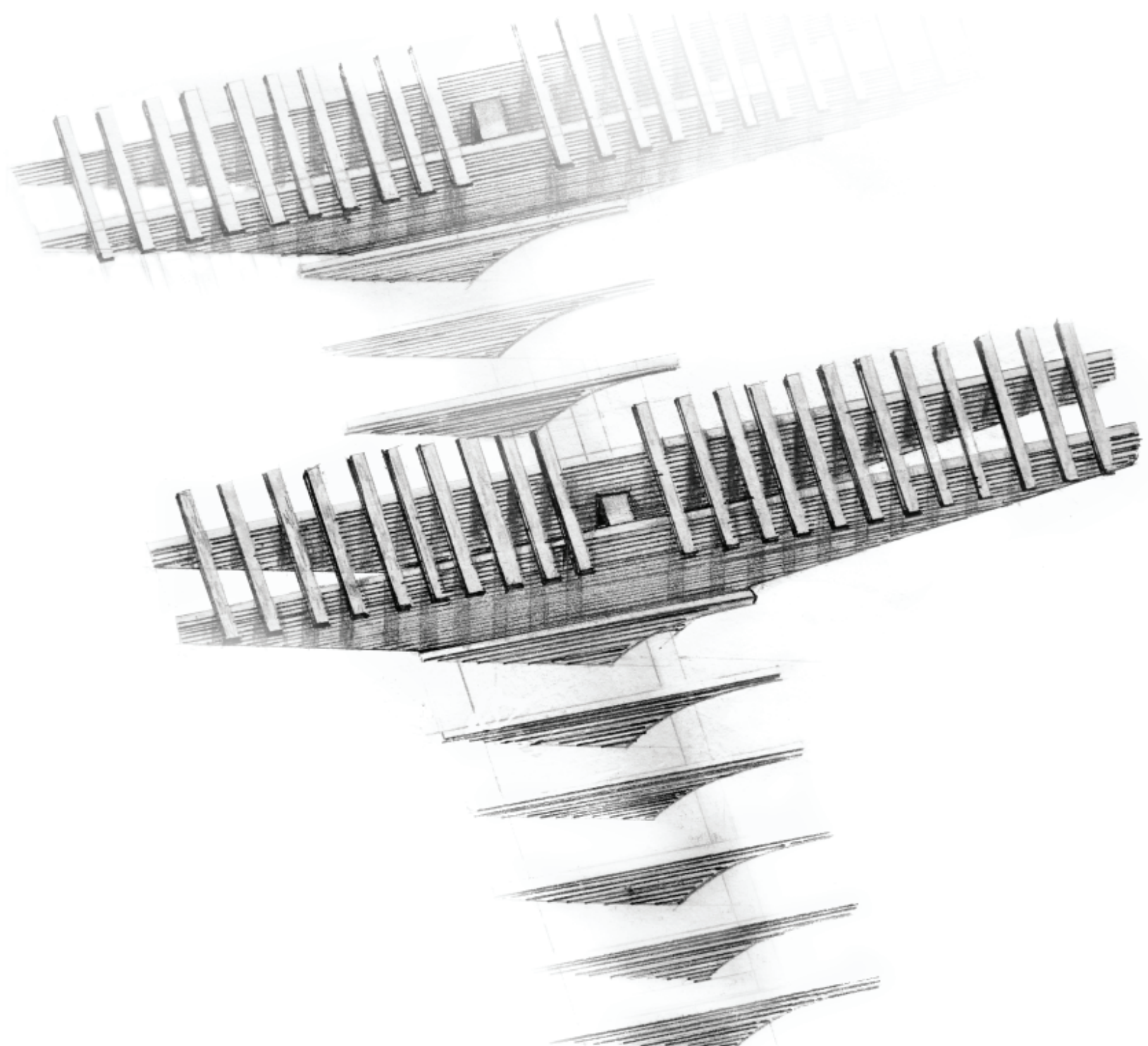


Fig. 3.3.30. Allegorical Drawing Fragment: The first sea wall of the Wellington waterfront.

The curved angled typologies taken from the previous drawing fragment represent the vertical 'ribs' holding up the structure of the infilled reclaimed land of Wellington.

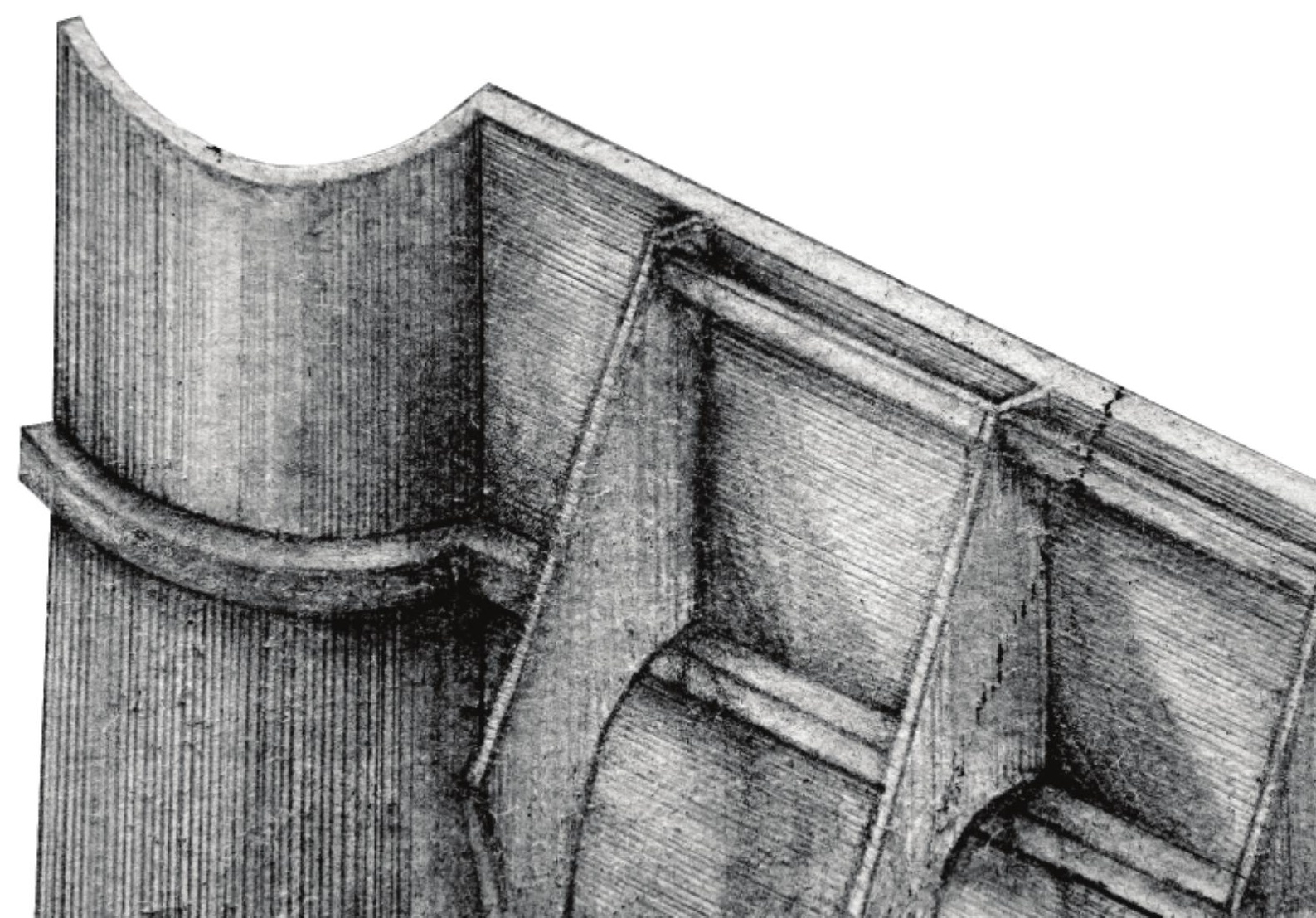




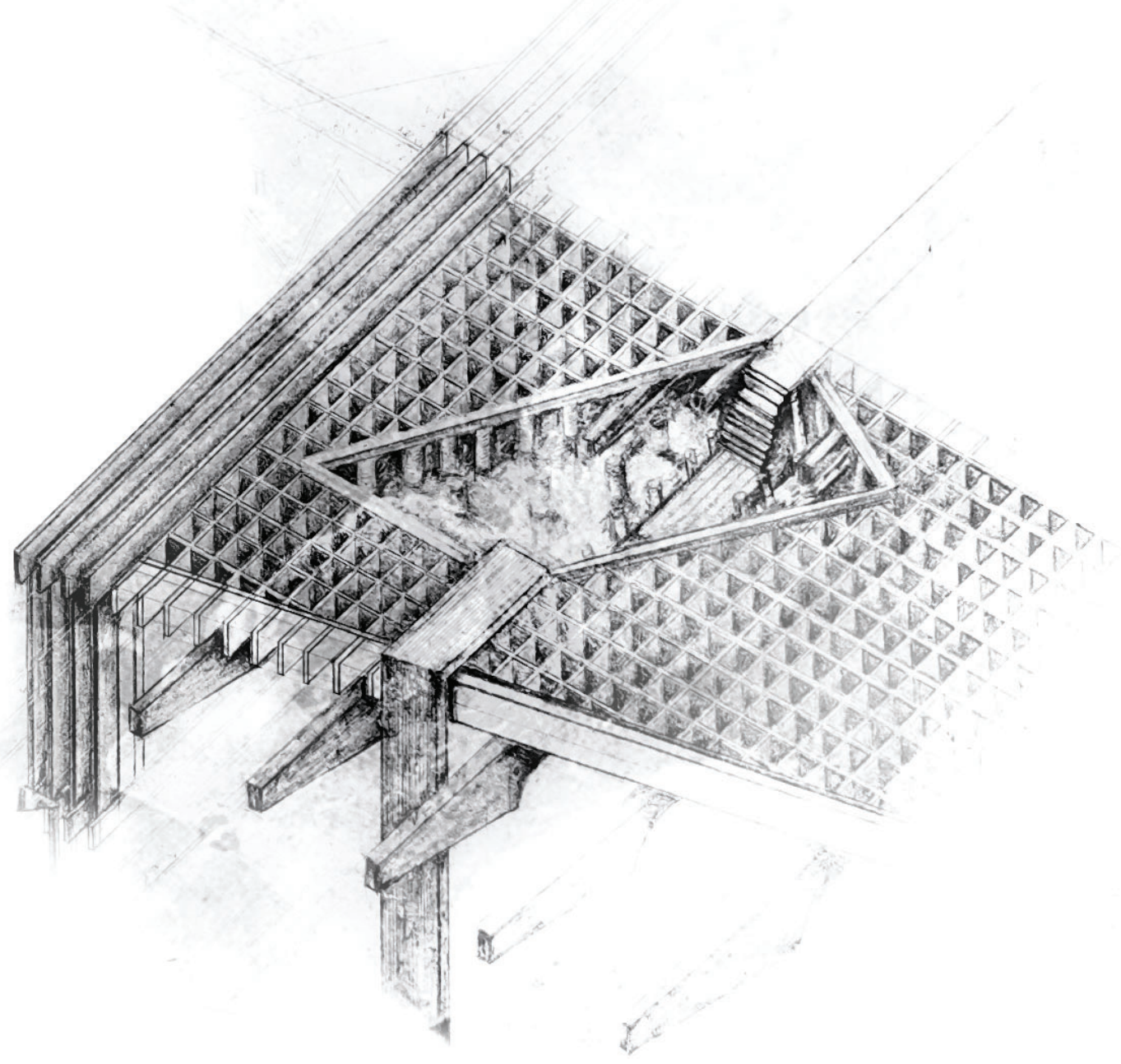

Fig. 3.3.31. Allegorical Drawing Fragment: The Taranaki Wharf Cut-out.

This fragment presents the site as a floating man-made structural landscape. The curved angled typology beneath the gridded surface presents the site as a structure positioned on the 'ribs' of the city, a historic wharf structure. 


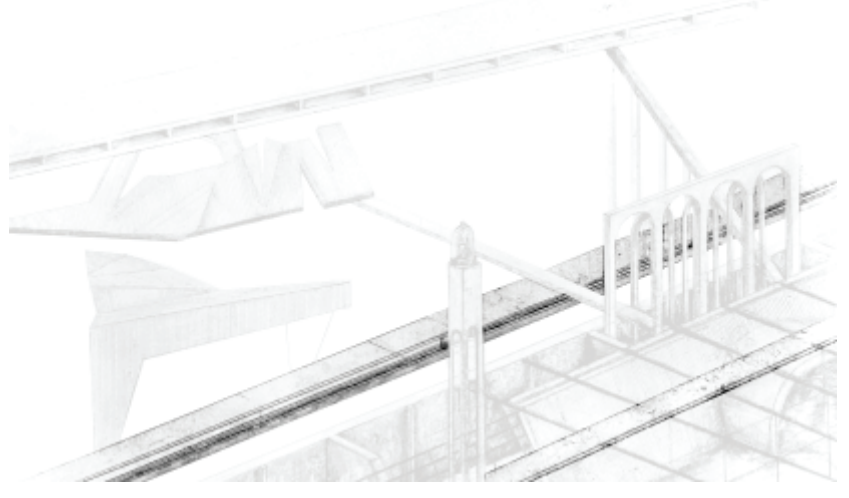

Fig. 3.3.32. Allegorical Drawing Fragment: A fragment of the urban concrete. The street cuts across the Kumututo Stream Outlet site.

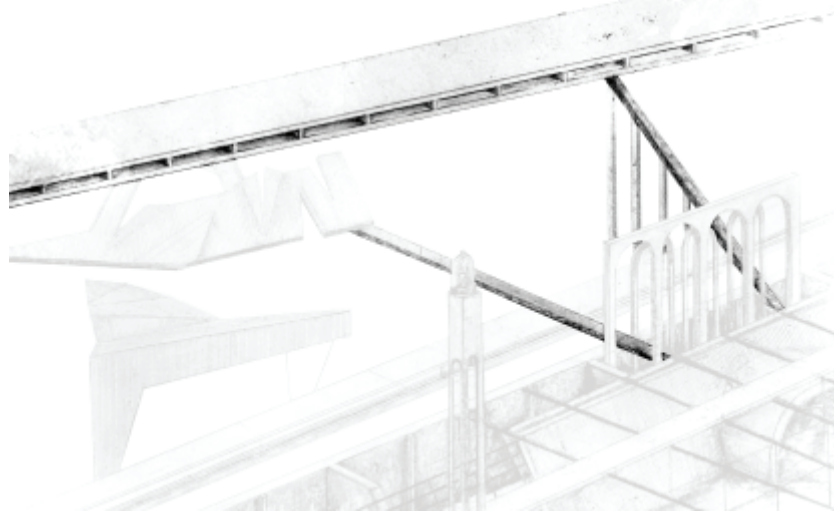

Fig. 3.3.33. Allegorical Drawing Fragment: The Kumutoto Outlet structure and wharf passes over the outlet. 


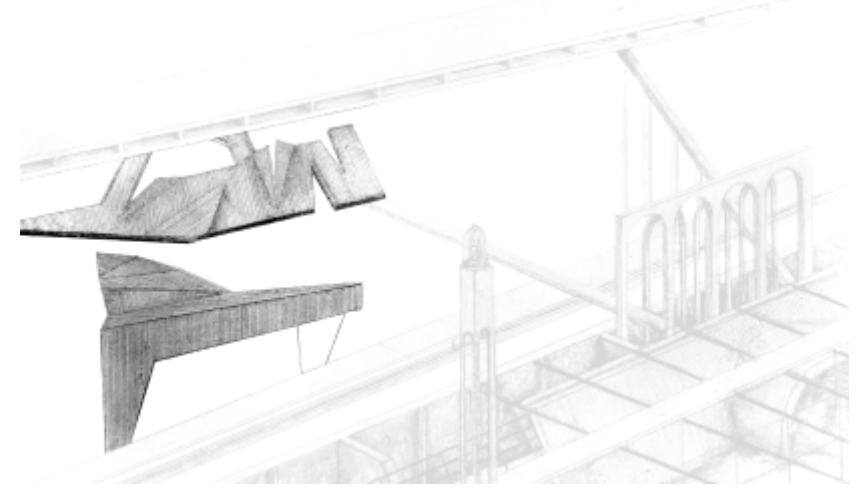

Fig. 3.3.34. Allegorical Drawing Fragment: The Kumutoto Site pavilion, identifiable elements of the site locating the drawing fragment in place.

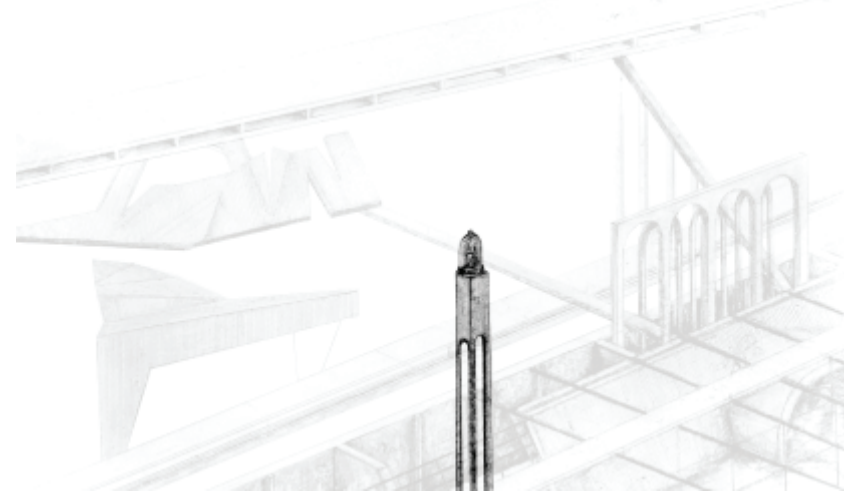

Fig. 3.3.35. Allegorical Drawing Fragment: The historic architecture of the city preserved as timeless monuments, a bell jar on a plinth. This fragment is drawn from fig 3.3.20. 


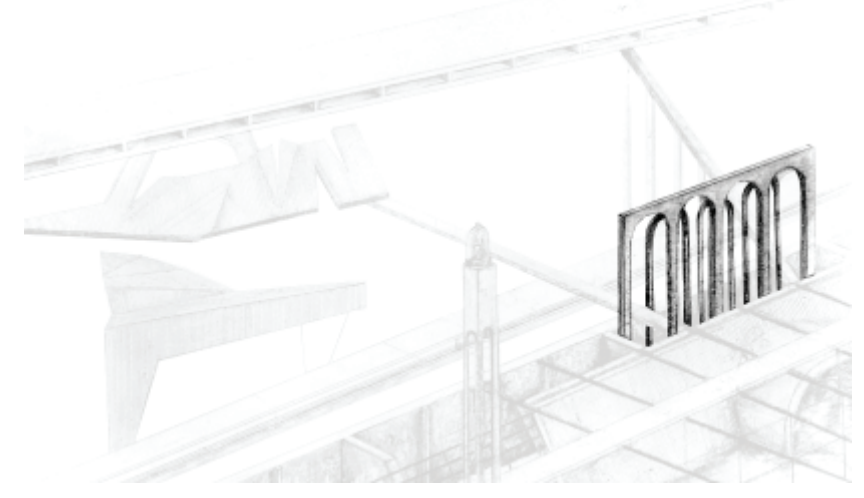

Fig. 3.3.36. Allegorical Drawing Fragment: The arches of the colonial structures that once stood in the path of the stream outlet.

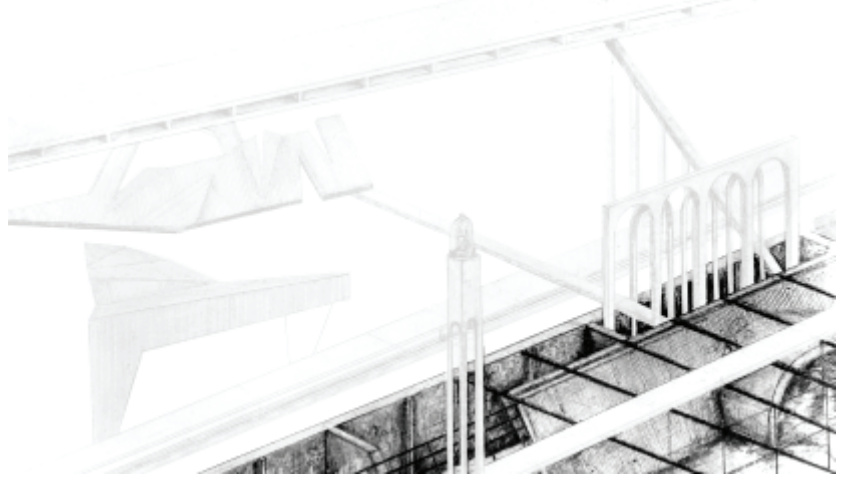

Fig. 3.3.37. Allegorical Drawing Fragment: The lost layers of the shifting shoreline walls. The additional culvert pipe of the Kumutoto Stream was added to extend the stream's path to the sea as the land was reclaimed. 
Fig. 3.3.38. Allegorical Drawing Fragment: The

fragments of the Kumutoto Stream Outlet. Fragments from different times are positioned together in a dialogue revealing elements of the site that make up its identity.






\section{CRITICAL REFLECTION}

\begin{abstract}
Frascari, Neil Spiller, Robin Evans, Johnathan Hill, Tim Edensor and Christina Boyer, who theories were combined to generate a multi-layered theoretical framework of allegorical drawing and the storytelling capability of drawn fragments, to generate a series of fragments visually representing lost voices of the two research sites and surrounding context of Wellington's Waterfront. The objective of these design experiments was to explore various techniques to generate series of de-contextualised fragments that present varying ways an allegorical drawn fragment can visually represent fragments of stories and convey meaning when presented individually out of context and in dialogues with other fragments.
\end{abstract}

Edensor proposes the provocative notion of perceiving fragments as ruins, declaring there is an excess of meaning in the remains that invite interpretation. The notion of ruins is evidenced in Aldo Rossi's San Cataldo Cemetry to represent historic symbolism. Fig 3.3.10 and 3.3.11 incorporated the learnings from both Edensor's theory alongside the theoretical framework of allegorical drawing to generate a drawing fragment of a building as a 'ruin', an allegorical mask for lost voices that can only be viewed when a facade is destroyed.

Spiller proposed that the integration of allegory into the interpretation of fragments can enable fragments to reveal metaphoric meaning both physical and metaphysical. Drawing from Reiter's case studies as the allegorical interpretation of sites conditions and stories as signs, figures 3.3.12-3.3.17 were conceived to represent the relationship between the built and natural landscape through the allegorical interpretation of a wharf pylon as the roots of the waterfront. Built elements, presented as structural 'gaps', explored Johnathan Hills' proposition of 'gaps' in drawing, that can add layers of meaning that remain 'open to interpretation' to the viewer, an example of Haralambidou's trait of double meaning.

Figure's 3.3.18-3.3.29 take fragments from the two research sites and allegorical reinterpret them as characters and drawn artefacts. Figures 3.2.29-3.2.38 similarly draw out allegorical interpretations of abstracted fragments from the surrounding context of the Wellington Waterfront. Boyer's reinterpreted theory of Rossi's Urban Artifact is 
represented through these allegorical drawing fragments, as the sites and elements of the surrounding Wellington Waterfront are abstracted and conceived as architectural memory devices that reveal traces of architectural forms as symbolic forms that preserve memories of the past. Drawing from Reiter and Rossi's case studies as a series of fragments placed in dialogues with one another to reveal meaning, drawn fragments in these series are pieced together through the series to reveal how the meaning and stories a fragment tell shifts and grows when placed in dialogues with other fragments. Exploring fragments in this was conceived to explore Robin Evans' theory of conceiving drawings in parts to reveal the structural fullness of the form and layers of fragmented stories of a drawing

Rather than simply representing elements of the landscape as they stand, or did in the past that can no longer be observed, drawing fragments re-present fragments of sites and contextual relationships of conditions of the landscape in ways previously unseen, rendering fragments of the stories invisible, visible. The allegorical drawings in this chapter generate a preliminary foundation for the CODA-the final series of allegorical drawings that integrate collage and mapping with allegorical drawing fragments in the final developed design chapter of the thesis. 




Fig. 4.1. Allegorical Drawing Fragment: Through the Portal. By author. 


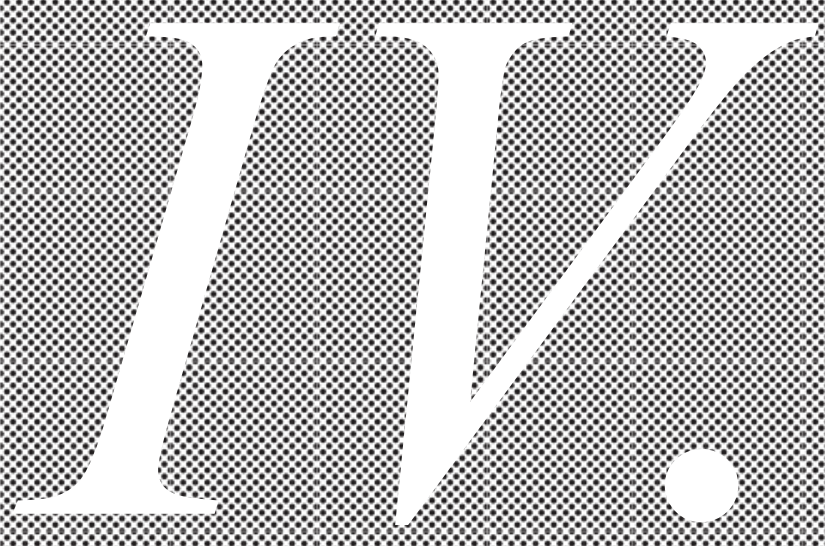


${ }_{\text {the }} C \otimes D A$.

000 
187

"Storytelling, like designing...



is a creative process of selecting and organising fot Guv

diverse elements come together to form meaningful



[RA]: to explore how the lost voices of a place can be reawakened and unveiled as speculative architectural outcomes through mapping the field of imagination, collage and the creation of dreamscapes, and allegorical drawing fragments.

$[R 01]+[R 02]+[R 03]$ 


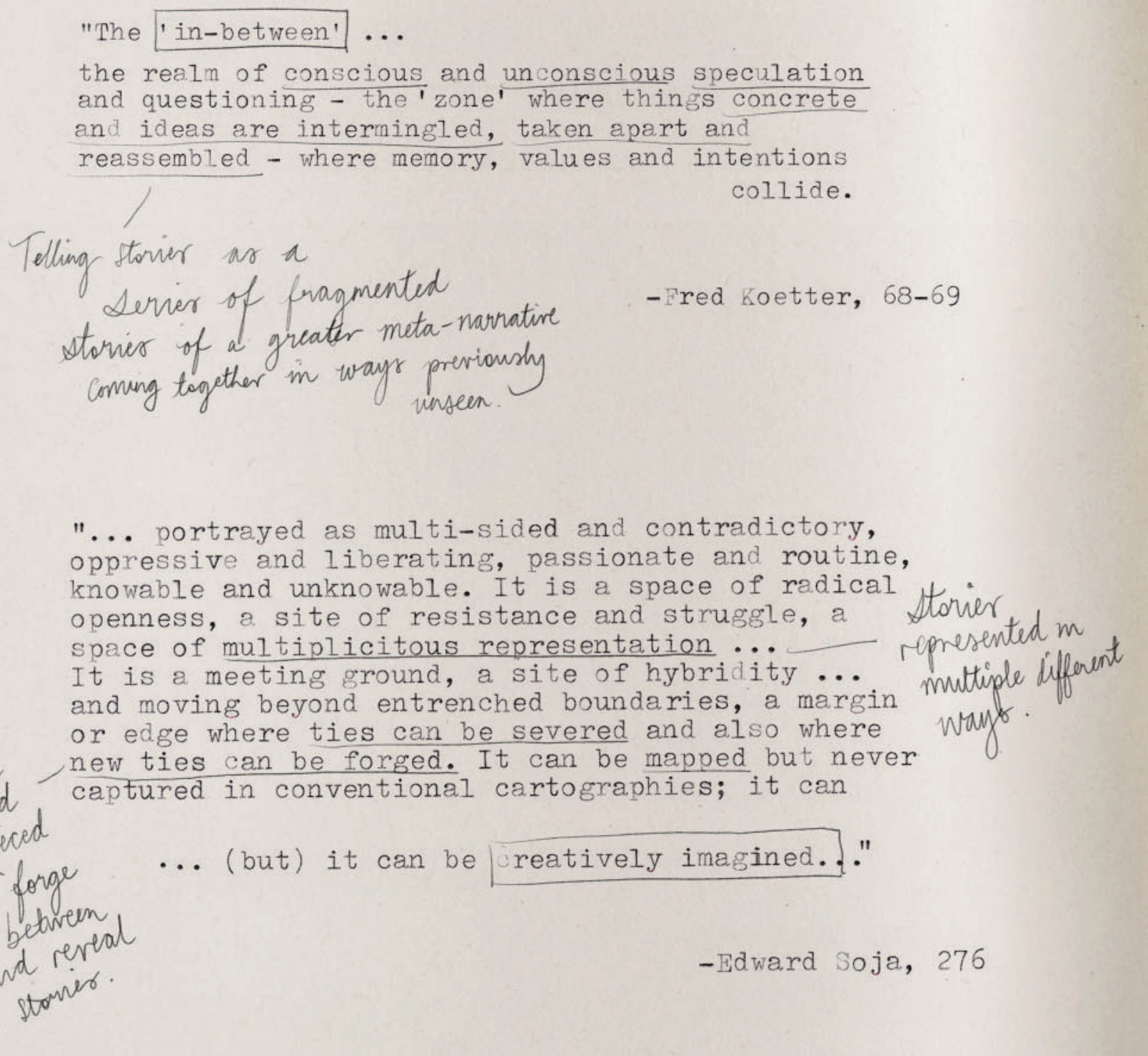

Fig 4.2. Speculation by author of quote's by Fred Koetter and Edward Soja. 


\section{PROLOGUE}

Chapter IV, titled CODA is a series of developed design explorations that explore the potential of speculative architectural outcomes to reawaken and unveil lost voices of place and capture them as allegorical drawings that allow their voices to be heard even when they have already partially faded away.

The outcomes in this series draw from findings of the two previous chapters exploring narrative, allegory and techniques of mapping, collage and allegorical drawing fragments. The design outcomes integrate a varying combination of these methods to generate a range of speculative allegorical drawing outcomes. These outcomes aim to unveil the overall meta-narrative of place as fragments told through a range of visual modes from multiple perspectives.

The CODA exists in the realm of the 'In-Between'-an imaginative realm of speculation, where series of fragmented stories from within a greater meta-narrative have been ripped apart and pieced together in a range of provocative and previously unseen ways to evoke the imagination. The goal is to reawaken lost stories of place by bringing their voices to life as fragmented visual artefacts. These visual artefacts, presented as a cabinet of curiosities, aim to provoke a viewer to imagine, dream and speculate over the multitude of fragmented stories that make up the identity of a place.

The Coda presents five developed design outcomes that represent Haralambidou's five critical methods for arriving at an allegorical architectural project: Double Meaning, Unfinished, Visual \& Verbal, Progress \& Battle, and Figurative Geometries.

Each of the five drawings incorporates components of all five methods, while privileging one in particular. These design-led research outcomes investigate how lost stories of time and place can be brought to life by capturing and reassembling the lost layers and fragments of place and time, through speculative drawings. 
"In a drawing, in architecture,

a double presence is to be observed and witnessed.

-that one of the "place" we see and experience, and that one of the mind

with emotions in the process of 'conceiving it'.

000 
To think is to see, to see is to draw. to draw is to be,

\section{to seek and remember...}

an already visited and inhabited place."

- Giuliano Fiorenzoli 
...dreaming of Lost Voices

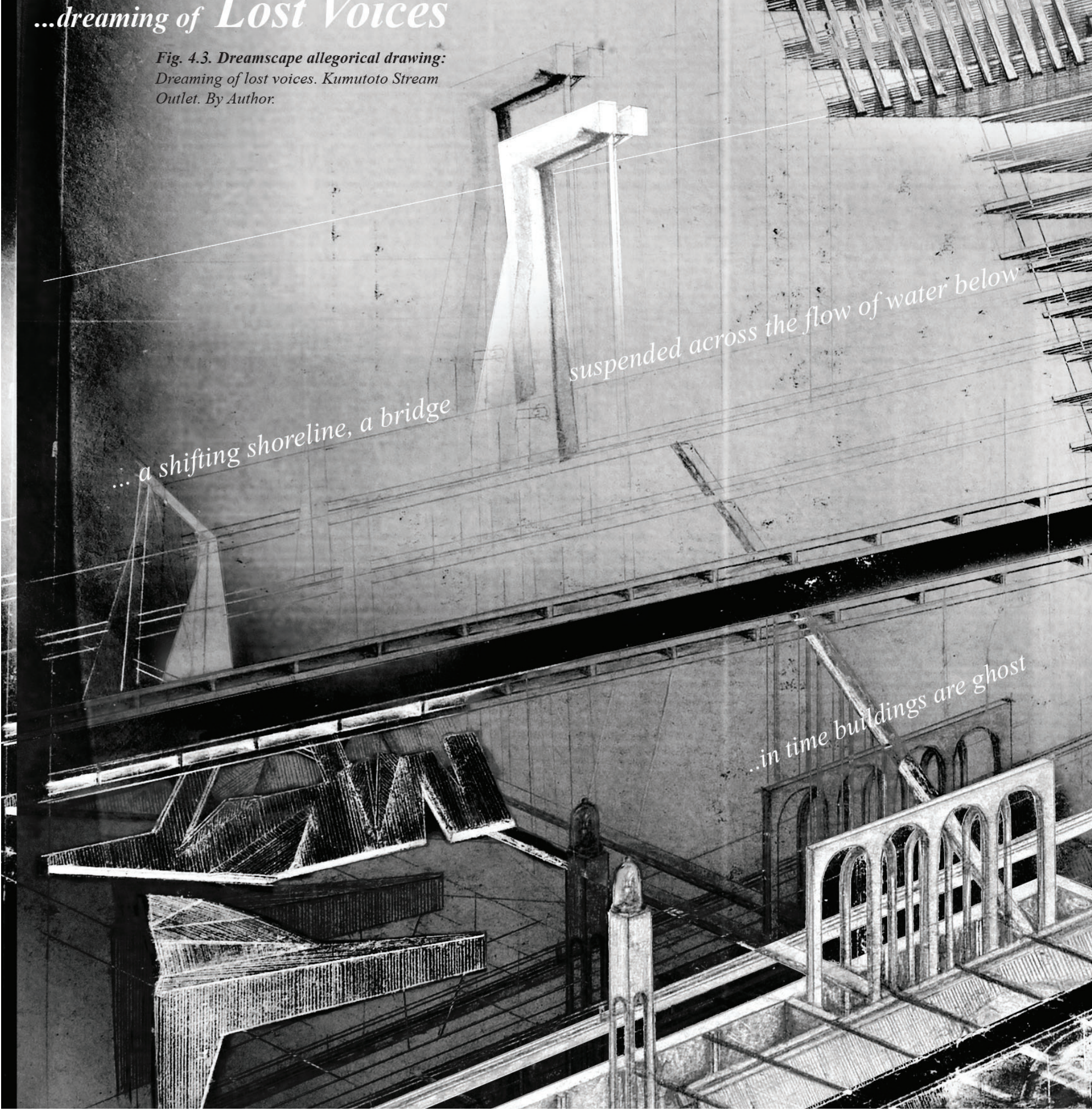


"A clock strikes eight times in the distance. The young patent clerk lifts his head from his desk, stands up and stretches, walks to the window. Outside, the town is awake".

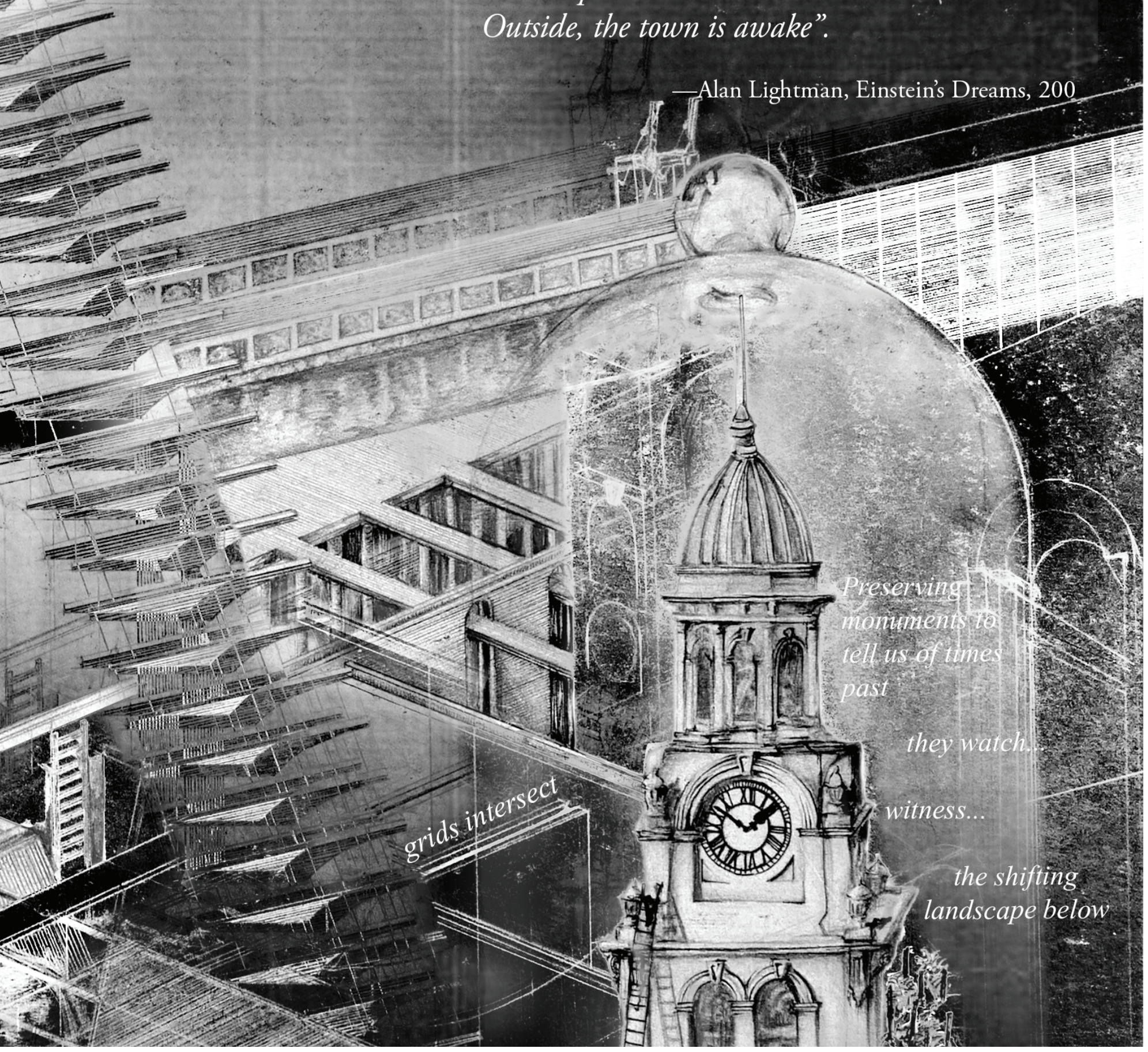




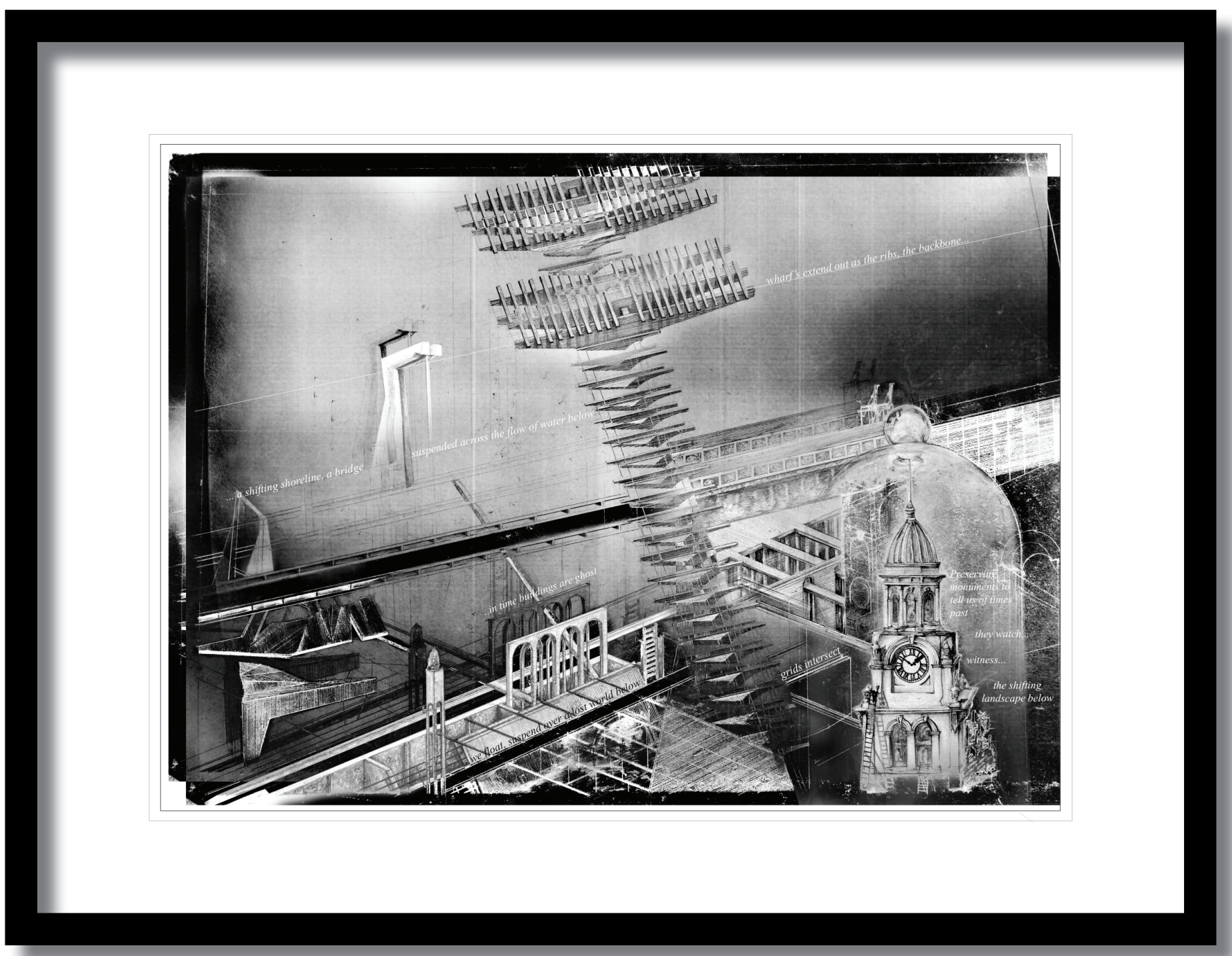

Fig. 4.4. Dreamscape allegorical drawing. By Author. 


\section{DREAMING OF LOST VOICES}

\section{KUMUTOTO STREAM OUTLET}

As the first of the five Developed Design outcomes, Dreaming of Lost Voices: Kumutoto Stream Outlet incorporates components of all five of Haralambidou's methods for constructing an allegorical architectural project, while privileging one in particular. Dreaming of Lost Voices: Kumutoto Stream Outlet privileges 'Visual \& Verbal' by incorporating collage fragments together with text to achieve its principal aim.

This design outcome is an allegorical drawing of 'memory' fragments of the Kumutoto Stream Outlet (left) and surrounding waterfront as an allegorical dreamscape. Fragments are drawn from preliminary design research outcomes of all three sections of chapter 3 as a collage of allegorical drawing fragments mapped upon a field of imagination. The rigid structure of the landscape is representative of the colonial prescribed grid of the landscape that has shaped the reclaimed land of surrounding the Kumutoto Stream Outlet.

The clock tower preserved in a bell jar is a fragments of history-a time stamp-locating the dreamscape in the past, symbolic of the historic buildings of Wellington that are often prioritised in history as preserved artefacts. The bell jar is drawn from Italo Calvino's Invisible Cities in relation to the allegorical cities of Clarice and Fedora and is engaged in this investigation as a metaphoric curation device. Bell jars are used by museums to safeguard fragments, when a fragment is 'curated' within a bell jar and situated in relation to other fragments, it is able to convey its part of a greater narrative in a museum setting. In this allegorical drawing the clock tower preserved in a bell jar presented as a fragment disconnected from the structure of the city, represents that the true story of place cannot only be seen from the fragments of its architecture, but within the structure of the landscape transforming, shifting and building up over time. Architectural fragments sit upon the surface of the city as temporary structures, they live for a short time and then become ghosts watching over the shifting landscape.

"And I hear, from your voice, the invisible reasons which make cities live, through which perhaps once dead, they will come to life again." -Italo Calvino, Invisible Cities, 136

"He envies the people who live in their own time, who can act at will, oblivious of the future, ignorant of the effects of their actions. But he cannot act. He is an inert gas, a ghost, a sheet without soul. He has lost his personhood. He is an exile of time." 


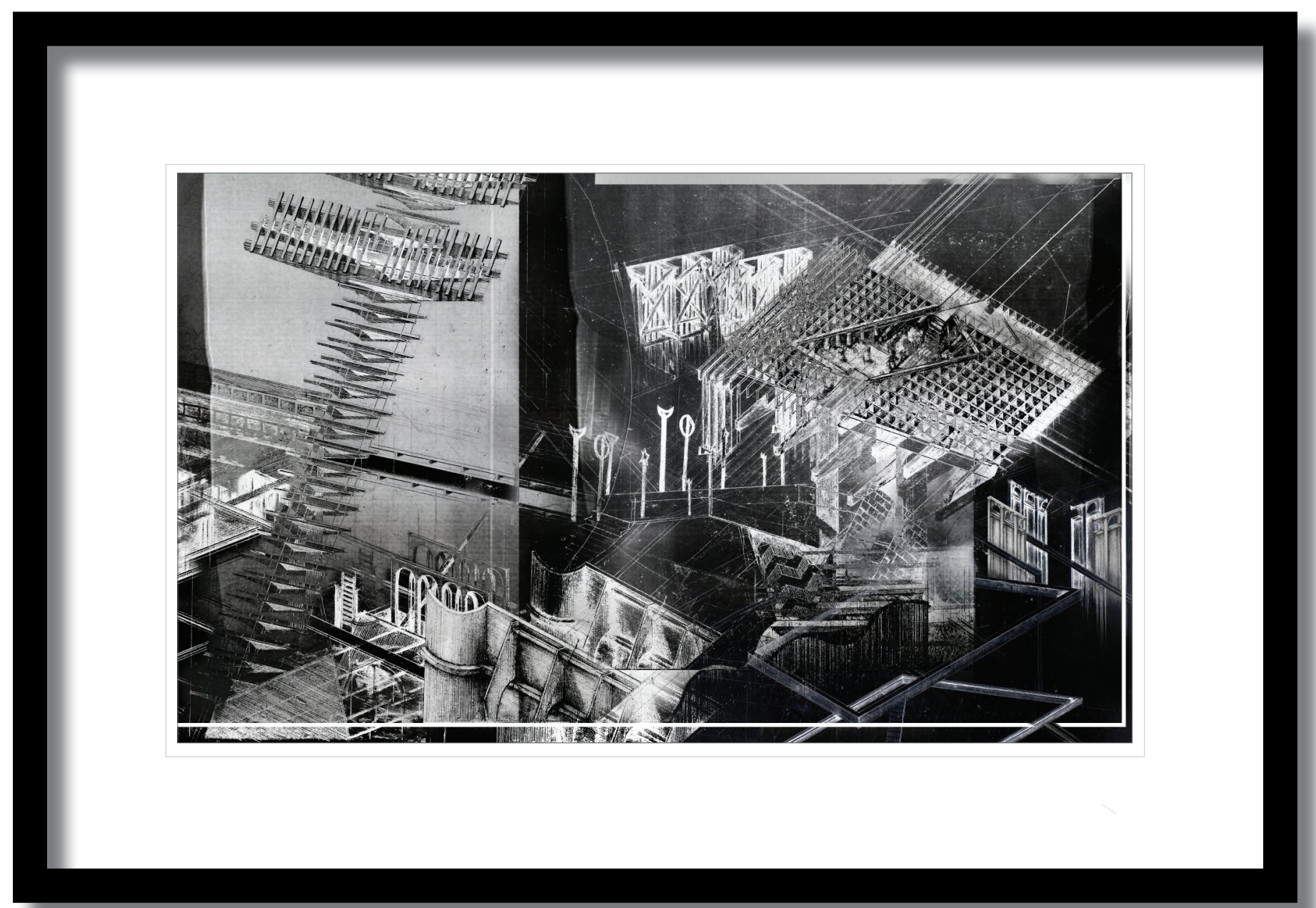

Fig. 4.5. Dreamscape allegorical drawing. By Author. 
DREAMING OF LOST VOICES TARANAKI WHARF CUTOUT
As the second of the five Developed Design outcomes, Dreaming of Lost Voices: Taranaki Wharf Cutout incorporates components of all five of Haralambidou's methods for constructing an allegorical architectural project, while privileging one in particular. Dreaming of Lost Fragments: Taranaki Wharf Cutout privileges 'Double Meaning' by setting up a duality (expressed through black and white oppositions) that invites open interpretation to achieve its principal aim.

This drawing presents an allegorical drawing of 'memory' fragments of the Taranaki Wharf Cut-out and surrounding waterfront as a dreamscape. In this dreamscape, unlike the previous dreamscape, fragments of time are fleeting and constantly shifting, suspended over a dark void of the sea below.

"After the dream they set out in search of that city; they never found it, but they found another; they decided to build a city like the one in the dream. In laying out the streets, ... they arranged spaces and walls differently from the dreams, so she would be unable to escape again."

- Italo Calvino, Invisible Cities, 45

"His dreams have worn him out, exhausted him so that he sometimes cannot tell whether he is awake or asleep. But the dreaming is finished. Out of many possible natures of time, imagined as many nights, one seems compelling. Not that the others are impossible. The others might exist in other worlds." 


\section{6}

An invisible landscape

conditions the visible one."

Fig. 4.6.

\section{a LOST MAPof}

\section{TIME}


THE GHOST OF THE LAND

The Lost Natural Landscape

199

THE COLONIAL SCAFFOLD

1840 colonial town plan grid

SILENCING THE PULSE

The Kumutoto Stream and lost shoreline, lost voices of the land

THROUGH THE PORTAL

The Taranaki Wharf Cut-out

BONES OF THE CITY

Map of city layers

THE VOICES LIVE ON

Lost voices below the surface reawakened and reveiled

“...architectural tracings are apparitions, outlines, figments. They are not diagrams by ghots."

—John Hedjuk 


\section{A LOST MAP OF TIME}


"...each act is an island in time to be judged on its own". -Alan Lightman, Einstein's Dreams, 53
THE GHOST OF THE LAND
Fig. 4.6a. The lost natural landscape is a ghost. Prior to colonisation the Kumutoto Stream flowed freely, cascading down the steep slopes of Wellington's topography. The stream and surrounding forest a vital life source, the pulse of the landscape. 


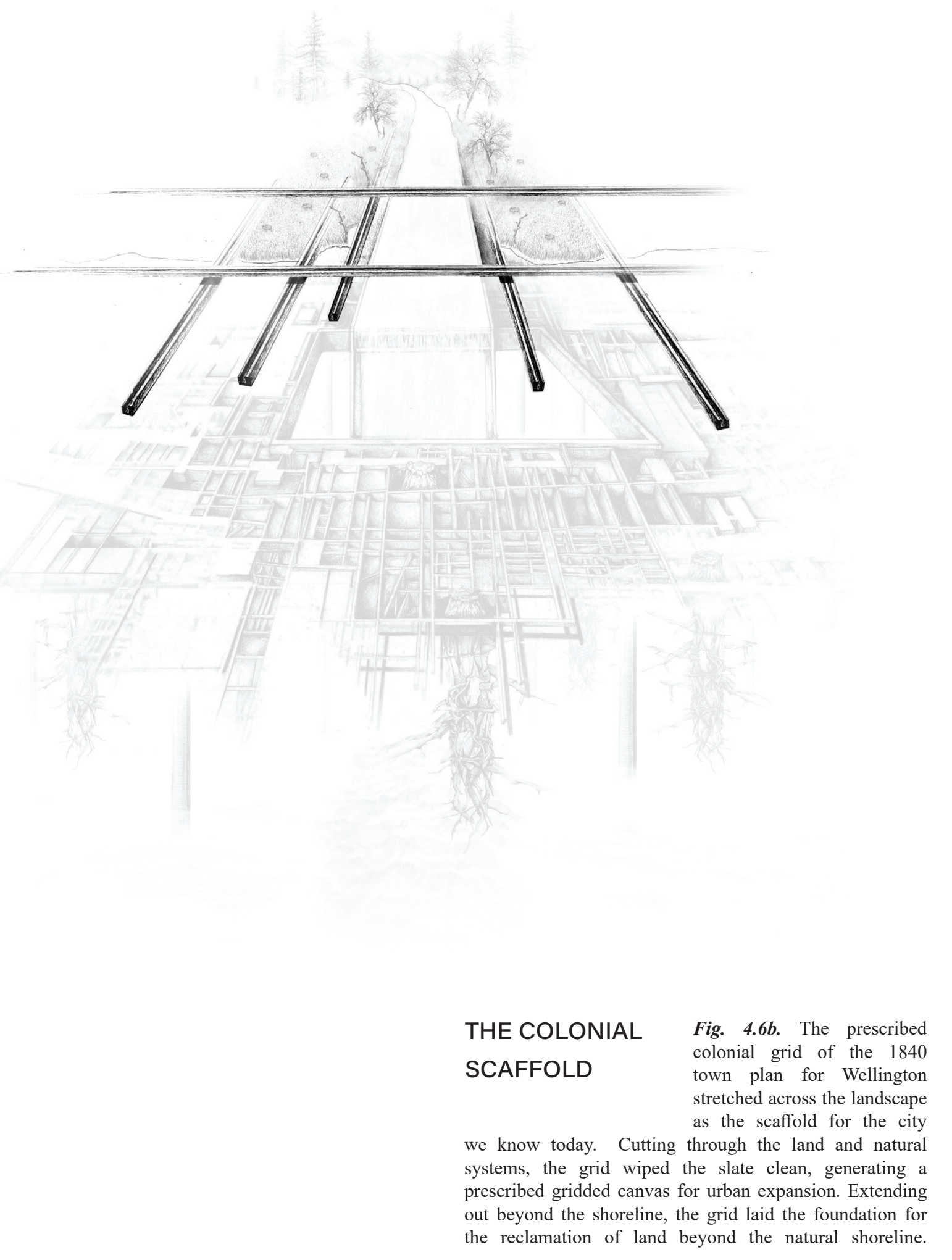



were vital life sources of the land-the ladscapes pulse. As the colonial grid was overlaid upon the landscape, their voices were silenced. Their pulse, the flow of water entrapped deep below the surface - as the tide of the harbour flowing beneath the wharf edge to the lost shoreline beneath, and the streams flowing trapped within a culvert. This map presents an inverted map of the lost layers of the city where the natural landscape is brought up to the surface to have its voice heard once again. 


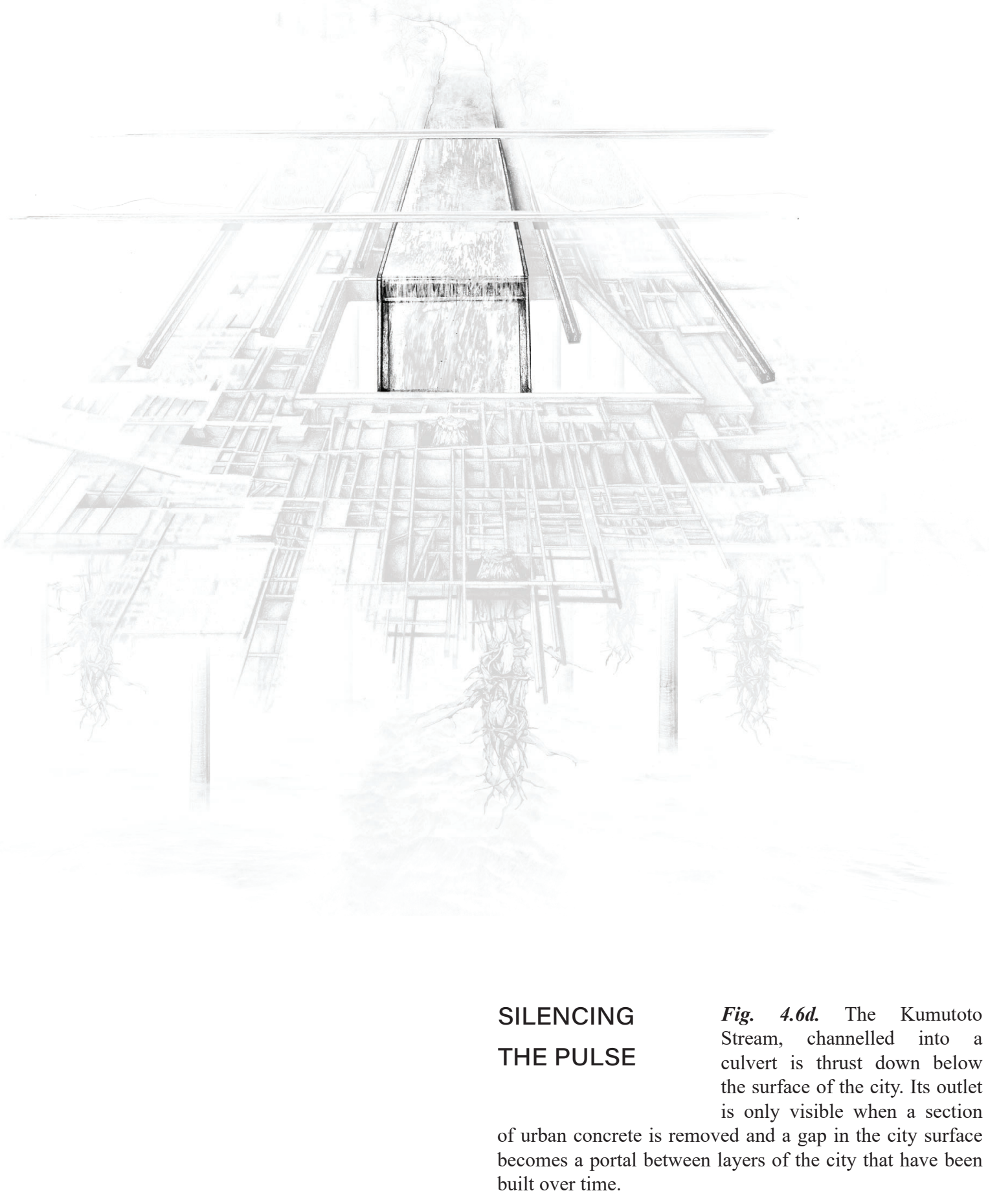



a void in the city surface, a portal, between the lost layers of the city. Through the portal the seemingly flat surface of the city reveals its hidden depth of lost layers below and forgotten shorelines beyond. 


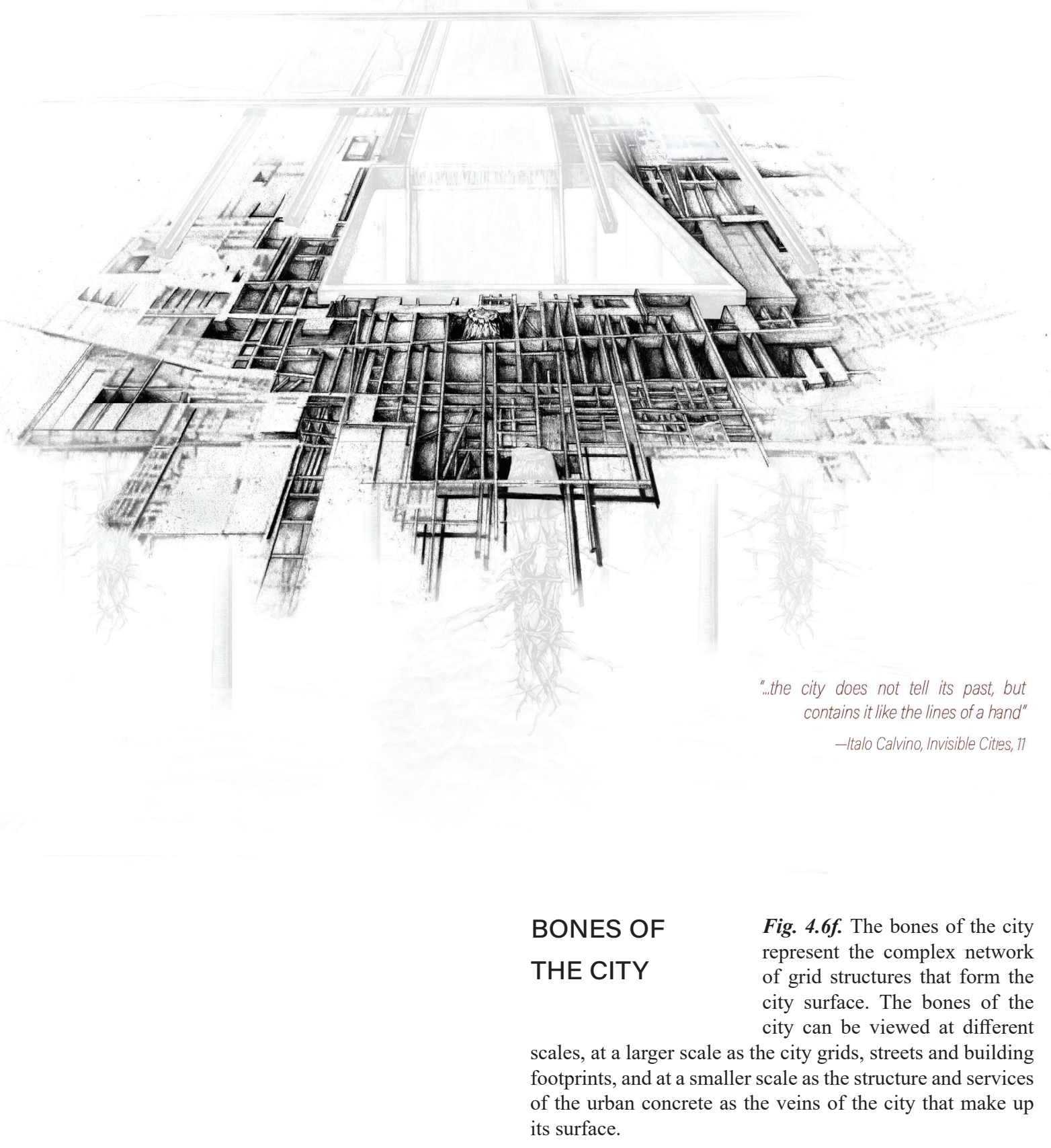


"Isaura, city of a thousand wells, is said to rise over a deep, subterranean lake. On all sites, whenever inhabitants dig long vertical holes in the ground, they succeed in drawing up water, as far as the city extends and no farther.

... an invisible landscape conditions the visible one; everything that moves in the sunlight is driven by the lapping waves enclosed beneath the rock's calcareous sky."

\section{THE VOICES LIVE ON} and the flow of water of the streams thrust out from beneath the urban surface of the city are bought to the forefront, reawakened and unveiled. The map is revealing how the identity and the connection to the natural landscape have shifted as the landscape has transformed over time, from the natural flow of the stream surrounded by trees, to the release of the Kumutoto Stream back out to sea from beneath the urban concrete, surrounded by the wharf pylons and roots that represent the suspended 'shoreline' of the harbour today. 


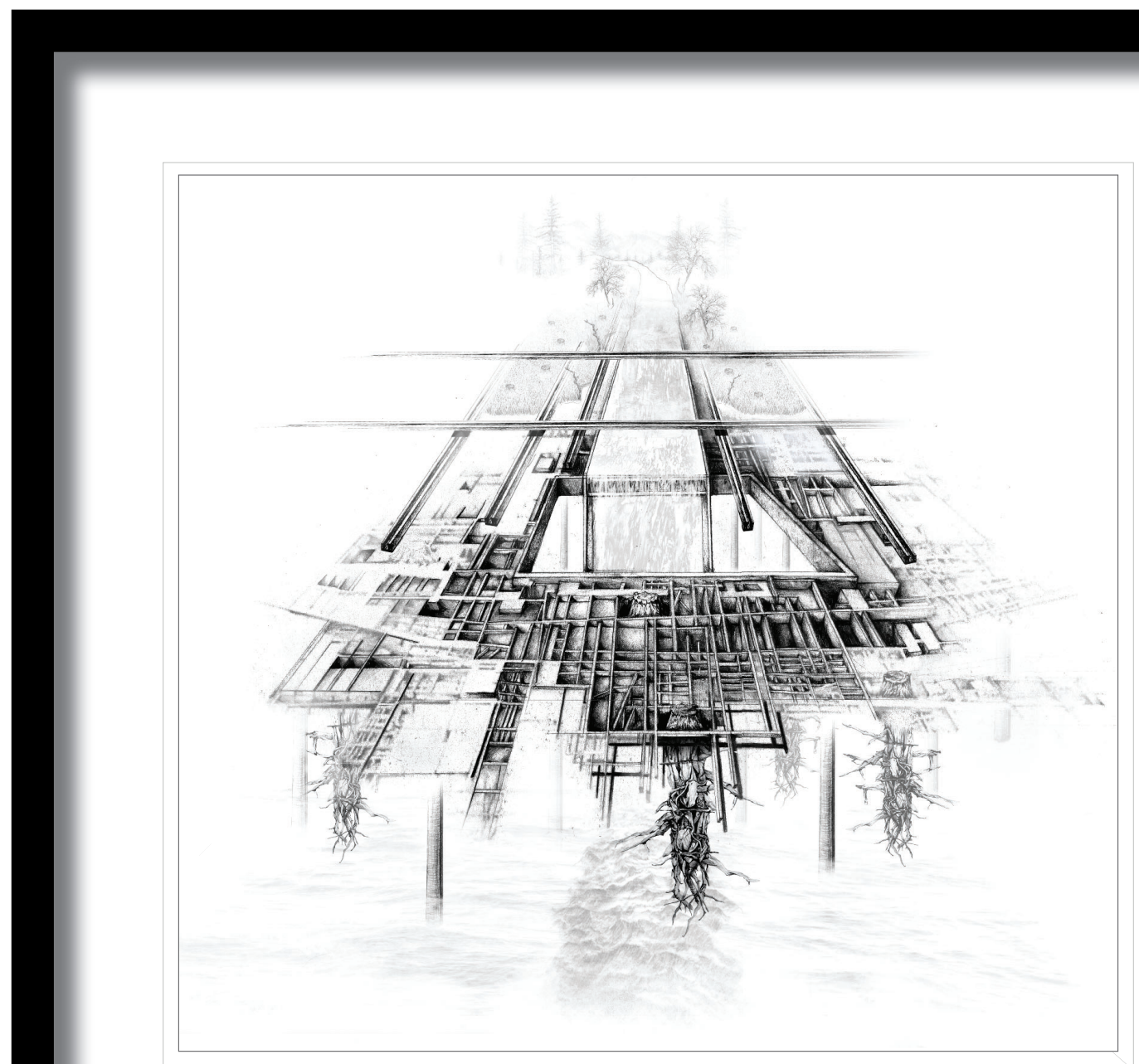

Fig. 4.7. A Lost Map of Time. Drawing by Author. 


\section{A LOST MAP OF TIME}

"A map ... should include ... all these routes, solid and liquid, evident and hidden." - Italo Calvino, Invisible Cities, 89

"Many walk with maps, directing the map-holders from one arcade to
the next in the city they have lived in all their lives, in the street they have
traveled for years. Many walk with notebooks, to record what they have
learned while it is briefly in their heads. For in this world, people have no memories." outcomes, A Lost Map of Time incorporates components of all five of Haralambidou's methods for constructing an allegorical architectural project, while privileging one in particular. A Lost Map of Time privileges 'Unfinished' by setting up a drawing composed of fragments (representing that the whole story is no longer there) to achieve its principal aim. 


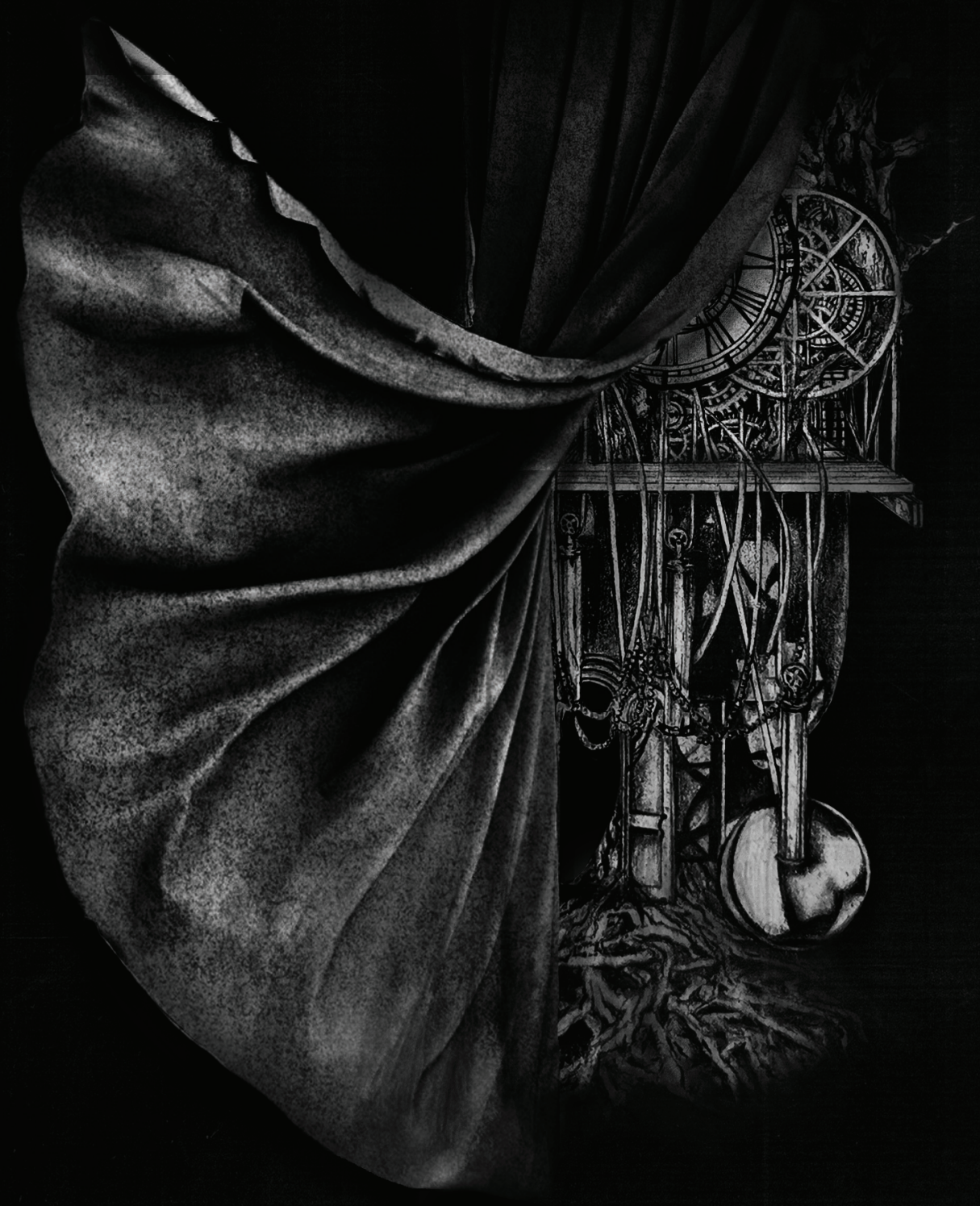




\section{Unveiling an Artefact of Time}

66

We shall all not cease from exploration

And the end of all our exploring

Will be to arrive where we started

And know the place for the first time.

Through the unknown, unremembered gate

When the last of earth left to discover

Is that which was the beginning." 


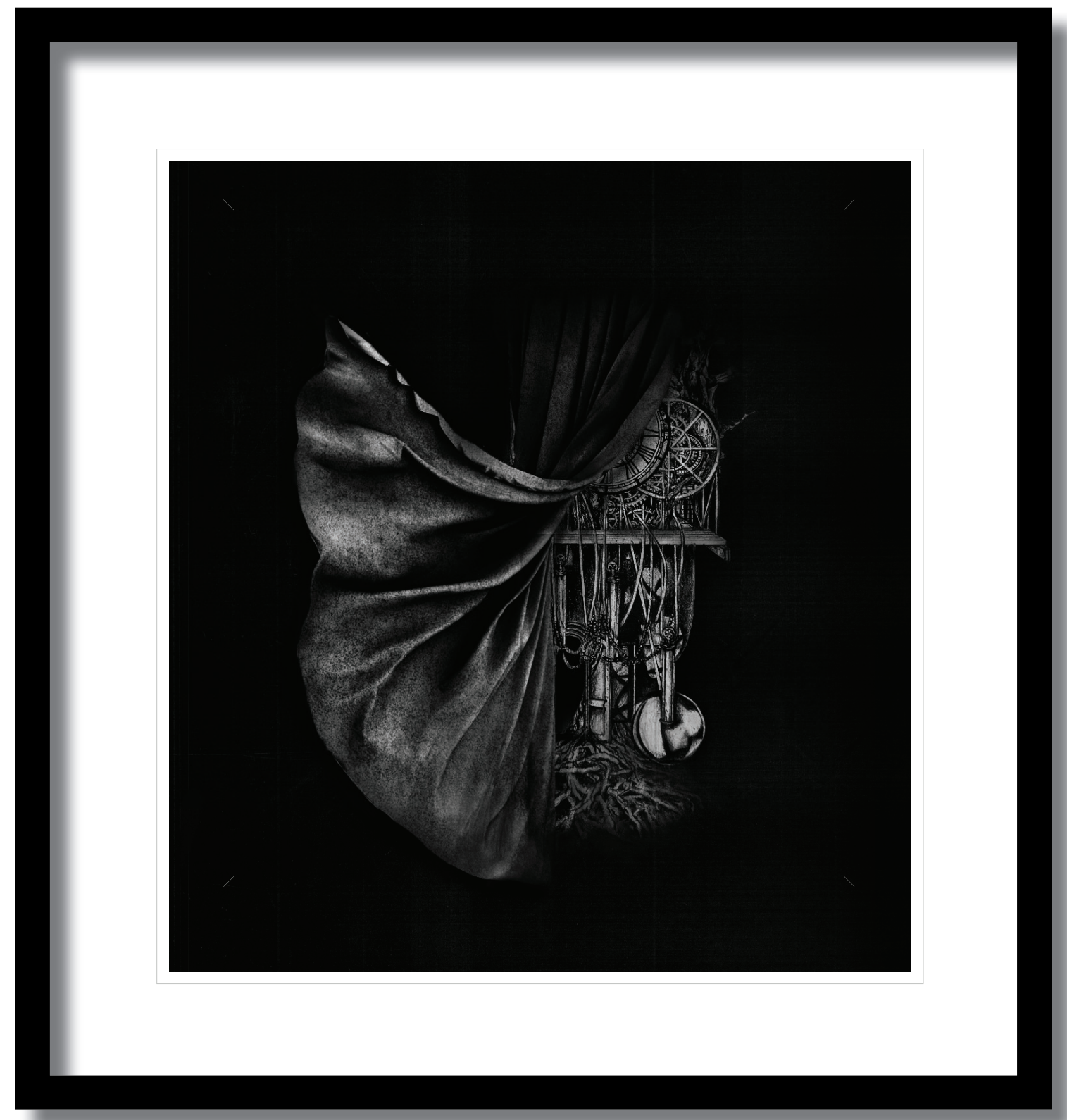

Fig. 4.9. Unveiling an Artefact of Time. By Author. 


\section{UNVEILING AN}

ARTEFACT OF TIME
As the fourth of the five Developed Design outcomes, Unveiling an Artefact of Time incorporates components of all five of Haralambidou's methods for constructing an allegorical architectural project, while privileging one in particular. Unveiling an Artefact of Time privileges 'Progress \& Battle' by capturing the temporal nature of the story (progress) through the unveiling of a dialectic relationship (battle) to achieve its principal aim.

Fragments of time lay dormant below the surface of the city waiting to be unveiled beneath layers that have built up over time. Threaded together these fragments reveal vital stories that shape the identity of place.

This provocative allegorical drawing presents the unveiling of the lost voices of time as fragments. These fragments narrate lost stories of place-revealed in the following design series, the Bell Jar: an Artefact of Time-and this drawing is an allegorical interpretation of the act of removing the 'veil' the surface of the city-a layer-to reveal the hidden fragments of stories of different time that live beneath waiting to be uncovered.

"A woman in black comes along, showing her full age, her eyes restless beneath her veil, her lips trembling.... Something runs among them, an exchange of glances like lines that connect one figure with another and draw arrows, stars, triangles, until all combinations are used up in a moment, and other characters come on to the scene..." - Italo Calvino, Invisible Cities, 51

"When sunrise comes, those born at sunset are overwhelmed by the sudden sight of trees and oceans and mountains, are blinded by daylight, return to their houses and cover their windows, spend the rest of their lives in half light." 


\section{the BELL JAR 。}

\section{6}

The shards of the destroyed city,

that have been saved ...

were now preserved under glass bells,

$\square \square \square \quad$... and not because they might still be used for anything

but because people wanted to reconstruct through them

a city of which no one knew anthing now. 


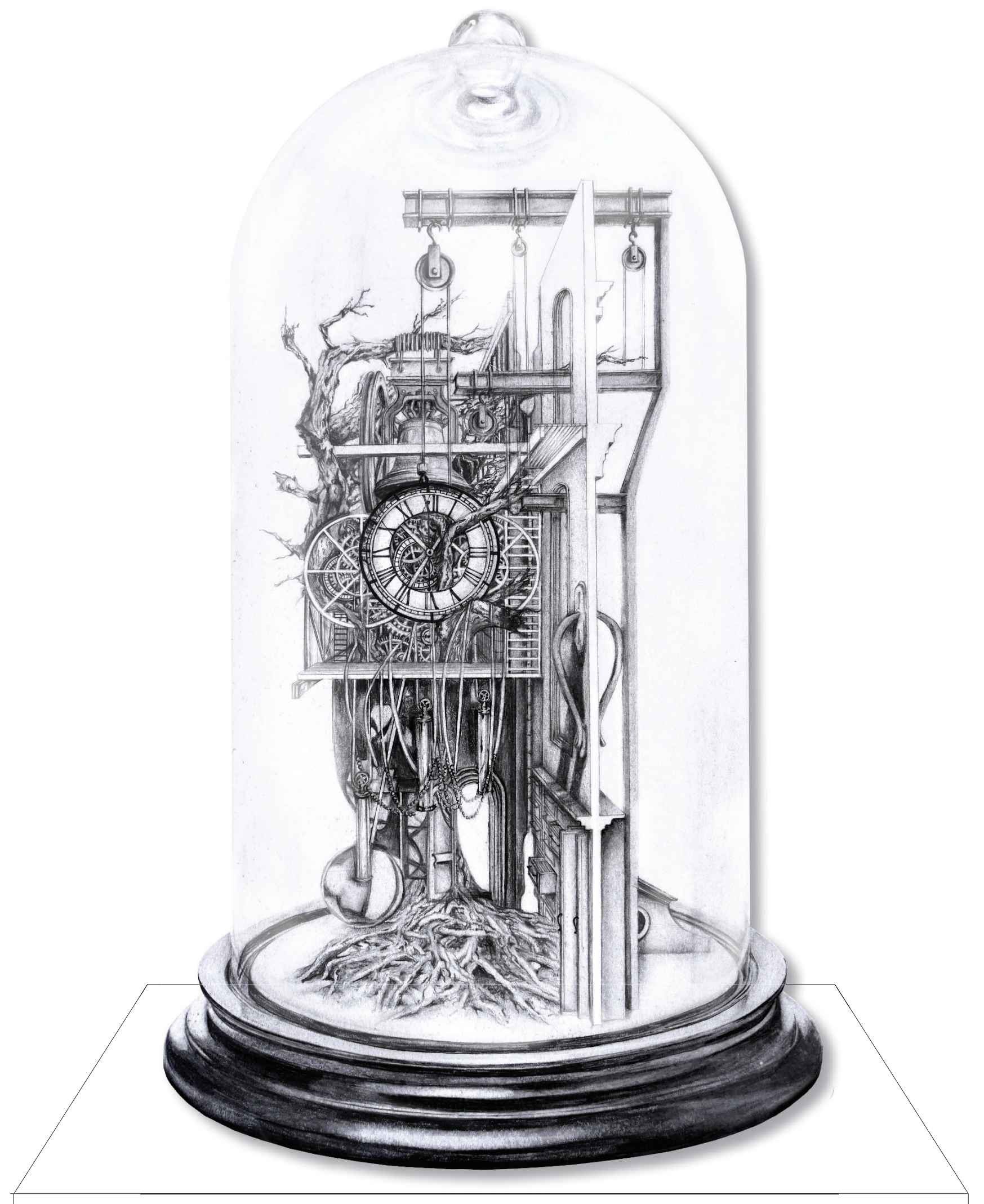

Fig. 4.10. The Bell Jar. An Artefact of Time. Drawing by Author. 


\section{the BELL JAR}

As a city continues to transform, the stories of place that make up its identity fragment and fade over time. Within the dream city of Clarice in Italo Calvino's Invisible Cities, the residents protect the most important parts of the city's identity as fragments in bell jars to protect and preserve them. This is not because the fragments are intended to recreate history directly or be integrated back into the city, but because these fragments, archived and curated, narrate important stories of place that make up its identity, that may have faded, fragmented or become lost below the city's surface over time.

The Bell Jar-an artefact of time-captures and stores fragments of time from beneath the urban concrete of Wellington. These fragments of time unveil lost voices of place, curated as a timepiece to allow their voices to be heard even when they have partially faded away. These stored fragments as lost voices of place are not the direct re-creation of history or specific sites' stories. Instead, these voices capture a broader context of Wellington and the complex relationships between time, place and the lost fragments and layers of the built and natural landscape that lie hidden below the city's surface. These contextual voices living within a vessel, stored forever as artefacts, give the lost stories of Wellington a voice, allowing them to be heard even when their traces in the landscape may have fragmented or faded away as the city continues to transform.

The Bell Jar is the narrator of this story-Archiving Fragments of Time.

"Without a boundary that marks beginning and end, what matter would anything have? I reckon life inside a jar is special because of what it is under glass. Break the glass and nothing's destroyed, but everything changes." 


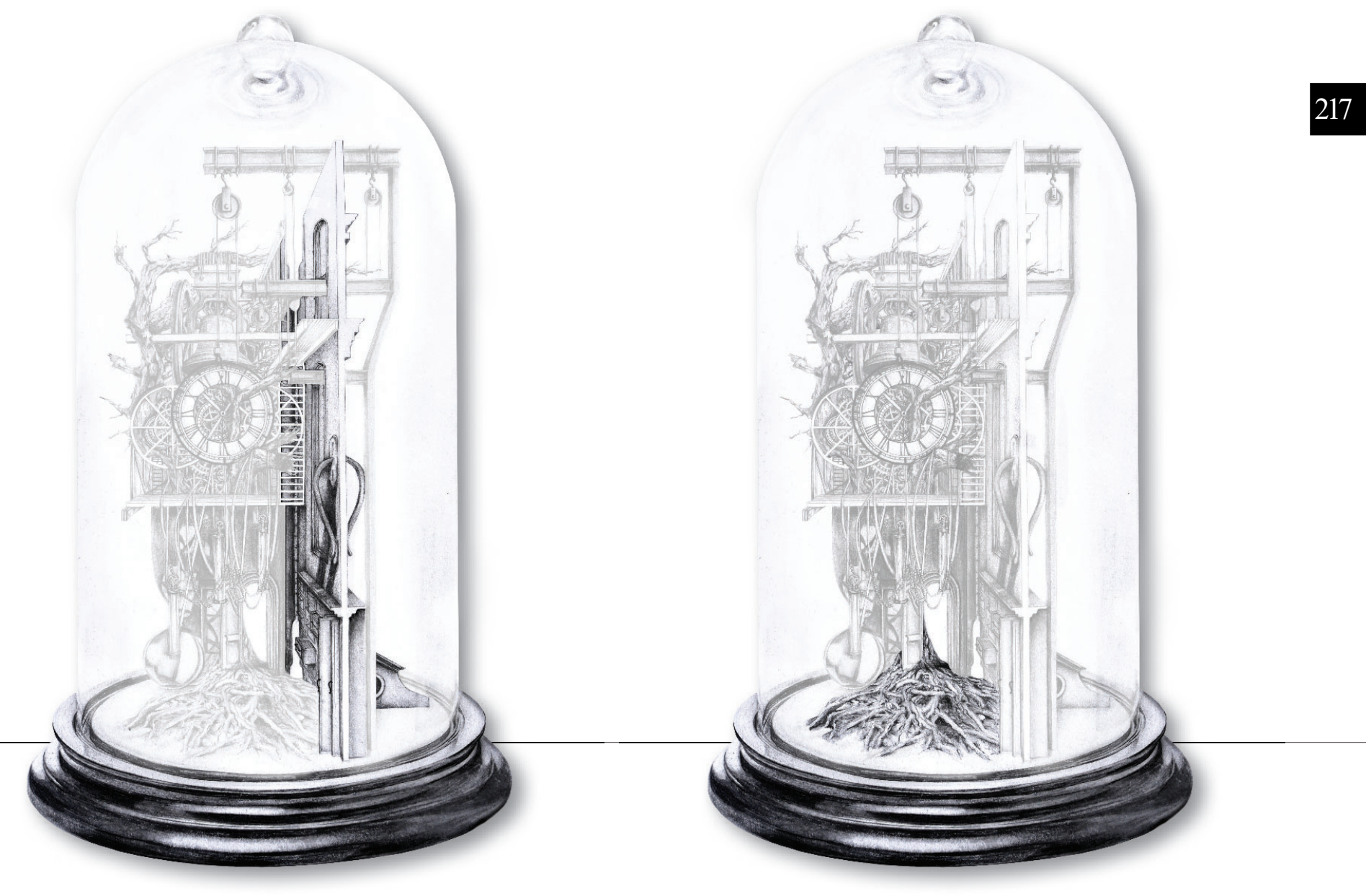

THE MASK

Fig. 4.10a. A preserved architectural facade is allegorically represented as a mask, a static moment in time. It is not until you look behind this mask that you can recognise the complex stories of time and place that live hidden behind the surface. At the base of this facade, behind the surface of the buildings of the city, lives the archive of lost stories of the changing face of the city (represented as the draws at the bottom of the wall). The bell jar becomes an archive of the ever-changing architectural masks that have been removed from the face of the city over time. The archive is the foundation upon which the city is built.

\section{THE ROOTS}

Fig. 4.10b. The hidden roots of the natural landscape upon which the city is built. The roots live within the archive as the natural foundation of the city. These roots contain an archive of stories of the natural landscape that have been lost over time. The connection between the roots and its tree are severed as the natural landscape has been covered over by the city. But below the city these roots continue to grow, transforming as the landscape above continues to grow and change shape. The roots are the life source of the natural landscape, and the essential foundation with which their voices (the tree) can survive above ground. Destroy the roots and the tree dies. The roots signify the voices of the natural landscape such as the Kumutoto Stream still alive below the surface of the city. Its 'roots' are forever growing and changing as the built landscape transforms and alters its path. 




THE PORTAL

Fig. 4.10c. The only access to the stories that lay below the surface of the city is through portals in the landscape, doorways that invite us to witness the lost world below - such as the Kumutoto Stream Outlet and the Taranaki Wharf Cut-out. These doorways allow 'roots' of lost stories to thread out and grow up through the layers of the city to have their voice heard once again (the silenced voice of the Kumutoto Stream-coming up through the outlet). In order to fully understand the true stories of place living within 'the archive' below, you must search for traces ('portals') in the landscape that invite you to witness the rich layers of lost stories that live below. Traces ('portals') of lost stories cannot always be seen within the ever-changing surface of the city. They are often overshadowed as time shifts (represented by the pendulum constantly shifting back and forth covering the door). Over time doorways are covered over, and revealed once again as fragments and layers of the city built up or are removed (the layers of concrete added and then removed from the two sites).
THE TIME PIECE

Fig. 4.10d. The true stories of time cannot be revealed through the static masks of preserved architectural facades fixed in time but are measured by the timepiecethe constantly shifting city-that is never static and forever ticking. The city is constantly transforming over time; the complex array of mechanisms that make up the city (the shifting built landscape and its architecture, represented as the clock's mechanisms) are constantly evolving both individually and in relation to one another. The city's mechanisms are all interconnected. To fully understand the city's identity, one must explore how parts are interrelated to other parts shifting together across time, altering the relationships and the identity of the elements through time. Time and place are multi-dimensional, constantly shifting and evolving. Time does not pause or stand-still. The mechanisms of the city that make up its face (the clock) can only be seen when the surface of the clock is removed. 

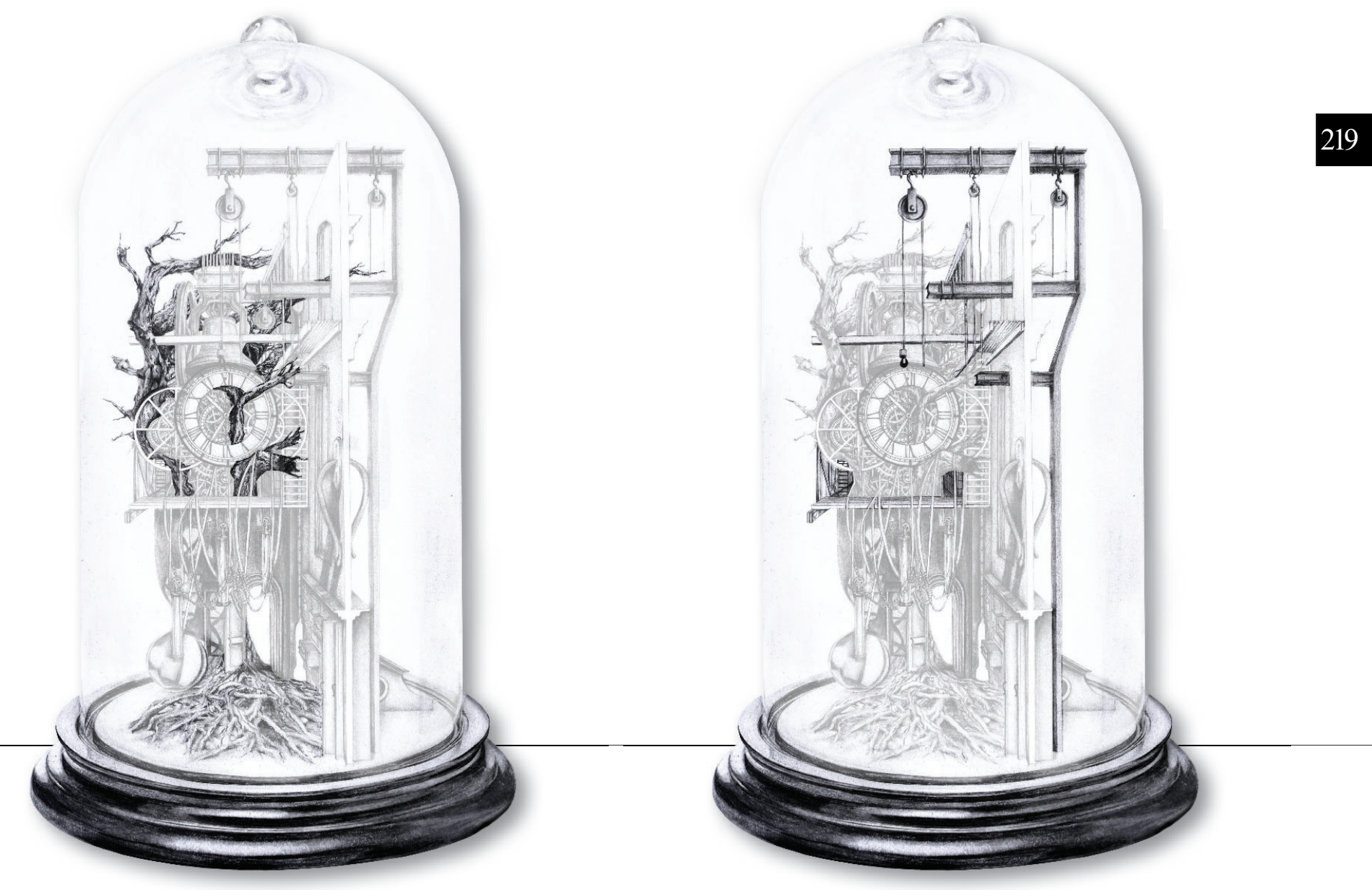

THE BRANCHES

Fig. 4.10e. The branches are the lost stories of the natural landscape growing up and threading through the built landscape. They pierce through gaps in the urban concrete fighting to have their voices heard again. The branches only reveal fragments of these voices; the trunk of the tree can never be seen (such as the Kumutoto Stream Outlet and the Taranaki Wharf Cut-out, both the stream and the lost shoreline cannot be seen; these sites only reveal traces ('branches') of its existence). The branches also signify that the life of the city continues to grow and transform. The relationship between the built and natural landscape is constantly shifting, evolving over time, living together as one.
THE SCAFFOLD

Fig. 4.10f. The city is under constant construction. The city and its architecture are never finished, adapting and transforming as they are reshaped by man over time. The pulleys pulling up the 'clock' represent the city growing upwards as layers of time build up over time. The architecture of today is rarely intended to be permanent. It is either intended to live out its life span and be destroyed to make room for something new, or it is destined to remain a shell undergoing alteration and adaptation to reverse the aging effects of time, or the shifting demands of its use. The city and its architecture today are the scaffold of future cities to come. 


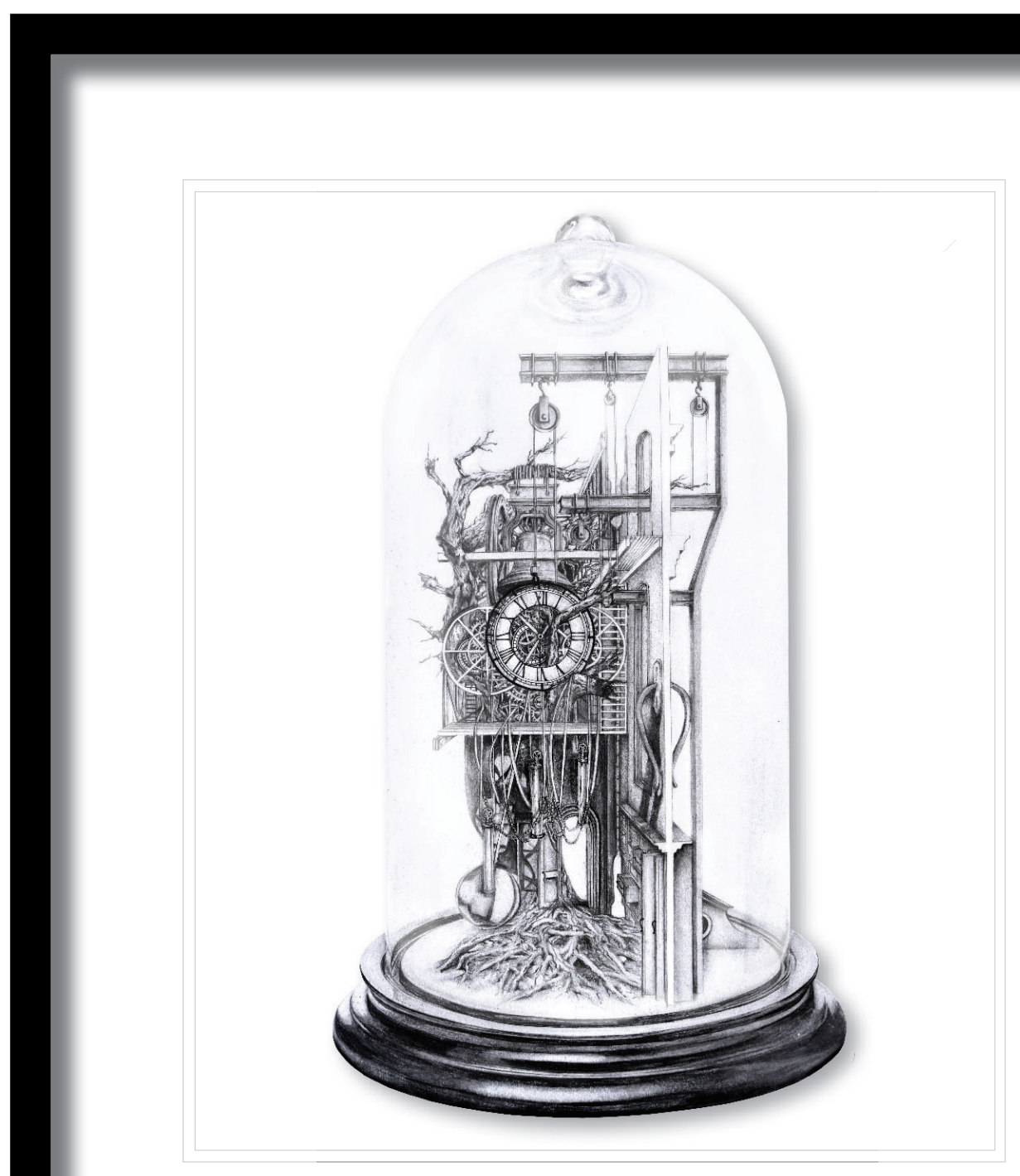

Fig. 4.11. Trapped and preserved with a vesselthe Bell Jar-lost fragments become an artefact, a resulting voice of exploration who's curated fragments narrate the stories found through the journey of this thesis investigation. 


\section{AN ARTEFACT OF TIME}

As the fifth of the five Developed Design outcomes, An Artefact of Time incorporates components of all five of Haralambidou's methods for constructing an allegorical architectural project, while privileging one in particular. An Artefact of Time privileges 'Figurative Geometries' by setting up fragments of stories into figurative allegorical relationships, to achieve its principal aim.

"She walks slowly towards them with a bell jar, knows she has no chance of entrapping a bird, drops her jar to the ground and begins weeping. And she is not alone in her frustration. Indeed, each man and each woman desires a bird. Because this flock of nightingales is time." 


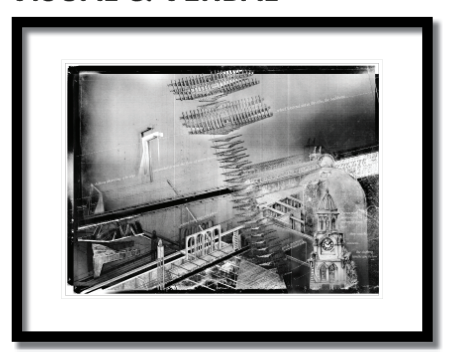

\section{DOUBLE MEANING}

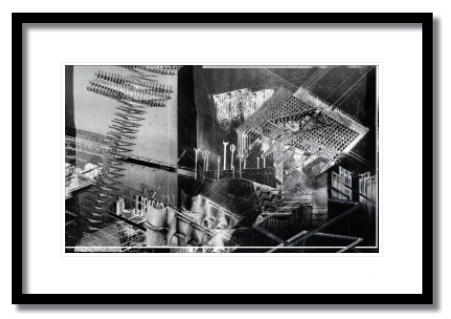

\section{UNFINISHED}

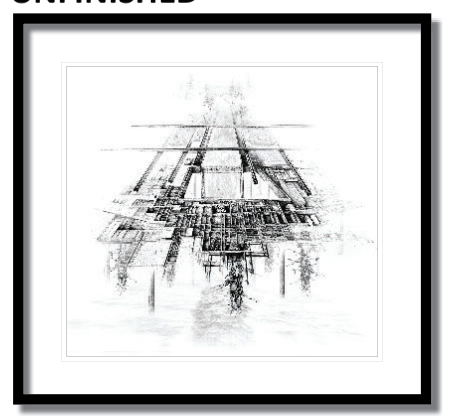

PROGRESS \& BATTLE



FIGURATIVE GEOMETRIES

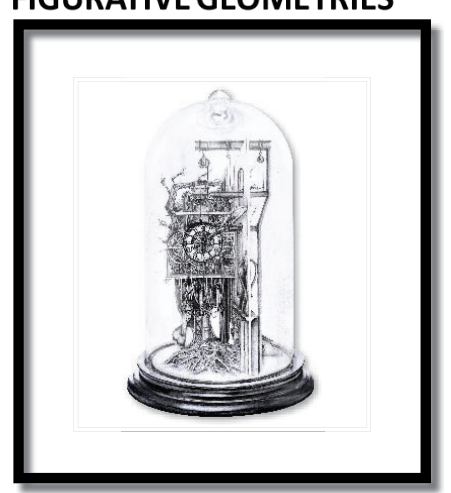

CRITICAL REFLECTION design-led research outcomes investigate how lost stories of time and place can be brought to life by capturing and reassembling the lost layers and fragments of place and time, through speculative drawings

The first Developed Design outcome, Dreaming of Lost Voices: Kumutoto Stream Outlet privileges 'Visual \& Verbal' by incorporating collage fragments together with text to achieve its principal aim.

The second Developed Design outcome, Dreaming of Lost Fragments: Taranaki Wharf Cutout, privileges 'Double Meaning' by setting up a duality (expressed through black and white oppositions) that invites open interpretation to achieve its principal aim.

The third Developed Design outcome, A Lost Map of Time, privileges 'Unfinished' by setting up a drawing composed of fragments (representing that the whole story is no longer there) to achieve its principal aim.

The fourth Developed Design outcome, Unveiling an Artefact of Time, privileges 'Progress \& Battle' by capturing the temporal nature of the story (progress) through the unveiling of a dialectic relationship (battle) to achieve its principal aim.

The fifth Developed Design outcome, An Artefact of Time, privileges 'Figurative Geometries' by setting up fragments of stories into figurative allegorical relationships, to achieve its principal aim 
The physical and metaphysical characteristics of these five speculative and allegorical Developed Design outcomes reawaken and unveil a series of lost voices of place, and allow their voices to be heard even when they have already partially faded away, as they are visually brought to life with varying levels of success.

Techniques of mapping, collage, and the creation of dreamscapes and allegorical drawing fragments are integrated through the media of speculative drawing and collage to re-present stories of place in various different modes from different points of view.

The first two dreamscape outcomes represent a dreamscape view of the structure of the waterfront as an array of overlapping fragments. The third reveals an allegorical characterisation of the stages of transformation of the landscape and shifting shoreline as land was reclaimed, and the final two drawings unveil the allegorical narrator of this investigation. This series as a whole represents Archiving Fragments of Time by capturing and curating fragments of stories that narrate the complexities of the layers of stories that live below the surface of Wellington.

Through the series, each drawing gains allegorical and metaphoric depth as design outcome becomes an increasingly allegorical interpretation and re-presentation of the stories-and fragments of stories - that establish the identity of the two sites. While the first two design outcomes, presenting the fragmented stories of the landscape as provocative dreamscapes that allows multiple voices to be heard at once, the following three outcomes enable a greater depth of metaphoric meaning and contextual relationships between fragmented stories to be revealed as fragments are further abstracted as figurative geometries engaging increased complexity of metaphoric forms to visually capture a greater depth and duplicity of meaning.

These design outcomes do not attempt to recreate nor visually represent a linear account of the events of the history of Wellington's Waterfront and the two research sites, the Kumutoto Stream Outlet and Taranaki Wharf Cut-out, but rather, they are intended to help unveil a series of fragmented artefacts that visually bring to life and re-present lost voices of the stories and contextual relationships of Wellington's Waterfront, with the goal of provoking a viewer to engage with the rich layers of stories that make up the constantly shifting and changing multi-layered meta-narrative of place that may not be recognised upon the surface of the Wellington city. 
fin.

"The catalogue of forms is endless, until every shape has found its city, new cities will continue to be born. When the forms exhaust their variety and come apart, the end of cities begins." -Italo Calvino, Invisible Cities, 139 
"Einstein gives her his manuscript, his theory of time. It is six minutes past eight. He walks to his desk, glances at the stack of files, goes over to a bookshelf, and starts to remove one of the notebooks. He turns and walks back to the window. ... He feels empty."

- Nan Lightman, Einstein's Dreams, 201-202

"At times all I need is a brief glimpse, an opening in the midst of an incongruous landscape, a glint of lights in the fog, the dialogue of two passersby meeting in the crowd, and I think that, setting out from there, I will put together, piece by piece, the perfect city, made of fragmetns mixed with the rest, of instants separated by intervals, of signals one sends out, not knowing who receives them."

-Italo Calvino, Invisible Cities, 164

\section{for now...}



ד


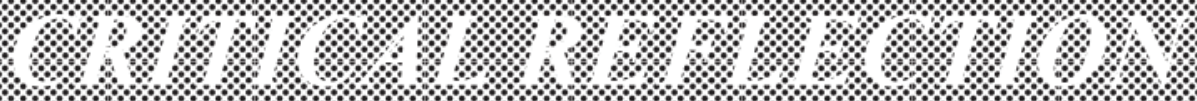

\%O\% 
"A film, artwork or text is not necessarily architecture but it can, at the very least, be architectural in specific ways, whether spatial, material or temporal, especially if is considered as a series of strategies, elements and techniques rather than an indivisible whole. This suggests that anyone wanting to produce architecture should, first, discard the preconceived boundaries of the discipline and, second, be prepared to learn from architecture wherever it is found, whoever it is produced by." 


\section{PRÉCIS}

For this allegorical architectural project, two literary works, Alan Lightman's Einstein's Dreams and Italo Calvino's Invisible Cities were engaged as allegorical provocateurs to reawaken and unveil lost voices of two research sites-the Kumutoto Stream Outlet and the Taranaki Wharf Cut-out, and surrounding context of the Wellington Waterfront. The goal was to help bring these voices to visual life as provocative speculative architectural outcomes that allow their voices to be heard even when they have already partially faded away. Einstein's Dreams was engaged as a generator for recognising the implications of time in the understanding of the history of a site as a non-linear and multi-layered construct, and Invisible Cities was engaged as a generator to recognise the subjective nature of place as memories, where the understanding places change depending on how people remember, perceive and experience them. Engaging these allegorical works as provocateurs acted as springboards for the imagination and provided a foundation to draw out more meaningful and unexpected discoveries, provoking unique architectural outcomes that enable lost voices to be heard and represented in ways previously unseen.

Through iterative design experiments, Haralambidou's five traits for conceiving an Allegorical Architectural Project alongside a theoretical framework of narrative and placemaking were explored through speculative design techniques of mapping, collage and the creation of dreamscapes and allegorical drawing fragments. A broad range of theorists addressing the three research objectives-along with related case studies-contributed to the diverse range of speculative techniques that were tested through design experiments in the preliminary design chapter 3 , after which they were integrated within the developed design series, the CODA-a series of drawn artefacts that take the form of maps, collages and fragments. 
A series of predicted, as well as unexpected discoveries were made throughout the course of this design research. The most profound involved the role of design and the integration of allegory when interrogating and architecturally representing the narratives and history of place that lie hidden beneath the surface of the city. Both the physical and intangible elements that contribute to the greater story of a place could not have been as fully brought to visual life again if not for the role of design, particularly through the narrative capabilities of speculative techniques of mapping, collage and drawing as the multi-layered threads of the methodology. The allegorical re-presentation of stories of site rather than direct representation enabled the contextual relationships between a range of fragmented lost stories that have shaped the identity of the landscape of the Wellington Waterfront, as it continually shifts and transforms, to be simultaneously explored. The role of design was significant in unveiling unexpected outcomes and discoveries that may not have been brought to light through a traditional written historical account or conventional methods of site analysis of the selected sites.

The research challenged architecture to blur disciplinary boundaries, blending speculative methods of mapping, collage and allegorical drawing with the integration of literary allegory and narrative into the process of design. This was enabled by interrogating the allegorical architectural project as a synthesis of theory and design to visually investigate innovative and critical articulations of concepts, and the material, spatial and temporal characteristics of sites and speculative design outcomes.

If this thesis were to progress further beyond the scope of this investigation, the research could have been further enhanced through a greater development of fragmented design outcomes. While the CODA explored the integration of all three techniques of mapping, collage and drawing links between design outcomes within each of these sections could also be explored in greater depth to generate a greater body of work of developed outcomes. 
As a site transforms, essential stories and voices of a site often fade, fragment or are completely lost over time. The heritage conditions of a place often cannot be physically returned to their sites without disrupting the contemporary urban context. Similarly these stories and voices often cannot be visually witnessed through a traditional written account of history. In response to this issue this investigation addressed how an allegorical architectural project could be used as a critical method to reawaken lost voices of two selected research sites and allow them to be heard even when they have already partially faded away, by visually bringing them as speculative design outcomes. Were the investigation to proceed further, there are opportunities to explore additional sites in Wellington and to explore the application of the methodology for reawakening lost voices of sites of urban landscapes further afield. Due to the multidisciplinary nature of this design-led research investigation and the broad range of speculative techniques and design outcomes explored within, the findings begin to suggest applications that extend beyond the scope and initial research aim.

Rather than arriving at one fixed design outcome that narrates a single story told from one limited point of view, the investigation exhibits a range of speculative outcomes as fragmented artefacts that re-present and unveil multiple fragments of lost voices told from multiple different points of view through varying visual modes that when viewed as a collection-an Archive of Fragments of Time-unveil the polyvocal narrative of place that shapes its identity as a constantly transforming and multilayered construct. Within the context of this investigation, an allegorical architectural project was generated and interrogated to bring the lost stories of the two selected sites and surrounding context to visual life in provocative and previously unseen ways to draw attention and engagement with the plethora of fragmented stories that live below the surface of the city. The goal was to ultimately help us better engage with the places we inhabit and understand humanity's role in shaping and narrating place identity.

"The Archive, then, is not so much an accumulation of texts as the process whereby texts are written; a process of repeated combinations, of shuffling and re-shufflings ruled by heterogeneity and difference. It is not strictly linear as both continuity and discontinuity, held together in uneasy allegiance. ... they are both erased and a memory of their own demise, keys to a filing system now abandoned, but they retain their archival quality, their power to differentiate, to space."

-R.G. Echevarría, 374 



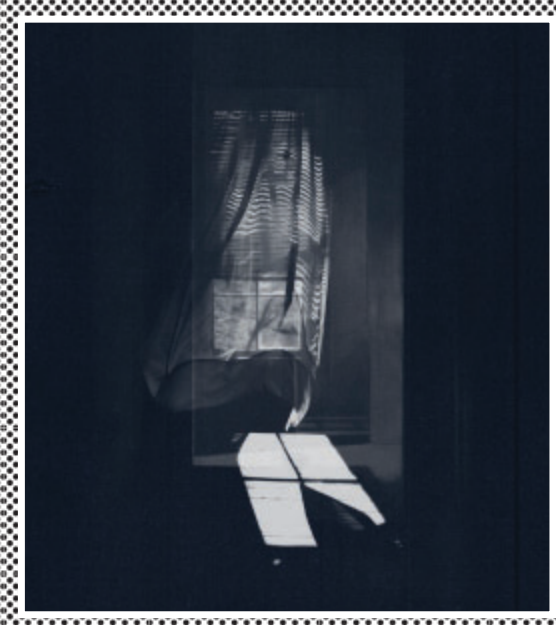


Benjamin, Walter. "Theses on the Philosophy of History." Illuminations, edited by Hannah Arendt and Harry Zohn, Harcourt, Brace \& World, 1968, pp. 245-55.

Boyer, M. Christine. The City of Collective Memory: Its Historical Imagery and Architectural Entertainments. MIT Press, 1996.

Burns, Carol. "On Site: Architectural Preoccupations." Drawing, Building, Text: Essays in Architectural Theory, edited by Andrea Kahn, Princeton Architectural Press, 1991.

Calvino, Italo. Invisible Cities. Random House, 1997.

Corner, James. "Drawing and Making in the Landscape Medium." The Landscape Imagination: Collected Essays of James Corner 1990-2010, edited by Alison Bick Hirsch, Princeton Architectural Press, 2014.

Corner, James. "The Agency of Mapping: Speculation, Critique and Invention.” The Map Reader, John Wiley \& Sons Ltd, 2011, pp. 89-101. Wiley Online Library, doi:10.1002/9780470979587.ch12.

Corner, James. The Landscape Imagination: Collected Essays of James Corner 1990-2010. Princeton Architectural Press, 2014.

Danko, Sheila. "Humanizing Design through Narrative Inquiry." Journal of Interior Design, vol. 31, no. 2, 2006, pp. 10-28. Wiley Online Library, doi:https://doi. org/10.1111/j.1939-1668.2005.tb00408.x.

Echevarría, R. G. (1984), “Cien años de soledad: The Novel as Myth and Archive”, Vol. 99, No. 2, Hispanic Issue (Mar. 1984), The Johns Hopkins University Press, pp. 358-380

El-Bizri, Nader. "Imagination and Architectural Representations." From Models to Drawings: Imagination and Representation in Architecture, edited by Marco Frascari et al., Routledge, 2007, pp. 34-42.

Evans, Robin. Translations from Drawing to Building and Other Essays. Architectural Association, 1997.

Fiorenzoli, Giuliano. "Exhibition of Architectural Drawings." Giuliano Fiorenzoli Architects, 2011, http://giulianofiorenzoli.com/_Pages/Drawings/Drawings/ExhibitionOfDrawingMain. html.

Fletcher, Angus. Allegory: The Theory of a Symbolic Mode. Cornell University Press, 1964.

Frascari, Marco, et al. From Models to Drawings: Imagination and Representation in Architecture. Routledge, 2007. 
Hackwith, AJ, The Archive of the Forgotten, New York: ACE Publishers, 2020.

Haralambidou, Penelope. "The Fall: The Allegorical Architectural Project as a Critical

Method." Critical Architecture, Routledge, 2007, pp. 225-36.

Harbison, Robert. Eccentric Spaces. MIT Press, 2000.

Hejduk, John. "Thoughts of an Architect." Theories and Manifestoes of Contemporary Architecture, by Karl Kropf and Charles Jencks, Academy Editions, 1997.

Hejduk, John. "Diary Constructions." The Collapse of Time and Other Diary Constructions, London: Architectural Association, 1987. (This text has no page numbers).

Herron, Simon. "Plug-In, Clip-On, Tune-Up." Architectural Design: Drawing Architecture, vol. 83, no. 5, 2013, pp. 94-101. Wiley Online Library, doi:https://doi.org/10.1002/ad.1640.

Hill, Jonathan. Immaterial Architecture. Routledge, 2006.

Hirsch, Alison Bick. "Introduction." The Landscape Imagination: Collected Essays of James Corner 1990-2010, by James Corner, Princeton Architectural Press, pp. 13-37. 2014.

Hogue, Martin. "The Site as Project: Lessons from Land Art and Conceptual Art." Journal of Architectural Education (1984), vol. 57, no. 3, [Taylor \& Francis, Ltd., Association of Collegiate Schools of Architecture, Inc.], 2004, pp. 54-61.

Koetter, Fred. "Notes on the In-Between." The Harvard Architecture Review, M.I.T. Press, Spring 1980.

Kulper, Perry. "A World Below." Architectural Design: Drawing Architecture, vol. 83, no. 5, 2013, pp. 56-63. Wiley Online Library, doi:https://doi.org/10.1002/ad.1663.

Lee, Christina. Violating Time: History, Memory, and Nostalgia in Cinema. Bloomsbury Publishing USA, 2008.

Lightman, Alan P. Einstein's Dreams. Pantheon Books, 1993.

Lim, C. J. “Dream Island,” Opticon1826, Issue 6, Spring 2009

Lim, C. J. "London Short Stories: Drawing Narratives." Architectural Design: Drawing Architecture, vol. 83, no. 5, 2013, pp. 102-07. Wiley Online Library, doi:https://doi. org/10.1002/ad.1641.

Lim, C. J., and Ed Liu. Short Stories: London in Two-and-a-Half Dimensions. Routledge, 2011. Nouvel, Jean. Sofitel Vienna Stephansdom. Ateliers Jean Nouvel. 2010. Web.

Nouvel, Jean. Ycone. Ateliers Jean Nouvel. 2019. Web.

Owens, Craig. "The Allegorical Impulse: Toward a Theory of Postmodernism." October, vol. 12, The MIT Press, 1980, pp. 67-86. JSTOR, doi:10.2307/778575. 
Pallasmaa, Juhani. "Foreward: The World Is a Collage." Collage and Architecture, by Jennifer A. E. Shields, Routledge, 2014.

Pallasmaa, Juhani. "Hapticity and Time: Notes on Fragile Architecture." The Architectural Review (London), vol. 207, no. 1239, Emap Limited, 2000, pp. 78-.

Pallasmaa, Juhani. "Inhabiting Time." Architectural Design, vol. 86, no. 1, 2016, pp. 50-59. Wiley Online Library, doi:https://doi.org/10.1002/ad.2001.

Phillips, Patricia. "Forward." Vessels and Fields, by Wellington Reiter, Princeton Architectural Press, 1999.

Potteiger, Matthew, and Jamie Purinton. Landscape Narratives: Design Practices for Telling Stories. John Wiley \& Sons, 1998.

Reiter, Wellington. Vessels and Fields. Princeton Architectural Press, 1999.

Rendell, Jane, et al. Critical Architecture. Routledge, 2007.

Ross Johnston, Rosemary. "Landscape as Palimpsest, Pentimento, Epiphany: Lucy Maud Montgomery's Interiorisation of the Exterior, Exteriorisation of the Interior." CREArTA, vol. 5, no. Special Issue, 2005, pp. 13-31.

Rossi, Aldo. The Architecture of the City. MIT Press, 1984.

Shields, Jennifer A. E. Collage and Architecture. Routledge, 2014.

Spiller, Neil. "Architectural Drawing: Grasping for the Fifth Dimension." Architectural Design, vol. 83, no. 5, 2013, pp. 14-19. Wiley Online Library, doi:https://doi.org/10.1002/ ad.1657.

Spiller, Neil. "Drawing as Communicating Vessels: An Apologia (or Not)." Drawing Futures - Speculations in Contemporary Drawing for Art and Architecture, edited by Laura Allen and Luke Caspar Pearson, UCL Press, 2016.

Stockhausen, Karlheinz. Die Reihe. Volume 1 - Electronic Music. Theodore Presser, 1965.

Tschumi, Bernard. “The Manhattan Transcripts 1976-1981.” Bernard Tschumi Architects, http://www.tschumi.com/projects/18/\#. Web. Accessed 28 Mar. 2021.

Tschumi, Bernard. The Manhattan Transcripts. Wiley, 1994.

Urbach, Henry. "Introduction." Ironic Diversions, by Mas Yendo, Princeton Architectural Press, 2000.

Waldman, Diane. Collage, Assemblage, and the Found Object. H.N. Abrams, 1992.

Yendo, Mas. Ironic Diversions. Princeton Architectural Press, 2000. 
Fig. 0.1. Wellington harbour and Customhouse Quay. Ref: 1/2019556-F. ATL, Wellington, New Zealand. http://natlib.govt.nz/ records/22676270

Fig. 0.14. Wellington City, around Mercer and Wakefield Streets. Tyree Studio: Negatives of Nelson and Marlborough districts. Ref: 10x81022-G. Alexander Turnbull Library, Wellington, New Zealand. http:// natlib.govt.nz/records/22719010. Edited by Author

Fig. 0.15. Fig. 0.15. Elevated view of Wellington Harbour. Date Unknown. Wellington City Council Archives, 00138-14958. https://archivesonline.wcc.govt.nz/ nodes/view/14586

Fig. 0.17. Unknown Author. National Centre of Music Will Confirm Wellington as Capital of Culture. Victoria Univesity of Wellington. 10/05/2017. Web. https://www.wgtn.ac.nz/fhss/ about/news/national-centre-of-music-will-confirm-wellington-as-capital-of-culture. Edited by Author.

Fig. 1.11. Homer, Lloyd. “Wellington Fault Lines.” Science Learning Hub, GNS Science Limited, 2007, www.sciencelearn.org.nz/images/345-wellington-fault-lines.

Fig. 1.14. "Wellington Aerial ." Victoria University of Wellington, 2017, www.wgtn.ac.nz/ fhss/about/news/national-centre-of-music-will-confirm-wellington-as-capital-of-culture.

Fig. 1.15. Unknown Author. Friends of the Solent Flying Boat: ZK-AMM. Date unknown. Web. https://friendsofthesolentflyingboat.wordpress.com/zk-amm/

Fig. 2.1.2. Haralambidou, Penelope. "The Fall: The Allegorical Architectural Project as a Critical Method." Critical Architecture, Routledge, 2007, pp. 233. www-taylorfrancis-com. helicon.vuw.ac.nz, doi:10.4324/9780203945667-36.

Fig. 3.1.4. Heaphy, Charles, 1820-1881. [Heaphy, Charles] 1820-1881 :Birdseye view of Port Nicholson, in New Zealand, shewing the site of the town of Wellington, the river and valley of the Hutt and adjacent country, taken from the charts and drawings made during Col[one]l Wakefield's survey, [1839] and now in the possession of the New Zealand Company. Drawn, lithographed by T. Allom [from a drawing by Charles Heaphy]. Printed by Hullmandel \& Walton. London, Published by Trelawney Saunders, [1843?]. Ref: C-029006-b. Alexander Turnbull Library, Wellington, New Zealand. /records/22875686

Fig. 3.1.5. Day \& Haghe (Firm). Smith, William Mein 1799-1869: The harbour of Port Nicholson and the town of Wellington (sketched in the middle of the year 1842). [right-hand portion].. Wakefield, Edward Jerningham 1820-1879 :Illustrations to "Adventure in New Zealand”. Lithographed from original drawings taken on the spot by Mrs Wicksteed, Miss King, Mrs Fox, Mr John Saxton, Mr Charles Heaphy, Mr S. C. Brees and Captain W. Mein 
Smith. London, Smith Elder \& Co, 1845.. Ref: PUBL-0011-16-3. Alexander Turnbull Library, Wellington, New Zealand. /records/22904386

Fig. 3.1.6. Proposed plan of the city of Wellington, drawn by Samuel Cobham. Ref: 1/2051659-F. Alexander Turnbull Library, Wellington, New Zealand. /records/23125982

Fig. 3.1.7. Smith, W. M., et al. Plan of the Town of Wellington, Port Nicholson : the First and Principal Settlement of the New Zealand Company / W.M. Smith, Surveyor-General. Smith, Elder \& Co. for the New Zealand Company, 1840.

Fig. 3.1.8. Unidentified author. Edited by Andersen, Johannes Carl. Courses of the Wellington streams. 1940. Ref: MapColl-832.4799cdc/A/ca.1940/Acc.3783-84. Alexander Turnbull Library, Wellington, New Zealand. http://natlib.govt.nz/records/22612149

Fig. 3.1.9. Land reclamation, Thorndon, Wellington. Evening post (Newspaper. 1865-2002) :Photographic negatives and prints of the Evening Post newspaper. Ref: EP-0114-1/2-F. Alexander Turnbull Library, Wellington, New Zealand. /records/22523626

Fig. 3.1.11. Phillip Capper. Flickr: Phillip Capper Wellington, New Zealand, 10th December 2010. https://www.flickr.com/photos/flissphil/5253716950/in/photolist-91fF1J-6xsuA4tU51F-32G3C-CLbU-CBRz8-54Fgww-3drjJc-sXpb-gNkVU-WpsB-a8ge5V-Mta7-2LjprmiY85-4xiNeq-jYXUD-4xeJ3B-A5T3-a8gdT6-syDPK-sXsb-5Ed5ki-9iohCy-4xeEr88KYGox-9inEuu-FG3di-9ijy5n-7rsdK1-6x9bo-iChud-tWZV-9dt1GZ-2DnkY-6Sbn6N4QNag-nEv9L-vSiAo-4r3TV-8Rmur-aMFoM-6xaxn-zGxEX-9iog6N-snJYC-A79Rs4EAgPv-9ik9t2-EERh

Fig. 3.1.19. Williams, William. Kaiwharawhara Creek, Wellington. 1886.Ref: 1/1-025976-G. National Library of New Zealand, Wellington, New Zealand. https://www.flickr.com/photos/ nationallibrarynz_commons/3817048172/in/album-72157619127674978/

Fig. 3.1.20. View of buildings on Customhouse Quay, Lambton, Wellington, including warehouses of W \& G Turnbull and Company, and the Chief Post Office, with ships docked at the quay, and houses on the Terrace in background. Davis, William Henry Whitmore, 1812-1901 :Photographs of Wellington and district. Ref: 1/1-039918-G. Alexander Turnbull Library, Wellington, New Zealand. http://natlib.govt.nz/records/23526633

Fig. 3.1.21. Muir \& Moodie (Firm). Muir and Moodie fl 1898-1916 :Shipping Wellington. New Zealand Broadcasting Corporation :Negatives relating to the programme on Katherine Mansfield - "The White Gardenia”.. Ref: 1/4-016223-F. Alexander Turnbull Library, Wellington, New Zealand. http://natlib.govt.nz/records/23050671

Fig. 3.1.22. Whites Aviation. Aerial View of Wellington 1947, City, Bunny Street to Willis Street. Archives Online, Wellington City Council, 00278-10-4, archivesonline.wcc.govt.nz/ nodes/view/811642.

Fig. 3.1.23. Looking up Woodward Street from Lambton Quay, Wellington. Evening post (Newspaper. 1865-2002) :Photographic negatives and prints of the Evening Post newspaper. 
Fig. 3.1.25. "1972. The area from Taranaki Street at the top to the Tug Wharf at the bottom has been reclaimed. From the late 1960s there were plans for a highway from the railway Station to Courtenay Place and the demolition of all buildings in the photo fronting Customhouse and Jervois Quays..” Discover Stqry: Kumutoto, Area 360, https://discover.

Fig. 3.1.30. Denton, F. J. “Te Aro, Wellington, 1863.” New Zealand Geographic, 2000, www. nzgeo.com/stories/the-day-the-earth-shifted/.

Fig. 3.1.31. Overlooking Wellington city. Burton Bros. Ref: BB-2236-1/1-G. Alexander Turnbull Library, Wellington, New Zealand. /records/23225199

Fig. 3.1.32. Wellington Harbour southern wharf area with Cable and Taranaki Streets and city, with Kelburn Park and Victoria University, Wellington City. Whites Aviation Ltd: Photographs. Ref: WA-40792-G. Alexander Turnbull Library, Wellington, New Zealand. / records/30113905

Fig. 3.1.33. "1912. Drays Wait to Discharge Cargo from the Vessel at Taranaki Street Wharf. The Original Clyde Quay Wharf, Built in 1910, Is in the Background." Discover Stqry: Taranaki Street Wharf, Area360, https://discover.stqry.com/v/Taranaki-Street-Wharf/s/ dcf60a1f185a0c7372cac727441e9d48.

Fig. 3.1.34. "1968. The Future Te Papa Site Is Being Reclaimed for Cargo Purposes in Preparation for the Trans-Tasman Roll-on Roll-off Shipping Trade. The New Taranaki Street Breastwork Wharf Is Also Being Constructed." Discover Stqry: Te Papa Tongarewa , Area 360, https://discover.stqry.com/v/Te-Papa-Tongarewa/s/6fbd67883a060bee4d86f $3 c 262019165$.

Fig. 3.1.35. Taranaki Street Wharf, Wellington. Evening post (Newspaper. 1865-2002) :Photographic negatives and prints of the Evening Post newspaper. Ref: 1/4-021901-F. Alexander Turnbull Library, Wellington, New Zealand. /records/23166191

Fig. 3.1.36. Yendo, Mas. Book Cover. Ironic Diversions. Princeton Architectural Press, 2000.

Fig. 3.2.37. Yendo, Mas. Ptolemy Institute of Astrology. Ironic Diversions. Princeton Architectural Press, 2000.

Fig. 3.1.38. Yendo, Mas. Ptolemy Institute of Astrology. Ironic Diversions. Princeton Architectural Press, 2000.

Fig. 3.1.39. Tschumi, Bernard. Book Cover. The Manhattan Transcripts. Wiley, 1994.

Fig. 3.1.40. Tschumi , Bernard. “The Manhattan Transcripts ." Bernard Tschumi Architects, www.tschumi.com/projects/18/.

Fig. 3.1.41. Tschumi, Bernard. “'The Set and the Script' in Architecture: The Manhattan Transcripts (1976-1981) ." Socks Studio , 2015, socks-studio.com/2015/10/13/the-set-andthe-script-in-architecture-the-manhattan-transcripts-1976-1981-by-bernard-tschumi/. 
Fig. 3.1.42. Tschumi, Bernard. “The Manhattan Transcripts Project, New York, New York, Episode 4: The Block, 1980-81.” MoMA, www.moma.org/collection/works/66.

Fig. 3.2.1. Lim, C.J. Discontinuous Cities. BLDGBLOG Fiction and the City, 2011, www. bldgblog.com/2011/04/fiction-and-the-city/.

Fig. 3.2.2. Lim, C.J., and Ed Liu . Short Stories: London in Two-and-a-Half Dimensions Book Cover. Routledge Taylor \&amp; Francis Group , 2011, www.routledge.com/Short-StoriesLondon-in-Two-and-a-half-Dimensions/Lim-Liu/p/book/9780415573580.

Fig. 3.2.3. Lim, C.J. Discontinuous Cities. BLDGBLOG Fiction and the City, 2011, www. bldgblog.com/2011/04/fiction-and-the-city/.

Fig. 3.2.4. Lim, C.J. The Celestial River. BLDGBLOG Fiction and the City, 2011, www. bldgblog.com/2011/04/fiction-and-the-city/.

Fig. 3.3.1. Rossi, Aldo. Sketch Drawing for San Cataldo Cemetery. Fondazione Aldo Rossi, www.fondazionealdorossi.org/opere/1970-1979/cimitero-di-san-cataldo-modena-1971-1978-2/.

Fig. 3.3.2. Rossi, Aldo. Provisional sketches for the design of San Cataldo Cemetery. Fondazione Aldo Rossi, www.fondazionealdorossi.org/opere/1970-1979/cimitero-di-sancataldo-modena-1971-1978-2/.

Fig. 3.3.3. Rossi, Aldo. Visual montage of figurative geometries for the design of the San Cataldo Cemetry. Fondazione Aldo Rossi, www.fondazionealdorossi.org/opere/1970-1979/ cimitero-di-san-cataldo-modena-1971-1978-2/.

Fig. 3.3.4. Reiter, Wellington. Vessel of Time. Vessels and Field. Princeton Architectural Press, 1999. p.19

Fig. 3.3.5. Reiter, Wellington. Vessels and Field. Princeton Architectural Press, 1999. Book Cover.

Fig. 3.3.6. Reiter, Wellington. Islands of Time. Vessels and Field. Princeton Architectural Press, 1999. p.60-61

Fig. 3.3.7. Reiter, Wellington. History of New Orleans. Vessels and Field. Princeton Architectural Press, 1999. p.106-107

Fig. 3.3.8. Reiter, Wellington. History of New Orleans. Aaron Lim Experimental Illustration, 2011, aaronxillustration.wordpress.com/inspiration/techniques-visual-style/wellington-reiter history-of-new-orleans/.

Fig. 3.3.9. Reiter, Wellington. History of New Orleans. Vessels and Field. Princeton Architectural Press, 1999. p.108-109

Fig. 3.3.10. Reiter, Wellington. History of New Orleans. Vessels and Field. Princeton Architectural Press, 1999. p.104-105 
241 


\section{Statement of Authorship}

for MArch (Prof), MIA, MLA

Thesis 591 / Research Portfolio Document 593

(2020)

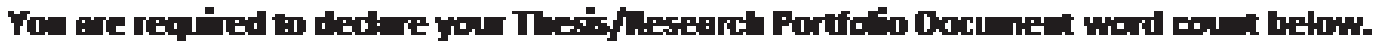

\begin{tabular}{|l|c|c|}
\hline \multicolumn{1}{|c|}{$\begin{array}{c}\text { Thesis/Research Portfolio } \\
\text { Document title: }\end{array}$} & \multicolumn{2}{|c|}{ Word limit } \\
\hline $\begin{array}{l}\text { Abstract, acknowledgments, chapter } \\
\text { text, footnotes and/or endnotes. }\end{array}$ & $\mathbf{2 2 , 0 0 0 \text { words }}$ \\
$\begin{array}{l}\text { Bibliography, image captions and } \\
\text { appendices }\end{array}$ & Yourd count \\
\hline
\end{tabular}

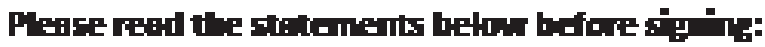

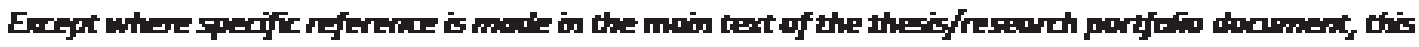

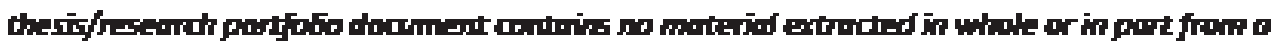


or ofinome.

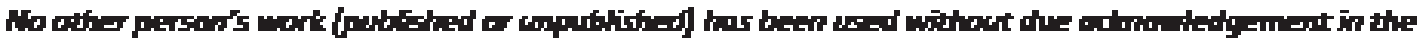
moin tort of the thesis/necorth portfolio documert

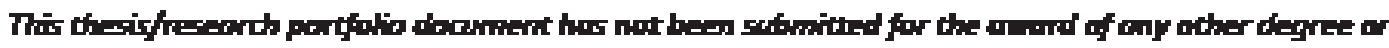
afplome in any ather tertiany institution.

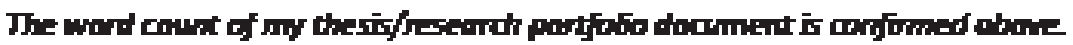

\begin{tabular}{|c|c|c|c|}
\hline Full name & Alix Gharles & Student ID & 300285102 \\
\hline Signature & $4 x^{2}+40$ & Date & 3 May 2001 \\
\hline
\end{tabular}

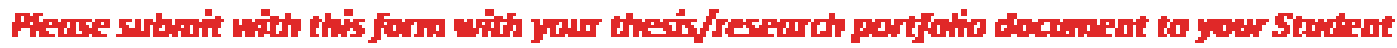
Adwior, Fanhy Office 


\section{Supervisor's Statement}

For Master's Thesis / Research Portfolio Document

\begin{tabular}{|l|l|l|l|}
\hline Candidate & Alice Victoria Charles & Degree & Master of Architecture (Profesional) \\
\hline Title & Archiving Fragments of Time & \\
\hline
\end{tabular}

As Principal Supervisor for the above candidate's thesis/research portfolio document, I confirm that to the best of my knowledge, Alice Victoria Charles has carried out his/her research according to the Victoria University of Wellington requirements for a Master's degree in Architecture (Profesional)

All other assistance received by the candidate is acknowledged in his/her thesis/research portfolio document.

\section{Additional comments}

\begin{tabular}{|l|l|l|l|}
\hline Supervisor's name & Daniel K. Brown & \multicolumn{2}{|l|}{} \\
\hline Signature & & Date & 3 April 2021 \\
\hline
\end{tabular}

